\title{
Fixed-interval performance as a function of previous temporal discrimination training
}

Stephanie Plyler da Silva

West Virginia University

Follow this and additional works at: https://researchrepository.wvu.edu/etd

\section{Recommended Citation}

da Silva, Stephanie Plyler, "Fixed-interval performance as a function of previous temporal discrimination training" (2001). Graduate Theses, Dissertations, and Problem Reports. 803.

https://researchrepository.wvu.edu/etd/803

This Thesis is protected by copyright and/or related rights. It has been brought to you by the The Research Repository @ WVU with permission from the rights-holder(s). You are free to use this Thesis in any way that is permitted by the copyright and related rights legislation that applies to your use. For other uses you must obtain permission from the rights-holder(s) directly, unless additional rights are indicated by a Creative Commons license in the record and/ or on the work itself. This Thesis has been accepted for inclusion in WVU Graduate Theses, Dissertations, and Problem Reports collection by an authorized administrator of The Research Repository @ WVU. For more information, please contact researchrepository@mail.wvu.edu. 
Fixed-Interval Performance as a Function of Previous Temporal Discrimination Training

\author{
Stephanie P. da Silva
}

Thesis submitted to the Eberly College of Arts and Sciences at West Virginia University in Partial Fulfillment of the Requirements for the Degree of

\author{
Master of Arts \\ in \\ Psychology \\ Kennon A. Lattal, Ph. D., Chair \\ David W. Schaal, Ph. D. \\ Kevin T. Larkin, Ph. D. \\ Department of Psychology \\ Morgantown, West Virginia \\ 2001
}

Keywords: behavioral history, fixed-interval performance, temporal discrimination 


\section{ABSTRACT \\ Fixed-Interval Performance as a Function of Previous Temporal Discrimination Training}

Stephanie P. da Silva

This experiment assessed whether FI performance is influenced by prior exposure to a temporal discrimination procedure. Pigeons first were exposed to a two-key free-operant psychophysical procedure for two sessions per day. Each trial lasted $60 \mathrm{~s}$ and reinforcement was available according to a variable-interval 60-s schedule for pecking one key (Key 1) during the first part of the interval and pecking another key (Key 2) during the second part of the interval. In the Fixed session, reinforcement availability switched from Key 1 to Key 2 after 30 s; whereas, in the Variable session, reinforcement availability switched from Key 1 to Key 2 after a variable amount of time. Following stable responding during each component, identical FI schedules were introduced in both sessions. There were no consistent differences in responding under the FI schedules, suggesting that FI patterns may not be sensitive to previous exposure to temporal discrimination training. 
Table of Contents

page

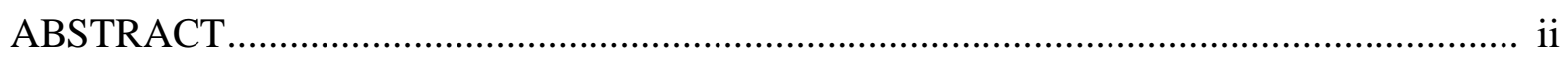

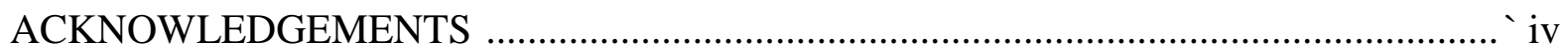

LIST OF FIGURE CAPTIONS AND FIGURES ............................................................

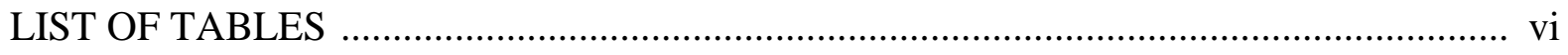

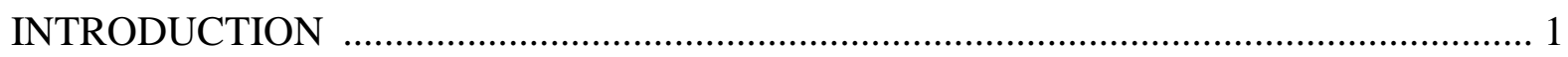

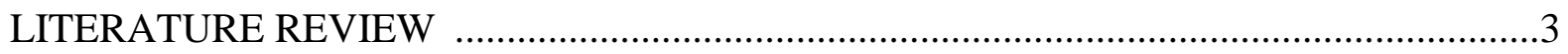

FIXED-INTERVAL SCHEDULES AND BEHAVIORAL HISTORY ..................................

TEMPORAL DISCRIMINATION AND TEMPORAL DIFFERENTIATION ......................11

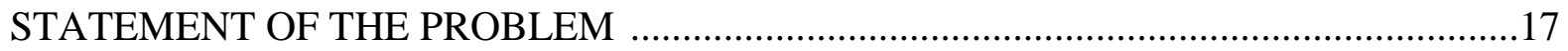

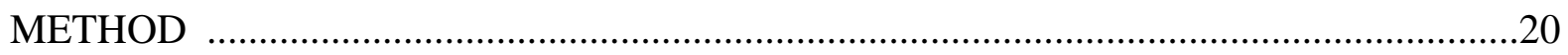

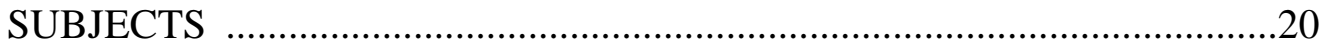

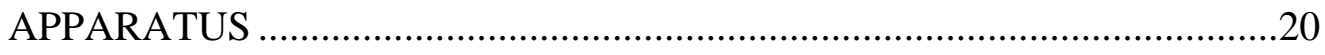

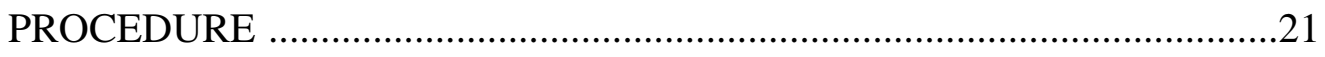

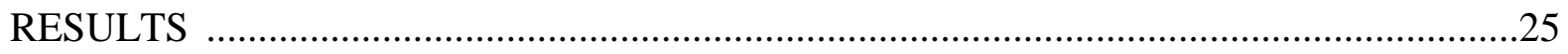

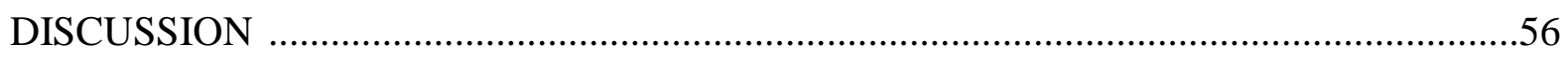

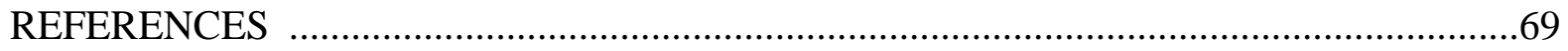

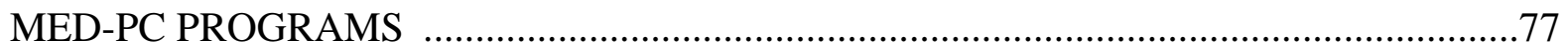

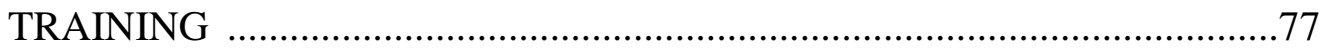

FREE-OPERANT PSYCHOPHYSICAL PROCEDURE ...............................79

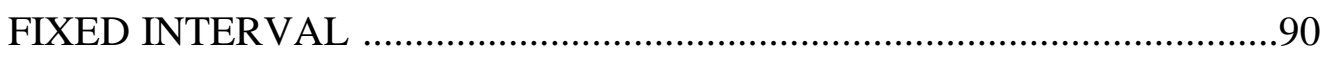




\section{Acknowledgements}

I want to begin by thanking the members of my committee. First and foremost, I thank Andy, for being the best advisor a graduate student can have and, specifically, for being so patient and supportive throughout the writing of this document and for his availability for asking any questions I had concerning the present experiment. I thank Dave Schaal for his consistent accessibility and help as well as his expertise in dealing with temporal discrimination procedures and FI schedules. I thank Kevin Larkin for his participation and for providing a fresh perspective.

I thank Adam Doughty for the many conversations regarding this project, including helpful input concerning the procedure and interpretations of the results. I thank the members of the Schaal lab, particularly Lori Murray, for having an open-door policy for answering questions and offering suggestions concerning everything from data analysis to the timing literature. I thank Ellie McCartney for the many hours she spent collecting data for this project. I'm not sure I would have had the patience to conduct this experiment consistently without her tremendous help.

And last, but certainly not least, I thank my husband, Rodrigo, for understanding why the late nights of data analyses and writing as well as the early mornings of data collection were necessary to finish this thesis. I also want to thank Rodrigo for his constant support and love that brings so much happiness to me. 
List of Figure Captions and Figures

page

Figure Caption 1

Figure 1: Mean Number of Reinforcers Obtained under the FOPP.........................................29

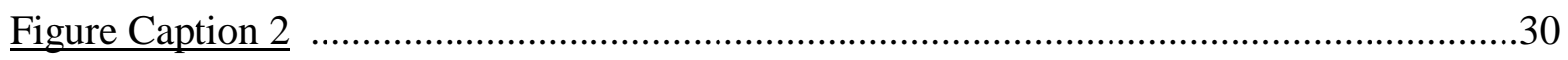

Figure 2: Mean Number of Changeovers under the FOPP ...................................................31

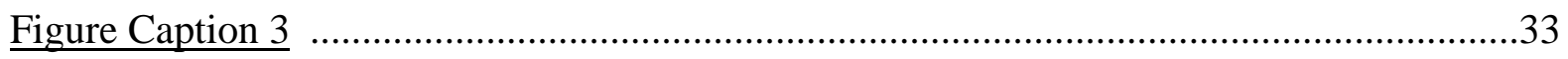

Figure 3: Number of Responses on Key 1 and Key 2 under the FOPP ..................................34

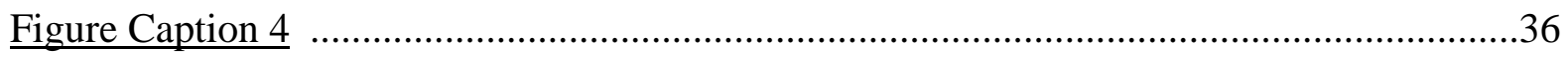

Figure 4: Probability of Key-2 Responses under the FOPP ..................................................

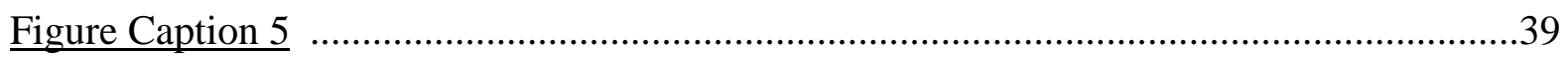

Figure 5: Mean Number of Responses on Four Trial Types for Each Pigeon..........................40

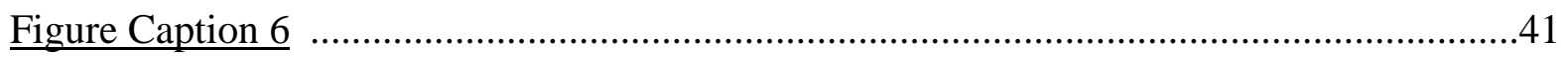

Figure 6: Responses, Reinforcers and Changeovers on Individual Trials for Pigeon 979 ......42

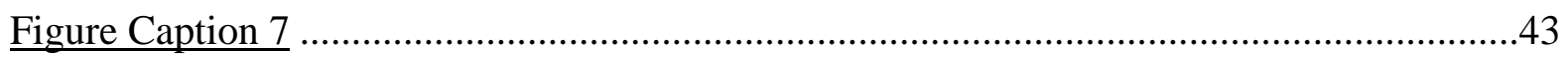

Figure 7: Responses, Reinforcers and Changeovers on Individual Trials for Pigeon 960 ......44

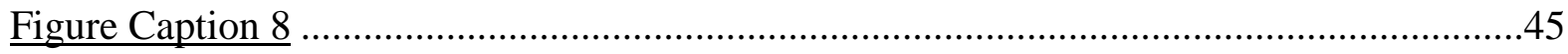

Figure 8: Responses, Reinforcers and Changeovers on Individual Trials for Pigeon 521 ......46

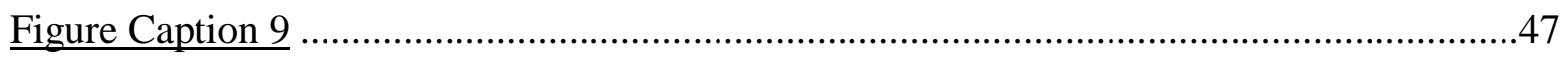

Figure 9: Responses, Reinforcers and Changeovers on Individual Trials for Pigeon 236 ......48

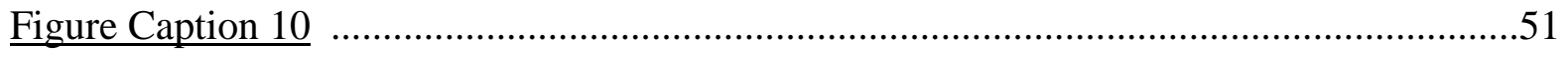

Figure 10: Cumulative Number of Responses for Each Pigeon under the FI ..........................52

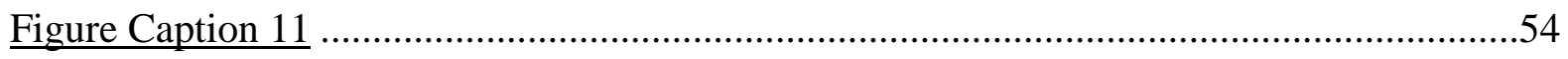

Figure 11: Number of Responses for Each Pigeon for 25 Sessions of Exposure to the FI .....55 
List of Tables

page

Table 1: Number of Sessions in Each Condition for Each Pigeon ......................................24

Table 2: Mean Number of Responses, Reinforcers, and Changeovers for Each Pigeon.........26

Table 3: Indexes of Curvature, Quarter-life Measures, and Post-reinforcement Pauses .........50 


\section{FIXED-INTERVAL PERFORMANCE AS A FUNCTION OF PREVIOUS TEMPORAL DISCRIMINATION TRAINING}

The importance of behavioral history has been recognized in the experimental analysis of behavior since its inception. Skinner (1953) noted that past environmental experiences must be taken into account when explaining present behavior. In his analysis of transition states, Sidman (1960) also emphasized the influence of historical factors on current behavior. He recognized that transition-state responding could not be studied without consideration of past experiences because this responding inevitably is affected by environmental variables that have maintained behavior previously. Although the importance of transition states may be rooted in the search for experimental control, behavior changes that occur during transition states and persist in subsequent steady states have become a topic of interest in their own right. These behavioral remains have been demonstrated in various conditions and various species, and are commonly referred to as behavioral history effects (e.g., Freeman \& Lattal, 1992; Ishida, Couvillon, \& Bitterman, 1992; LeFrancois \& Metzger, 1993; Weiner, 1964).

Because the behavior of all organisms is under the control of both current and past environmental conditions, history effects are important in various settings. For example, studying behavioral history can facilitate the development of new techniques in applied behavior analysis. Applied behavior analysts can learn what present contingencies are suited best to modify undesirable behaviors that were acquired and maintained under particular conditions (Wanchisen, 1990). Furthermore, knowing what environmental arrangements lead to the acquisition and maintenance of more persistent behavior may help to generalize newly learned alternative responses beyond clinical settings. For example, training appropriate classroom and 
employee behavior that will persist through changing conditions (e.g., a substitute teacher or a company's economic crisis) may result from behavioral history studies as well (Nevin, 1995).

In the laboratory, behavioral history has been defined as exposure to previous contingencies of reinforcement prior to some point in time. The effects of this history are defined by responding in subsequent conditions when different contingencies are operating. Different reinforcement contingencies are introduced, usually to produce differential rates or patterns in responding, to provide different behavioral histories. Following the establishment of the histories, new contingencies are effected and differences in responding due to the different histories are compared (e.g., Freeman \& Lattal, 1992; LeFrancois \& Metzger, 1993; Tatham, Wanchisen, \& Yasenchack, 1993; Urbain, Poling, Millam, \& Thompson, 1978; Wanchisen, Sutphin, Balogh, \& Tatham, 1998; Wanchisen, Tatham, \& Mooney, 1989). For the purposes of this paper, the former condition will be considered the history-building condition and the latter condition will be considered the history-testing condition.

A number of different schedules ranging from progressive-ratio (PR) to fixed-time (FT) schedules have been used in the history-building condition of behavioral-history studies (e.g., Johnson, Bickel, Higgins, \& Morris, 1991; Ono \& Iwabuchi, 1997; Trapold, Carlson, \& Myers, 1965; Wanchisen et al., 1989), although fixed-ratio (FR) and differential-reinforcement-of-lowrate (DRL), or interresponse time-greater-than- $t(\mathrm{IRT}>t)$, schedules are used most often (e.g., Freeman \& Lattal, 1992; LeFrancois \& Metzger, 1993; Tatham et al., 1993; Urbain et al., 1978). In the history-testing condition, fixed-interval (FI) schedules are used most often. Fixed-interval performance not only is affected by previous exposure to different schedules of reinforcement, such as a DRL schedule (Freeman \& Lattal, 1992; LeFrancois \& Metzger, 1993), but also by previous exposure to schedules of response-independent food delivery (Trapold et al., 1965). No 
published studies, however, have assessed how FI performance is affected by previous exposure to temporal discrimination procedures. Analyzing this type of history effect will not only extend the standing behavioral history literature beyond the use of schedules of reinforcement, but also further assess whether the effects produced by response-independent food delivery are a function of temporal properties present in the history-building condition. Following a literature review outlining the existing research on behavioral history, with an emphasis on the use of FI schedules to test for history effects, an experiment conducted to examine the effects of temporal discrimination training on FI responding will be discussed.

\section{LITERATURE REVIEW}

The frequent use of FI schedules to test the effects of behavioral history is, in part, a "history effect" itself: behavioral history studies originated with the examination of human responding in the presence of FI schedules (Holland, 1958). Because FI responding by humans in a laboratory setting varies across individuals (i.e., some humans respond consistently throughout the interval whereas others respond in a break-and-run pattern), many early behavioral history studies examined whether these differences in responding could be due to the complex history to which humans have been exposed (e.g., Weiner, 1964, 1969). Thereafter, basic researchers adopted procedures used in the human studies (including the FI) to assess history effects with nonhuman animals.

Fixed-Interval Schedules and Behavioral History

Fixed-interval responding yields more robust effects of behavioral history than responding under other schedules of reinforcement used to test for history effects, such as PR and VI schedules (Cohen, Pederson, Kinney, \& Myers, 1994; Freeman \& Lattal, 1992; Metzger \& Lattal, 1998). The differences between the susceptibility of FI responding and responding in 
the presence of other schedules to behavioral history is a function of variables in both the history-testing condition and the history-building condition.

\section{The History-Testing Condition}

There are two characteristics of FI schedules that may contribute to responding in their presence being sensitive (relative to responding in the presence of other schedules) to previous contingencies of reinforcement. First, FI schedules constrain responding to a lesser degree than do some other schedules of reinforcement. Second, FI performance allows measurement of different response rates and response patterns that may result from behavioral history.

\section{$\underline{\text { Response Constraint }}$}

Because, in the presence of FI schedules, reinforcement is delivered following a single response after a set interval has passed, optimal rates of reinforcement may be obtained when responding occurs at differential rates (e.g., low or high rates) or in differential patterns (e.g., steady responding or break-and-run patterns). Responding before the end of the nominal interval has no programmed effect and, thus, no effect on rate of reinforcement. Therefore, consistent responding throughout the interval and responding characterized by long post-reinforcement pauses both produce the same reinforcement rate. Rate of responding affects the rate of reinforcement in the presence of FI schedules only when IRTs are greater than the interval. This rarely occurs, however, therefore the rate of reinforcement typically is not dependent upon the rate or pattern of responding. This allowance for variability of behavior under FI schedules probably is related to the sensitivity of FI performance to past experience.

In the presence of VI schedules, by contrast, the rates and patterns of responding more directly affect the obtained rate of reinforcement (relative to FI schedules). Typically, VI schedules engender steady, consistent responding and, because there are short inter- 
reinforcement intervals (IRIs), beyond which reinforcement is available, responding inconsistently could lead to the loss of programmed reinforcement. Comparing the results of Urbain et al. (1978) and Poling, Krafft, and Chapman et al. (1980) reveals the differential sensitivity of FI and VI schedules to history effects. In both studies, current lever pressing by rats was compared following either a history of FR responding or IRT $>t$ responding. When FI schedules were used to test the effects of the differential histories by Urbain et al., rats previously exposed to the FR schedule responded at higher rates than did the rats previously exposed to the IRT $>t$ schedule throughout 93 sessions of identical FI exposure. When VI schedules were used to test the effects of the differential histories by Poling et al., however, rate differences dependent upon the differential histories only lasted through 47 sessions.

Urbain et al. (1978) and Poling et al. (1980) also administered d-amphetamine to test whether drug effects may be a function of the operant history of the organism. In the presence of FI schedules, the effects of d-amphetamine on responding were differentially affected by the previous contingencies in effect, but differences in the drug effects did not occur as a function of the differential history in the presence of VI schedules. These results suggest that, again, VI performance is less sensitive to past contingencies than FI performance, possibly because VI schedules constrain responding to a greater extent than FI schedules. The findings of Urbain et al. and Poling et al. also show that the magnitude of behavioral history effects is partly determined by the variables in the history-testing condition as well as variables in the historybuilding condition.

Fixed-interval performance

A second characteristic of FI responding that contributes to its appearing more sensitive to behavioral history (and a potential advantage of using FI schedules to assess history effects, 
cf. Cole, 2001), is the availability of response pattern as well as response rate for use as a dependent measure. When VI schedules are used to test for history effects, for example, steady responding occurs throughout the interval and, thus, only rates are used to assess the influences of the behavioral history. Examining changes in both rate and pattern may make FI schedules a more sensitive measure of history effects.

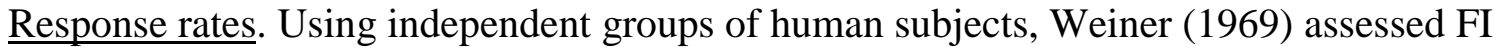
performance following exposure to DRL or FR schedules of reinforcement. Response rates in the presence of FI schedules were higher for subjects previously exposed to an FR schedule than for subjects previously exposed to a DRL schedule. Response rates in the presence of the FI schedules were similar between subjects previously exposed to similar schedules of reinforcement. This control of FI response rates by dissimilar behavioral histories was replicated by Freeman and Lattal (1992) using a within-subject design. Pigeons key pecked in the presence of FR and DRL schedules in a two-component multiple schedule. After stable and differential responding was established, FI schedules were effected in both components. Response rates were higher under the FI schedule in the presence of the stimuli previously correlated with an FR than under the FI schedule in the presence of the stimuli previously correlated with a DRL. Thus, response rates in the presence of FI schedules can be differentially affected by response rates previously maintained in the presence of different reinforcement contingencies using either between- and within-subject designs (e.g., Freeman \& Lattal, 1992; LeFrancois \& Metzger, 1993; Weiner, 1969).

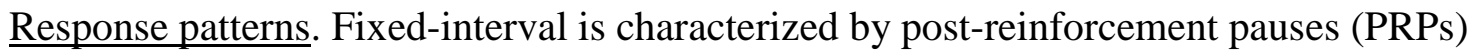
followed by progressively increasing response rates throughout the interval. This response pattern is known as the FI scallop. Fixed-interval performance does not always resemble a 
scallop, however. Variables, such as the length of the FI (e.g., FI 10-min schedules) and the length of exposure to the FI schedule, may lead to responding in a break-and-run pattern as seen in the presence of FR schedules (see Ferster \& Skinner, 1957). The specific pattern yielded by FI schedules also may depend on the level of data analysis conducted. Both Baron and Leinenweber (1994) and Schneider (1969), for example, showed that when FI responding was assessed on an interval-by-interval basis, then a break-and-run pattern resulted; whereas, a scallop pattern resulted when the intervals across an entire session were averaged before examining the pattern of responding.

Regardless of discrepancies between the specific pattern of responding that may result from FI schedules of reinforcement, FI responding may be described in terms of two different states of responding. In the initial (or interim) state, which begins after reinforcement, few responses occur; whereas, in the second (or terminal) state, responding occurs in a positively accelerated pattern until the reinforcer is delivered (Branch \& Gollub, 1974; Staddon, 1977). The point during the interval at which these two states cross, known as the point of maximum acceleration, or breakpoint, varies from interval to interval within subjects in single sessions (Schneider, 1969).

The sensitivity of these FI response patterns to behavioral history has been demonstrated, although the procedures used vary across experiments and the findings are equivocal. Tatham et al. (1993), for example, reported differential FI response patterns by rats following exposure to different DRL schedules. In the presence of an FI 30-s schedule, responding by rats previously exposed to a DRL 60-s schedule yielded longer IRTs than responding by rats previously exposed to either a DRL 10- or 30-s schedule and rats provided with no experimental history. Tatham et al.'s results are limited, however, because the IRTs were averaged across each session without 
examination of how the IRTs changed across each interval. That is, responding by the rats in all four groups may have been similar in pattern (e.g., steady responding), but yield differential IRTs because response rates by the rats in each group were discrepant. Post-reinforcement pauses (perhaps a better measure of patterns than aggregated IRTs) were significantly longer for responding by rats exposed to a DRL 60-s schedule when compared to the responding by rats provided with no experimental history. These differences in PRPs, however, were confounded by two sessions of training provided to each rat in which lever presses were reinforced according to an FR 1 schedule of reinforcement until 100 reinforcers were obtained. Exposure to these two training sessions may have shaped responding characterized by short IRTs by rats with "no experimental history" prior to testing FI response patterns.

Weiner $(1964,1969)$ and Cole $(2001)$ also found differences in FI response patterns following exposure to either FR or DRL schedules in humans and rats, respectively. Weiner, reported no quantitative measure of FI response patterns so differences in FI response patterns were determined by examination of the cumulative records provided. Cole reported that FI responding developed a scallop-like pattern more quickly in rats that had been exposed previously to both FR and DRL schedules than rats that had been exposed previously to only an FR or a DRL schedule. Cole found no differences, however, in FI patterns of responding between rats previously exposed to an FR schedule and rats previously exposed to a DRL schedule. This history effect, therefore, is related to a different issue concerning the efficiency of responding following exposure to multiple contingencies rather than FI response sensitivity to prior training on differential schedules of reinforcement (see also LeFrancois, Chase, \& Joyce, 1988; Weiner, 1969). 
Contrary to the discussed sensitivity of FI response patterns to behavioral history in these three studies, Freeman and Lattal (1992) found no systematic differences in FI response patterns as a function of behavioral history. They reported quarter-life measures (Herrstein \& Morse, 1957) to describe the FI performance by three pigeons following exposure to FR and DRL schedules of reinforcement in a two-component multiple schedule. FI responding between the two components by only one of the three pigeons was differentially described by the quarter-life measures, indicating that FI patterns were not affected by previous exposure to FR and DRL schedules of reinforcement. Overall, each of the studies that incorporated a between-subjects design (Cole, 2001; Tatham et al., 1993; Weiner, 1969), reported a difference in response pattern as a function of behavioral history, but no study using a within-subject design (Freeman \& Lattal, 1992) has revealed a systematic difference in response patterns as a function of behavioral history. The different results obtained by these studies also may relate to the different FI values used. Freeman and Lattal used FI values ranging from $19 \mathrm{~s}$ to $24 \mathrm{~s}$ whereas Cole and Tatham et al. used FI 30-s schedules. The diversity of procedures and dependent measures used and the mixed results yielded by this area of research suggest that further examination of the susceptibility of FI response patterns to behavioral history is required.

\section{The History-Building Condition}

A number of different schedules of reinforcement have been used in the history-building condition of behavioral-history studies to produce changes in subsequent FI performance (e.g., FR, DRL, and PR) (Baron \& Leinenweber, 1995; Freeman \& Lattal, 1992; LeFrancois \& Metzger, 1993; Tatham et al., 1993; Urbain et al., 1978; Wanchisen et al., 1989; Weiner, 1964; 1969). Because the use of these schedules was discussed indirectly in the preceding section, they will not be reviewed again here. It is important to note presently that each of the procedures used 
in the history-building condition reviewed thus far established a relation between a response and a reinforcer delivery. That is, each of the schedules produced differential responding (either across subjects in different groups or across multiple discriminative stimuli) in the historybuilding condition before FI schedules were effected. Following exposure to a multiple FR DRL schedule, for example, differences in response rates and patterns between the components will occur. Specifically, shorter IRTs may be reinforced in the presence of the FR and longer IRTs may be reinforced in the presence of the DRL. Therefore, differences in FI responding that result as a function of the differential histories may be a function of the differential rates or patterns already intact prior to the onset of the history-testing condition. In these situations, the history effect is the persistence of already established rates or patterns of responding in the presence of the FI schedule.

FI performance, however, can be affected by differential behavioral histories other than response-dependent schedules of food delivery that, in turn, produce differential responding. Response rates and patterns under FIs, for example, are sensitive to prior exposure to different patterns of response-independent food delivery. Trapold et al. (1965) exposed rats in different groups to one of three conditions: (1) no history-building training, (2) an FT 2-min schedule of food delivery, or (3) a variable-time (VT) 2-min schedule of food delivery. Each rat then was exposed to an FI 2-min schedule. Trapold et al. measured response patterns by assessing rates of responding during the each minute of the FI and by calculating what he termed a scallop index of responding during each session.

During the first minute of the FI, response rates were lower by the rats previously exposed to the FT schedule than by the rats previously exposed to the VT schedule. This difference in responding was observed during the first 12 sessions of exposure to the FI schedule. 
Response rates during the second minute of the FI were higher for the rats previously exposed to the FT schedule than for the rats previously exposed to the VT schedule. These response-rate differences in both the first and second minute of the FI occurred during each of the fifteen sessions of exposure to the FI schedule and the differences between the rates increased as exposure was extended.

To assess differences in FI patterns, Trapold et al. (1965) calculated scallop indexes (the ratio of the number of responses in the second minute of the interval to the number of responses throughout the entire interval). Scallop index measures were higher for responding by the rats previously exposed to the FT schedule than for the responding by the rats previously exposed to the VT schedule. This measure indicates a difference in response patterns that resulted between the two groups, but this difference in scalloping occurred only during the second through fifth session of exposure to the FI. Because differences in patterns occurred under the FI, these results suggest that food-pellet delivery according to an FT schedule may function as a discriminative stimulus for the passage of time. The discriminative control over the passage of time would then, in turn, lead to less responding early in the FI similar to the responding by the rats previously exposed to the FT schedule. Trapold et al., however, used a between-subjects design and did not provide response data from individual subjects. This restricts the reliability of his findings because, as stated previously, differences in FI response patterns following differential behavioral histories has not been demonstrated using a within-subject design and because the use of group means may have masked some of the results.

Temporal Discrimination and Temporal Differentiation

Temporal control of responding can be construed as either temporal discrimination or temporal differentiation. Temporal discrimination, defined by Catania (1970) as the control of 
responding by temporal patterning of events serving as discriminative stimuli, conventionally has been examined using psychophysical procedures. Conversely, temporal differentiation, defined by Catania as the temporal patterning of responses resulting from differential reinforcement, conventionally has been examined using temporally defined reinforcement schedules. Although temporal discrimination and temporal differentiation are distinct procedurally, the degree to which similar mechanisms underlie the occurrence of these two types of temporal control is unknown. Stubbs and Dreyfus (1981), for example, distinguished between temporal control resulting from schedules of reinforcement and psychophysical procedures because psychophysical procedures yield more "pure" temporal discrimination measures than do reinforcement schedules. Under reinforcement schedules, variables other than temporal properties of the environment may come to control responding, making it difficult to assess the extent to which responding is a function of discriminative temporal events versus other factors.

A complete analysis of the distinction between temporal discrimination and temporal differentiation is beyond the scope of this paper. But because the present thesis is concerned with differences in FI performance (a temporal differentiation procedure) as a result of differential temporal discrimination training, a review of common temporal discrimination procedures and their contribution to the standing literature is provided below. First, psychophysical procedures used to assess temporal discrimination are described, followed by a discussion of the possible contribution of temporal discrimination to temporal differentiation including a review of intermediate procedures developed to form a continuum between temporal discrimination and temporal differentiation. 


\section{$\underline{\text { Psychophysical Procedures }}$}

Temporal discrimination traditionally has been examined using psychophysical trials procedures (see Stubbs, 1979, for a review) consisting of series of trials presented across each session such that choice responses are required following stimulus presentations that define temporal intervals. Typically, a stimulus (such as a houselight or key light) is presented for a programmed length of time. This stimulus presentation is followed by a choice response to indicate the preceding stimulus duration.

Stubbs (1968), for example, trained pigeons' differential responding to one of two keys following short or long intervals. A single (observing) response to a center key changed the center key color from orange to white, and the key remained white for an interval between 1 and $10 \mathrm{~s}$ on different trials. The white light then was turned off and two side keys were transilluminated: one red and one green. Reinforcement was available according to a FR 6 schedule for pecking one of the two side keys, depending upon whether the center key remained white for a short (1-5 s) or a long (6-10 s) interval. A number of studies have used procedures similar to this conditional discrimination procedure described (e.g., Church, Getty, \& Lerner, 1976; Stubbs, 1976a) and similar methods, such as the interval bisection procedure (e.g., Church

\& Deluty, 1977; Stubbs, 1976b), to assess temporal discrimination. Overall, the discrimination of temporal intervals conforms to Weber's Law (i.e., discrimination is a function of relative rather than absolute differences between the intervals to be discriminated), and the point at which two intervals are perceived to be equivalent falls around the geometric mean of the intervals. Contribution of temporal discrimination to FI responding

In the presence of temporal discrimination procedures, responding comes under discriminative control of intervals differing by as little as $2 \mathrm{~s}$. In the presence of FI schedules, 
however, responding occurs prior to the end of the interval and sometimes near the beginning of the interval. Therefore, it appears that the contribution of temporal control to responding is differential between these procedures. This discrepancy between the accuracy of temporal control present in psychophysical procedures and the temporal control exerted by schedules of reinforcement has suggested caution in attributing control of FI performance strictly to temporally defined variables. Post-reinforcement pauses yielded by FI schedules, however, conform to the same laws (the psychophysical power law and Weber's law) as do the discrimination of temporal durations in psychophysical procedures (Lowe \& Wearden, 1981; Spencer, 1981). Therefore, temporal control under conditional discrimination procedures and under schedules of reinforcement may be functionally equivalent (Catania, 1970).

The extent to which response patterning in the presence of FI schedules is controlled by temporal factors is unknown. Other factors, such as delay of reinforcement gradients (Dews, 1962), may be involved in FI performance. Furthermore, psychophysical procedures may confine responding more than FI schedules, resulting in more control by temporal parameters of the procedure. For example, there is no explicit consequence for responding prior to the end of the interval in the presence of FI schedules, whereas incorrect responses in conditional discrimination procedures may lead to a time-out or correction procedure. This suggests that because reinforcement is contingent upon temporal discrimination, accurate discrimination occurs in the psychophysical procedures, but it does not imply necessarily that the temporal control involved in psychophysical procedures is functionally different from the temporal control involved in FI schedules. Thus, the contribution of temporal discrimination to FI performance seems to warrant further experimental analyses. 
To better understand the relation between FI patterns and temporal discrimination, procedures that integrate the psychophysical methods of assessing temporal discrimination and reinforcement schedules have been developed (Stubbs, 1980; Stubbs \& Dreyfus, 1981). Stubbs, Vautin, Reid, and Delehanty (1978), for example, alternated presentations of a center key on which responding was reinforced according to an FI schedule with presentations of a center key for either a short or long duration that served as a sample stimulus in a conditional discrimination paradigm. The accuracy of choice responses following stimulus presentations of either short or long intervals was positively correlated with the index of curvature for FI responding across different values of the FI. That is, as the FI value increased, the index of curvature and the accuracy of choice responses decreased. Because the accuracy of choice responses was correlated with FI performance, these results suggest that FI performance can be affected by temporal discrimination training.

\section{Free-operant Psychophysical Procedures}

Stubbs (1971, as cited in Stubbs, 1979) developed the free-operant psychophysical procedure (FOPP) to integrate discrimination aspects of a traditional psychophysical procedure with free-operant aspects of traditional schedules of reinforcement. In a standard two-key operant chamber, pigeons were exposed to a series of 20-s trials throughout each session. A blue left key and a green right key were presented for the entire 20-s trial, where left key responses were reinforced during the first $10 \mathrm{~s}$ of the trial and right key responses were reinforced during the last $10 \mathrm{~s}$ of the trial. Pigeons responded more often on the left key than on the right key at the beginning of each trial, but responding on the left key decreased and responding on the right key increased as the $20 \mathrm{~s}$ elapsed. The probability of right key pecks (calculated as the number of right key responses divided by the number of total responses on the left and right key) yielded an 
ogival function across 2-s intervals throughout each trial, with the probability of right-key responses beginning at zero and increasing steadily until a probability of 1.0 was reached a few seconds prior to the termination of the trial.

Stubbs (1980) used a similar a similar free-operant procedure, but with an added changeover key. In the presence of two response keys, pigeons were exposed to a series of identical trials, each beginning with the onset of a blue changeover key and an orange main key. A single peck on the changeover key changed the color of the main key from orange to green. Trial durations were varied across conditions, but in each condition, pecking the orange main key was reinforced during the first half of the trial and pecking the green main key was reinforced during the second half of the trial. There was no programmed consequence for pecking the green main key during the first half of the trial or the orange main key during the second half of the trial. Stubbs demonstrated that the point of subjective equality (PSE) using the FOPP indicates the time into the trial that comprises the discriminated interval of time and shifts in the PSE across conditions of different trial lengths was accurately described by the power law and other measures of temporal discrimination used previously with other psychophysical procedures.

The possible differences in the role that temporal control plays in psychophysical procedures and free-operant schedules of reinforcement have been minimized in the FOPP. Thus, the temporal differentiation that results from exposure to FI schedules of reinforcement may be more similar to the temporal discrimination produced by the FOPP than temporal discrimination produced by other psychophysical procedures, such as conditional discrimination or the interval bisection procedure. This similarity may make FI performance more sensitive to previous exposure to a FOPP than other methods of temporal discrimination training. 


\section{STATEMENT OF THE PROBLEM}

Fixed-interval schedules of reinforcement foster more persistent history effects than do other schedules of reinforcement, such as VIs (e.g., Freeman \& Lattal, 1992; Poling et al., 1980; Urbain et al., 1978). In the presence of FI schedules, various response rates and response patterns may yield similar reinforcement rates. Thus, responding produced by contingencies present in previous conditions may be more readily accommodated in the presence of FI schedules than in the presence of other reinforcement schedules.

Differential response rates as a function of previous exposure to FR and DRL schedules of reinforcement have been shown to persist in the presence of FI schedules for as many as 93 sessions (Urbain et al., 1978), and differences in response rates under FI schedules have been shown using between- (Weiner, 1964;1969) and within-subjects designs (Freeman \& Lattal, 1992). Results from studies assessing differential response patterns as a function of behavioral history are more equivocal, however. Tatham et al. (1993) and Cole (2001) reported differences in FI responding by rats following differential exposure to schedules of reinforcement. Both of these studies used between-subjects designs, however, and Tatham et al.'s measures of response patterns (i.e., IRTs and PRPs) are limited. Freeman and Lattal (1992) found no effects of behavioral history on FI response patterns using a within-subject design and quarter-life measures as indexes of response patterns, although the FI values used by Freeman and Lattal may have been too short to reveal such an effect. Therefore, further research assessing the sensitivity of FI response patterns to behavioral history is required.

Fixed-interval performance may be influenced by variables other than prior exposure to response-dependent schedules of food delivery. Trapold et al. (1965), for example, showed differences in FI response patterns by rats resulting from either no experimental history or 
exposure to FT or VT schedules of reinforcement. There was less responding during the first minute of the interval by the rats previously exposed to the FT schedule than by the rats with no history or a history of VT exposure. Additionally, response rates were higher during the second minute of the interval for the rats previously exposed to the FT schedule than for the rats previously exposed to the VT schedule.

There are two implications of Trapold et al.'s (1965) results. First, differences in FI performance as function of prior experiences may occur independently of responding generated by the history-building condition. Whereas experiments assessing history effects under FI schedules usually test for convergence of response rates (e.g., Freeman \& Lattal, 1992; Metzger, 1992), differential responding in the Trapold et al. experiment occurred following a historybuilding condition in which no responding was occurring by rats in either group. Second, Trapold et al.'s findings suggest that FI patterns can be affected differentially by the responseindependent delivery of food across discriminative periods of time without differential reinforcement of specific IRTs. Differences in FI patterns reported by Tatham et al., for example, indicated that FI responding was characterized by longer IRTs following DRL exposure than was such FI responding when no experimental history had been provided. This difference in response patterning presumably occured because longer IRTs were reinforced during exposure to the DRL schedule, and similar IRTs persisted in the presence of the FI schedule. Because, again, the rats in Trapold et al. were not responding in the presence of the FT schedules during baseline, however, the differential responding in the presence of the FI schedule cannot be attributed to a history of differential reinforcement of longer or shorter IRTs.

If differences in patterns of FI responding occur without training specific response rates and/or patterns in the history-building condition, then the manipulation of other variables in the 
history-building condition, aside from response rates and/or patterns per se, may produce differences in subsequent FI performance. Additionally, if exposure to food delivery at fixed times during the history-building condition affects subsequent patterns of responding under FI schedules, then perhaps other types of "temporal experience" in the history-building condition affect subsequent FI response patterns.

Often times FI responding has been assessed to determine the role of temporal factors in such performance. One such attempt to isolate the temporal control by FI schedules has been to develop procedures along the continuum between psychophysical procedures yielding temporal discrimination, such as conditional discrimination procedures (e.g., Stubbs, 1968), and schedules of reinforcement yielding temporal differentiation, such as FI schedules. The FOPP, first described by Stubbs (1971, as cited by Stubbs, 1979), incorporated aspects of both temporal discrimination and temporal differentiation present in psychophysical procedures and schedules of reinforcement, respectively. That is, responding is not only under the control of temporal stimuli (i.e., the time since the onset of the key lights), but responding is also characterized by temporal patterns within a free-operant situation (i.e., the probability of responding on one of the two keys shifts as time elapses).

The present experiment was designed to assess the sensitivity of FI response patterns to prior exposure to differential temporal discrimination training. In relation to extant studies of behavioral history effects, it is unique because it used a within-subject design and because it further isolated (relative to previous experiments) temporal variables in the history-building condition. In the history-building condition, pigeons were exposed to a Fixed FOPP and a Variable FOPP in two components of a multiple schedule to establish a history of differential 
temporal discrimination in each component. Each pigeon then was exposed to identical FI schedules in each component of the multiple schedule in the history-testing condition.

\section{METHOD}

Subjects

Four male White Carneau pigeons approximately two years old were used. Each pigeon had a short experimental history that consisted of around forty sessions of exposure to a conditional discrimination procedure. Each was maintained at $80 \%$ of its free feeding weight while water and health grit was freely available in the home cage.

Apparatus

Four standard operant chambers were used to conduct the experimental sessions. Three chambers contained three response keys $(2.54 \mathrm{~cm}$ in diameter) located $25.4 \mathrm{~cm}$ from the bottom of the chamber and $8.89 \mathrm{~cm}$ apart from each other (center to center). The two side keys were $6.35 \mathrm{~cm}$ from each side end of the panel. A rectangular aperture, centered between the sides of the panel and $8.89 \mathrm{~cm}$ from the bottom of the panel, provided access to a solenoid-operated food hopper. A fourth chamber contained four response keys ( $3 \mathrm{~cm}$ in diameter) arranged in a diamond pattern on the work panel. The top center key was located $6.5 \mathrm{~cm}$ from the top and 16.5 $\mathrm{cm}$ from the bottom of the chamber. The bottom center key was located $7.5 \mathrm{~cm}$ below the top key, and both the top and bottom key were situated $15 \mathrm{~cm}$ from the left wall and $16 \mathrm{~cm}$ from the right wall of the chamber. The side keys centered vertically between the top center and bottom center keys and separated horizontally by $15 \mathrm{~cm}$. A rectangular aperture, located in the bottom right corner of the panel $(2.75 \mathrm{~cm}$ from the right wall and $7.5 \mathrm{~cm}$ from the bottom), provided access to a solenoid-operated food hopper. The insides of the chambers were either black or white depending upon the session time (i.e., the effected component). Attaching pieces of black 
poster board to the walls with a removable adhesive provided the black interior. The absence of the poster board left the chambers with a white interior. The work panel remained brushed aluminum in each case.

Three keys (left, center, and right) were transilluminated either a color (red or green depending upon the chamber) or white during each session. A white light illuminated the hopper aperture during its 3-s presentations for access to grain (i.e., reinforcer delivery). White noise and the operation of an exhaust fan on the side of each chamber masked extraneous noises. The experiment was controlled by and the data were recorded using a Med-pc® interface and Medpc ${ }^{\circledR}$ for Windows ${ }^{\circledR}$ software. This equipment was located in a room adjacent to the rooms housing the chambers.

Procedure

\section{Training}

Each pigeon was exposed to five training sessions that began with the presentation of either a colored or white (the color was randomly selected) left key on which pecking was reinforced according to a VI 10-s schedule until 30 reinforcers were delivered. After the delivery of 30 reinforcers, the left key color was terminated and the right key (either colored or white) was presented on which pecking was reinforced according to a VI 10-s schedule of reinforcement until 30 reinforcers were delivered. The training session ended following 60 reinforcer presentations.

\section{$\underline{\text { Experimental Conditions }}$}

Sessions occurred twice per day, six days per week. The two sessions conducted each day can be conceptualized as two components of a multiple schedule (cf. Bloomfield, 1967, Exp. 2). The time of day (morning or afternoon) in which each component occurred was selected 
randomly by a coin flip, with the criterion that the components were not presented in the same order for more than four consecutive days. In the Fixed component, the interior of the experimental chamber and the keys were white and, in the Variable component, the interior of the experimental chamber was black and the keys were red for Pigeons 521 and 236 and green for Pigeons 979 and 960.

History-building condition. Sessions consisted of 45 trials. A 10-s blackout occurred between each trial, comprising the intertrial interval (ITI). Each trial began with the transillumination of the center key. A single peck to the center key turned off the center key light and transilluminated the two side keys for $60 \mathrm{~s}$. Two independent VI schedules operated on each of the side keys and a 3-s changeover delay (COD) between the side keys was in effect in both components. The COD was initiated following a response on the changed-to alternative (i.e., a peck-peck COD, see Shahan \& Lattal, 1998) and ended after 3 s providing that no other changeovers occurred during the 3-s delay. Each VI schedule timed only during the portion of the trial in which reinforcement was available for pecking its respective key. The portion of the trial in which reinforcement was available for pecking one of the two side keys was different in each component. In the Fixed Component, pecking on Key 1 (the left key for Pigeons 979 and 960 and the right key for Pigeons 521 and 236) was reinforced during the first $30 \mathrm{~s}$ of each trial, whereas pecking on Key 2 (the right key for Pigeons 979 and 960 and the left key for Pigeons 521 and 236) was reinforced during the second $30 \mathrm{~s}$ of each trial. In the Fixed Component, therefore, reinforcement availability for key pecking switched from Key 1 to Key 2 after 30 s on each trial. In the Variable Component, reinforcement availability for key pecking switched from Key 1 to Key 2 after a variable amount of time on each trial. Each 60-s trial ended with the onset of the ITI. 
The number of sessions that each pigeon was exposed to each condition are provided in Table 1. Initially, two VI 10-s schedules of reinforcement were in effect on the side keys. The VI value then was increased (10 s, 15 s, 25 s, 40 s, 60 s) over several sessions until a VI 60-s schedule was operating on each key. In the Fixed component of Conditions 1-4, only Key 1 was presented during the first $30 \mathrm{~s}$ of each trial and only Key 2 was presented during the second $30 \mathrm{~s}$ of each trial for each pigeon to facilitate discrimination of the 30 -s interval.

In the Variable component of Conditions 1-5, the list of intervals used to determine the time into the interval at which reinforcement availability switched from Key 1 to Key 2 was manipulated. The list was changed in an attempt to maintain responding on both Key 1 and Key 2 throughout each trial in the Variable component. The list of intervals, however, had minimal effect on the functions obtained in the Variable component. In the FOPP sessions analyzed for the purposes of this paper (i.e., Conditions 5 and 7), the time at which reinforcement availability switched from Key 1 to Key 2 in the Variable component was determined by randomly selecting without replacement one of the following intervals: $0.5 \mathrm{~s}, 2 \mathrm{~s}, 15 \mathrm{~s}, 30 \mathrm{~s}, 45 \mathrm{~s}, 58 \mathrm{~s}, 59.5 \mathrm{~s}$. Conditions 5 and 7 were identical and Condition 6 differed from Condition 5 and 7 only in its absence of a COD between Key 1 and Key 2 in the Variable Component. Condition 6 was conducted for each pigeon except Pigeon 521 to increase the number of changeovers between Key 1 and Key 2 in the Variable component. Because Pigeon 979 responded at low rates on the left key (i.e., Key 1), additional training sessions consisting of a VI 15-s schedule operating on the left key only were implemented between Conditions 1 and 2 for Pigeon 979.

The history-building condition was in effect until each pigeon had been exposed to the final FOPP for a minimum of 70 sessions and until the mean probability of Key-2 responses for the last five sessions under the FOPP and the five sessions preceding the last five sessions under 
Table 1

Number of sessions in each condition for each pigeon. A FOPP (as described in the text) was used in Conditions 1-7 (C1 - C7). The conditions are labeled on the top line, descriptions of the Fixed and Variable components are provided in the second and third lines, respectively. The Fixed component was changed only once (from C4 to C5) when both keys were presented together rather than individually for its corresponding portion of the trial. The Variable component was altered according to the list of time intervals determining when reinforcement availability switched from Key 1 to Key 2 (C1 to $\mathrm{C} 4)$ and according to the presence or absence of a change-over delay between the two response keys (C5 to C7). The list of intervals used in each condition are provided below the table.

\begin{tabular}{|c|c|c|c|c|c|c|c|c|c|}
\hline & Training & $\mathrm{C} 1$ & $\mathrm{C} 2$ & $\mathrm{C} 3$ & $\mathrm{C} 4$ & $\mathrm{C} 5$ & C6 & $\mathrm{C} 7$ & $\mathrm{C} 8$ \\
\hline Fixed & & $1 \mathrm{Key}$ & $1 \mathrm{Key}$ & $1 \mathrm{Key}$ & *1 Key & 2 Keys & 2 Keys & 2 Keys & FI \\
\hline Variable & & List A & List B & List C & $*$ List D & List D & $\begin{array}{c}\text { List D } \\
\text { No COD }\end{array}$ & List D & FI \\
\hline \multicolumn{10}{|l|}{ Subject } \\
\hline 979 & 5 & 11 & 3 & 2 & 2 & 45 & 3 & 47 & 25 \\
\hline 960 & 5 & 13 & 3 & 3 & 2 & 45 & 3 & 27 & 31 \\
\hline 521 & 5 & 14 & 3 & 3 & 1 & 84 & & & 25 \\
\hline 236 & 5 & 17 & 3 & 3 & 2 & 47 & 3 & 28 & 30 \\
\hline
\end{tabular}

*3-s COD present after ITI

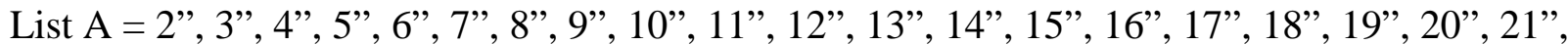
22”, 23”, 24”, 25”, 26”, 27”, 28”, 29”, 30”, 31”, 32”, 33”, 34”, 35”, 36”, 37”, 38”, 39”, 40”, 41", 42”, 43", 44”, 45”, 46”, 47”, 48”, 49”, 50”, 51”, 52”, 53”, 54”, 55”, 56”, 57”, 58 "

List B = 15", 30", 59.5", 15", 30", 59.5"

List C = 0", 16", 30", 58", 16", 30", 58"

List D = .05", 2", 15", 30", 45", 58", 59.5”, .5”, 2", 15”, 30", 45", 58”, 59.5" 
the FOPP were similar. Additionally, changeover rates in each component could not vary systematically across the last ten sessions.

History-testing condition. Identical FI schedules were effected in the Fixed and Variable components for pecking a white and a colored center key, respectively. The FI value was determined by the mean PSE (i.e., the time into the interval at which the probability of pecking on either key was equal) obtained for each pigeon under the last ten sessions of the historybuilding condition: Pigeon 979 was exposed to an FI 16-s schedule, Pigeon 960 to an FI 24-s schedule, and Pigeons 521 and 236 to an FI 25-s schedule. The order of components in which the FI schedules were introduced was counterbalanced across birds. Pigeons 979 and 236 were exposed to the FI schedule first in the Fixed component and Pigeons 960 and 521 were exposed to the FI schedule first in the Variable component. Each session lasted until 45 reinforcers had been obtained because this was a comparable number of reinforcers to what was obtained under the FOPP in the history-building condition.

\section{RESULTS}

The results will be described for each condition separately. Responding in each component under the FOPP will be reviewed first followed by a review of responding under the FI and analysis of the history effects.

\section{$\underline{\text { History-Building Condition }}$}

Table 2 shows the mean number of responses on each key, average time allocated to each key, mean number of reinforcers delivered for pecking on each key, and mean number of changeovers between keys over the last ten sessions under the FOPP. For each pigeon, except 
Table 2

Mean number of responses on Key 1 and Key 2, average time spent on Key 1 and Key 2, mean number of reinforcers on Key 1 and Key 2, and mean number of changeovers from Key 1 to Key 2 and Key 2 to Key 1 during the last ten sessions of exposure to the FOPP in the Fixed and Variable components for each pigeon.

\begin{tabular}{|c|c|c|c|c|c|c|c|c|c|c|c|c|c|c|c|c|}
\hline \multirow[b]{3}{*}{ Subject } & \multicolumn{4}{|c|}{ Responses } & \multicolumn{4}{|c|}{ Time } & \multicolumn{4}{|c|}{ Reinforcers } & \multicolumn{4}{|c|}{ Changeovers } \\
\hline & \multicolumn{2}{|r|}{ Fixed } & \multicolumn{2}{|c|}{ Variable } & \multicolumn{2}{|c|}{ Fixed } & \multicolumn{2}{|c|}{ Variable } & \multicolumn{2}{|c|}{ Fixed } & \multicolumn{2}{|c|}{ Variable } & \multicolumn{2}{|c|}{ Fixed } & \multicolumn{2}{|c|}{ Variable } \\
\hline & K1 & $\mathrm{K} 2$ & K1 & $\mathrm{K} 2$ & $\mathrm{~K} 1$ & $\mathrm{~K} 2$ & $\mathrm{~K} 1$ & $\mathrm{~K} 2$ & $\mathrm{~K} 1$ & $\mathrm{~K} 2$ & $\mathrm{~K} 1$ & $\mathrm{~K} 2$ & K1 & $\mathrm{K} 2$ & $\mathrm{~K} 1$ & $\mathrm{~K} 2$ \\
\hline 979 & 374.8 & 1586.1 & 546.4 & 2219.3 & 18.02 & 24.83 & 15.71 & 28.00 & 19.7 & 21.4 & 18.7 & 19.3 & 79.4 & 38.0 & 138.8 & 105.6 \\
\hline 960 & 934.7 & 2447.3 & 838.0 & 3870.0 & 22.28 & 21.12 & 16.22 & 27.55 & 20.9 & 20.9 & 19.2 & 19.7 & 55.8 & 13.2 & 213.2 & 179.7 \\
\hline 521 & 2007.1 & 1647.1 & 1833.2 & 2663.0 & 18.98 & 25.55 & 16.68 & 27.83 & 20.2 & 21.4 & 18.1 & 21.3 & 54.7 & 11.1 & 144.6 & 114.2 \\
\hline 236 & 963.5 & 1391.1 & 585.1 & 1577.4 & 19.37 & 24.28 & 9.90 & 33.87 & 20.6 & 21.8 & 15.3 & 20.8 & 47.4 & 2.8 & 46.5 & 2.2 \\
\hline
\end{tabular}


Pigeon 521, more responses occurred on Key 1 than Key 2 in both components. The amount of time allocated to each key is consistent with the noted differences in responding. The exceptions were Pigeon 960 in the Fixed component, where fewer responses occurred on Key 1 despite the allocation of slightly more time to Key 1, and Pigeon 521 in the Fixed component where more responses occurred on Key 1 despite the allocation of less time to Key 1.

The number of reinforcers obtained for pecking each key were similar for all pigeons. When differences in reinforcers obtained did occur, fewer reinforcers were delivered for Key-1 responding than Key-2 responding. Reinforcers were delivered for pecking on each key at variable times during the trial in the Variable component, but only during the first $30 \mathrm{~s}$ for pecking Key 1 and in the second 30 s for pecking Key 2 in the Fixed component (see Figure 1). There was only one systematic pattern of reinforcement delivery that resulted in both components for each pigeon: There was a high number of Key-1 reinforcers delivered during the first $3 \mathrm{~s}$ of each trial under the FOPP in both components. This is most likely due to the early switching from Key 1 to Key 2 by each pigeon. Because responding occurred on Key 2 for most of the trial, there was often a reinforcer available for responding on Key 1 at the beginning of a trial because it was not obtained in the preceding trial.

The mean number of changeovers and the number of changeovers as a function of time into the trial are shown respectively in Table 2 and Figure 2 . The number of changeovers from Key 1 to Key 2 was higher than the number of changeovers from Key 2 to Key 1 for all pigeons in both components. Additionally, the number of changeovers from Key 1 to Key 2 and from Key 2 to Key 1 was higher in the Variable component than in the Fixed component for three of four pigeons. In the Fixed component, approximately one changeover per trial occurred and the changeovers were usually from Key 1 to Key 2. In the Variable component, however, more than 
Fixed-Interval Performance 28

\section{Next Page}

Figure 1. Mean number of reinforcers in the Fixed component (left column) and the Variable component (right column) across twenty 3-s intervals in each trial. Each graph represents the last five sessions of exposure to the FOPP for each pigeon. Note: the y-axes are scaled differently for Pigeons 521 and 236. 
FIXED
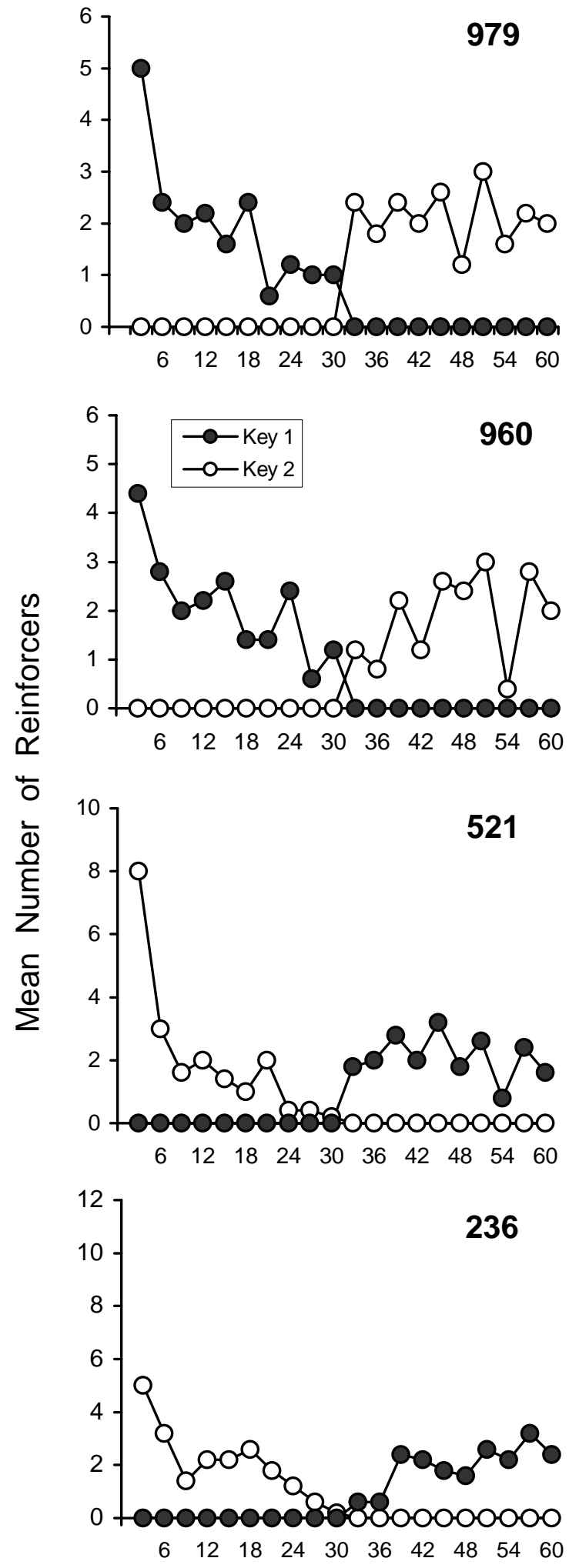

VARIABLE
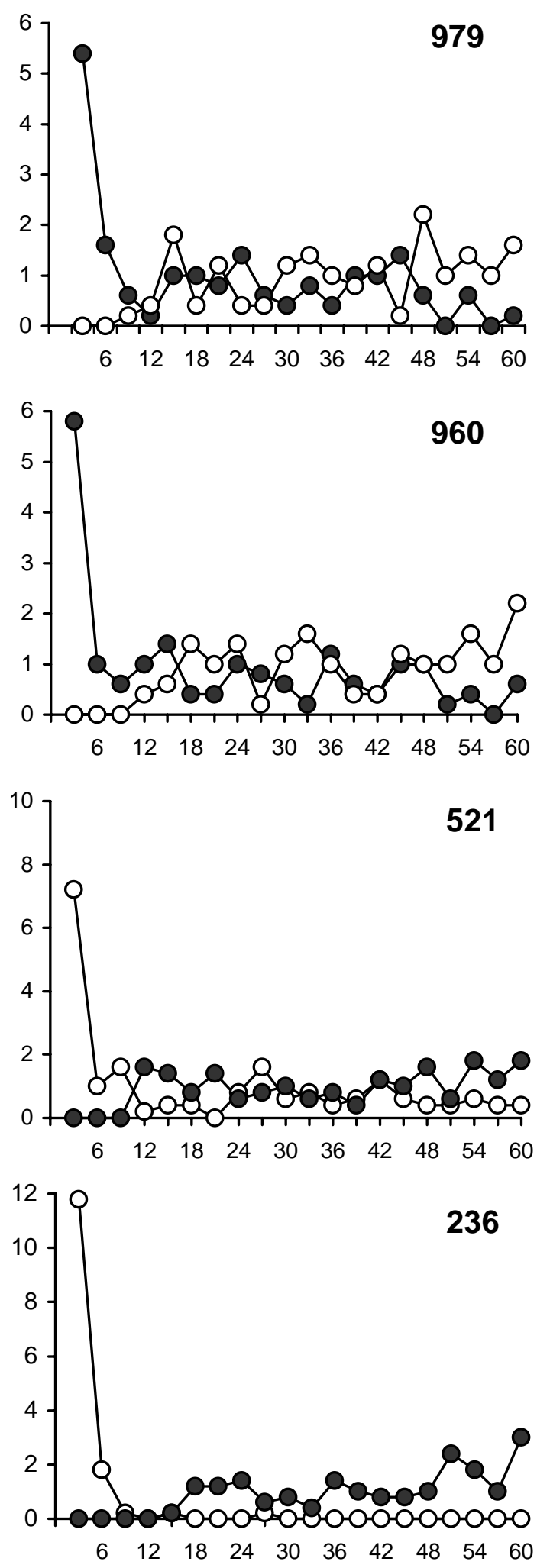

Time into Trial (s) 
Fixed-Interval Performance 30

\section{Next Page}

Figure 2. Mean number of changeovers in the Fixed component (left column) and the Variable component (right column) across twenty 3-s intervals in each trial. Each graph represents the last five sessions of exposure to the FOPP for each pigeon. 
FIXED
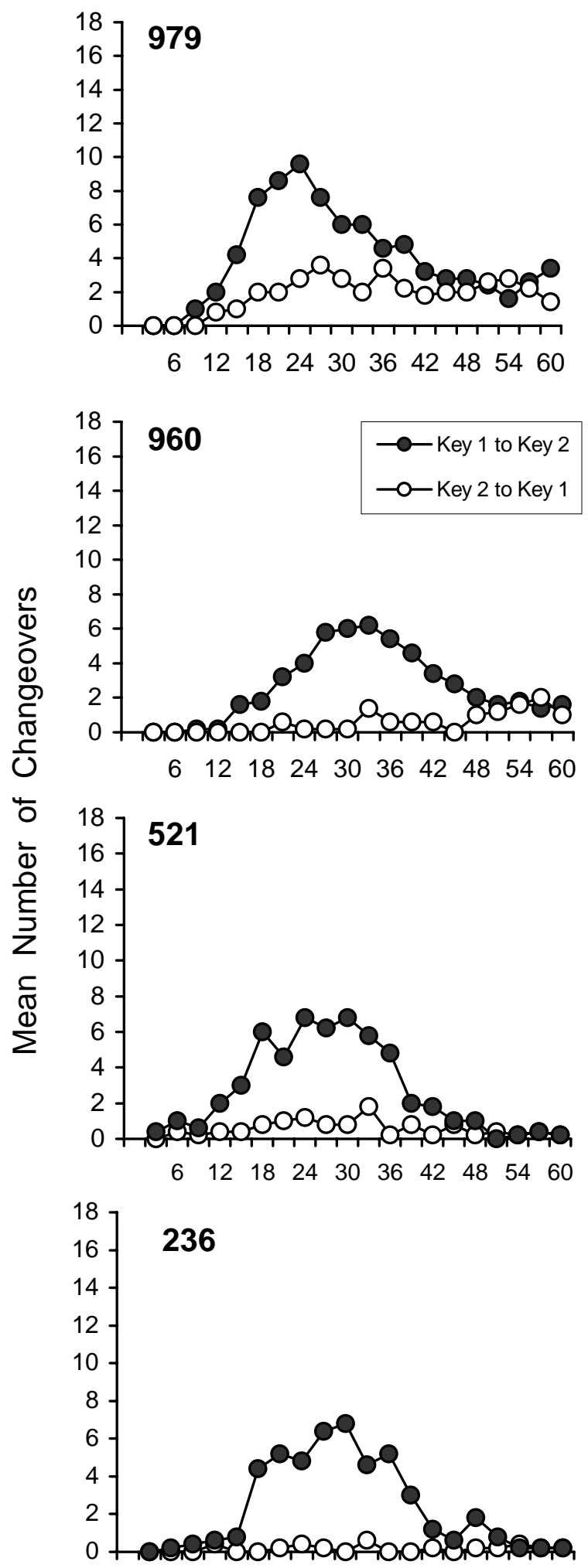

$\begin{array}{llllllllll}6 & 12 & 18 & 24 & 30 & 36 & 42 & 48 & 54 & 60\end{array}$
VARIABLE
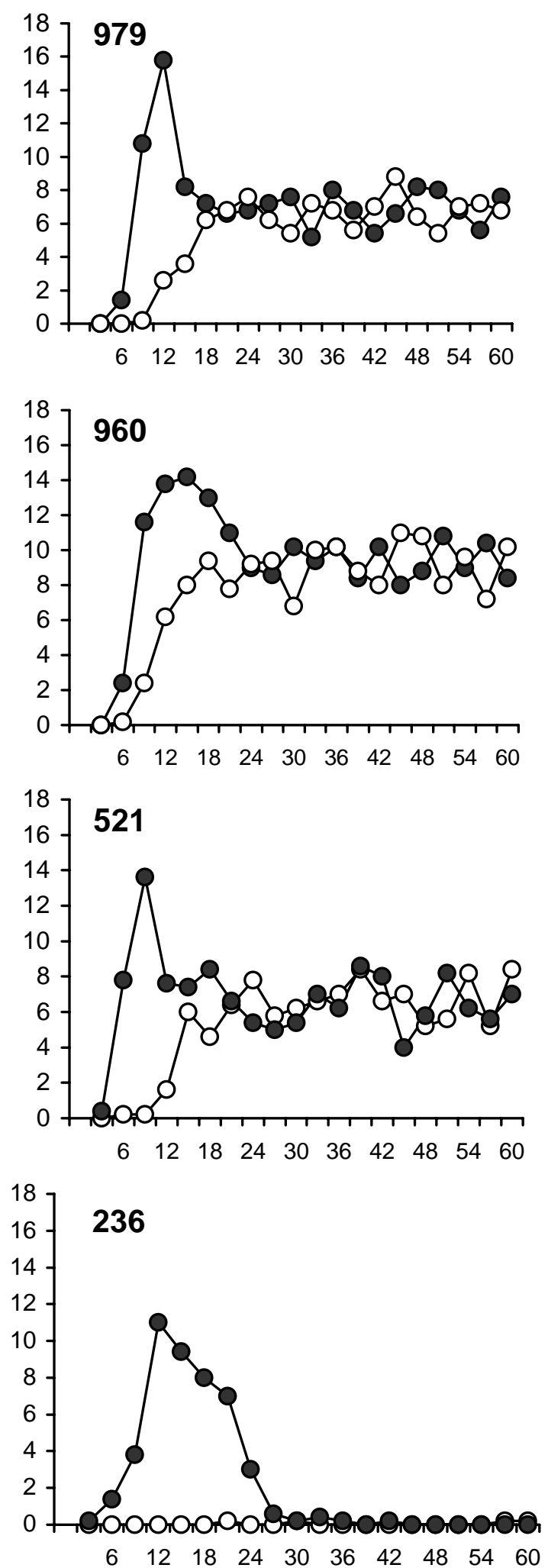

$\begin{array}{llllllllll}6 & 12 & 18 & 24 & 30 & 36 & 42 & 48 & 54 & 60\end{array}$

Time into Trial (s) 
one changeover per trial occurred, and changeovers in both directions (i.e., changeovers from Key 1 to Key 2 and changeovers from Key 2 to Key 1) occurred within more than half of the trials. For Pigeons 979 and 960, the greater number of changeovers in the Variable component resulted from exposure to three sessions (Condition 6) in which no COD was present in the Variable component. The absence of the COD facilitated contact with reinforcement availability for Key-1 pecking at intervals into the trial beyond 30 s. Although Pigeon 236 was exposed to the same three sessions with no COD and the number of changeovers in the Variable component increased during exposure to these sessions, the number of changeovers in the Variable component decreased to previously occurring levels when the COD was re-introduced in the Variable component (Condition 7).

The mean number of responses on Key 1 and Key 2 across each trial over the last ten sessions of the history-building condition is shown in Figure 3. Responding began on Key 1 at the beginning of each trial for all pigeons in both the Fixed and Variable components. However, responding on Key 1 persisted for longer times into each trial in the Fixed component than in the Variable component. The Variable component yielded similar functions as the Fixed component in that responding occurred on Key 1 early in the interval and on Key 2 later in the interval. The switching of reinforcement availability from Key 1 to Key 2 at variable times in the Variable component produced only one consistent effect across all pigeons: switching from Key 1 to Key 2 occurred earlier in the Variable component than in the Fixed component. Figure 3 shows that the Key-1 response function and the Key-2 response function cross one another at earlier points in the interval during the Variable component than during the Fixed component. Pigeon 521 was the only subject that yielded qualitatively different responding in the Variable and Fixed components. That is, for Pigeon 521, responding occurred at more similar rates on Key 1 and 


\section{Next Page}

Figure 3. Mean number of Key-1 and Key-2 responses during the Fixed component (left column) and the Variable component (right column) across twenty 3-s intervals of each trial. Each graph represents the last ten sessions of exposure to the FOPP for each pigeon. Note: the y-axes are scaled differently for each pigeon. 
FXED

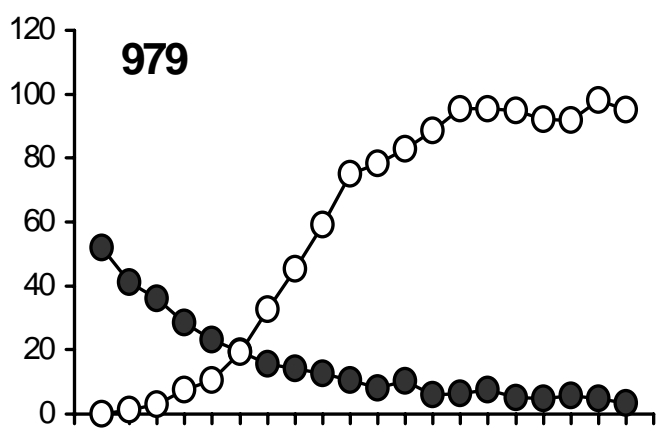

$\begin{array}{llllllllll}6 & 12 & 18 & 24 & 30 & 36 & 42 & 48 & 54 & 60\end{array}$
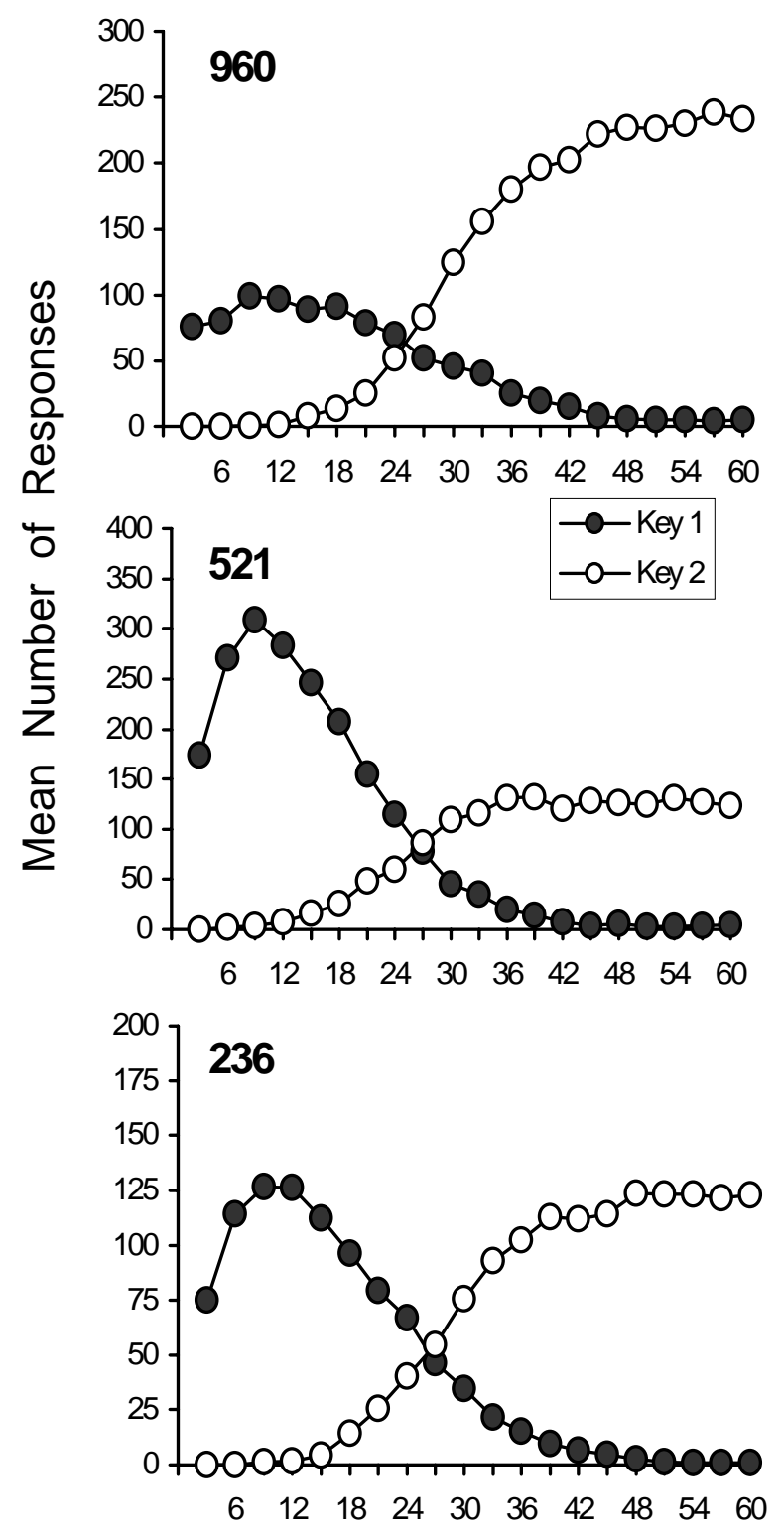

VARIABLE

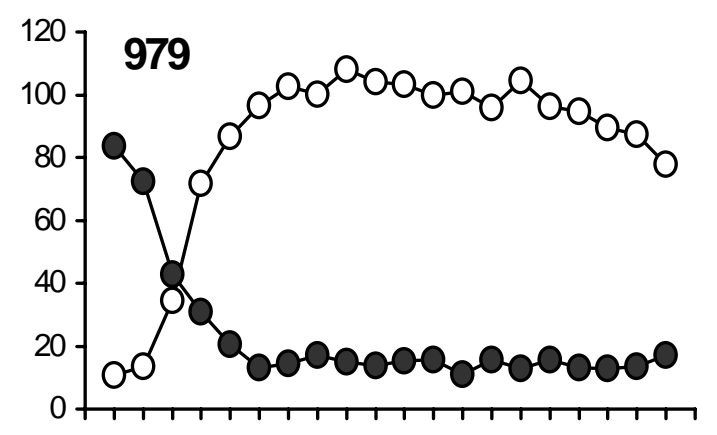

$\begin{array}{llllllllll}6 & 12 & 18 & 24 & 30 & 36 & 42 & 48 & 54 & 60\end{array}$
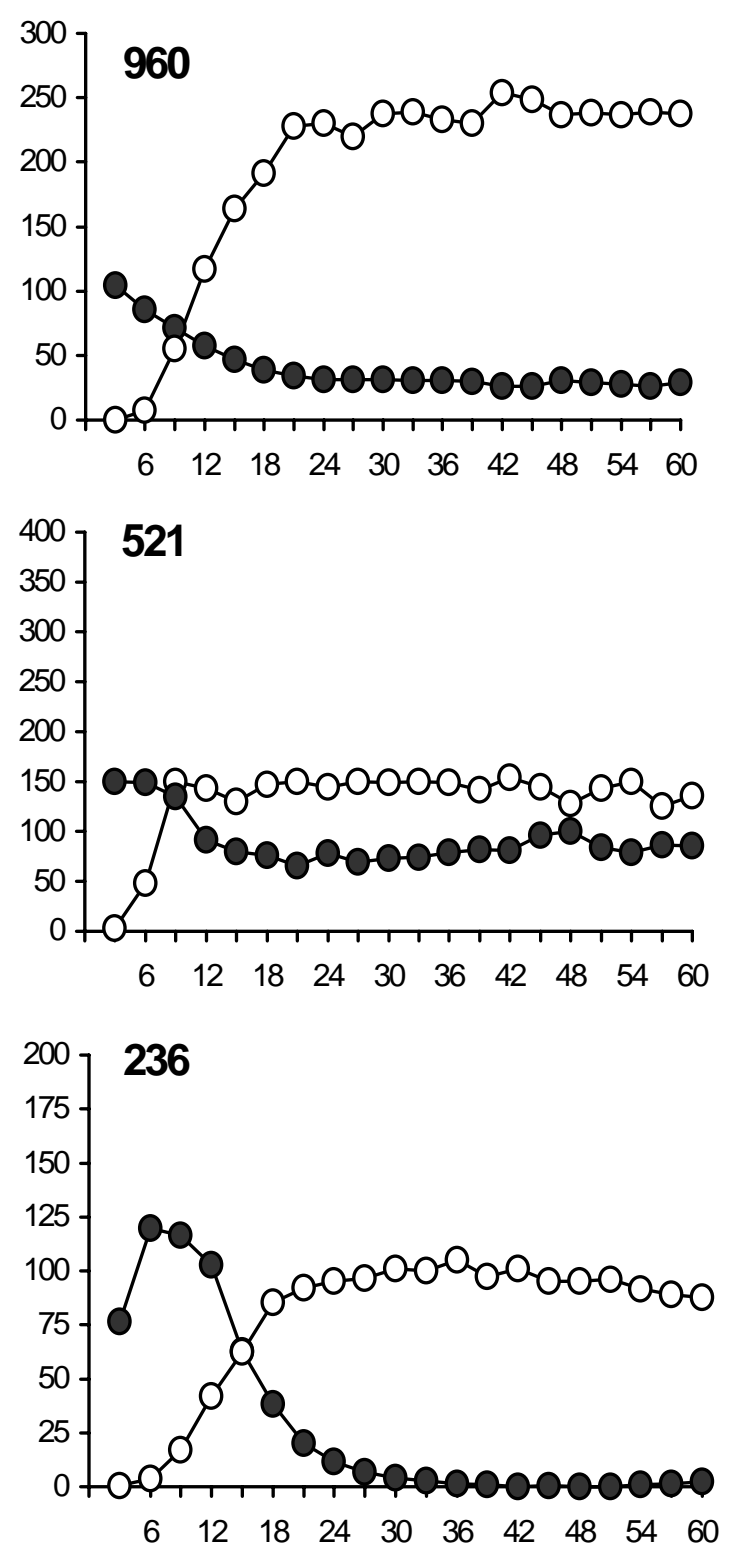

Time into Trial (s) 
Key 2 during the last $50 \mathrm{~s}$ of the Variable-component trials; whereas, responding occurred on Key 1 during the first $27 \mathrm{~s}$ and on Key 2 during the last $33 \mathrm{~s}$ of the Fixed-component trials.

Similar response effects are shown in Figure 4, where the probability of Key-2 responding is shown as a function of time into the trial. The probability of Key-2 responding was calculated by dividing the number of Key-2 responses by the total number of responses (Key 1 and Key 2). With the exception of Pigeon 979 (because of a strong right-key bias), the probability function for each pigeon in the Fixed component does not differ greatly from that typically obtained in studies utilizing a FOPP (see Machado \& Guilhardi, 2000). A comparison of the Fixed-component and Variable-component functions shows that the probability of Key-2 responses in the Variable component reached asymptotic levels after shorter periods of time into the trial than did the probability of Key-2 responses in the Fixed component. For three of four pigeons $(979,960$, and 236), Key-2 responding reached a probability of 1.0 before the end of the trial in the Fixed and Variable components. For Pigeon 521, however, the probability of Key-2 responding in the Variable component never increased beyond 0.7. This difference corresponds to that noted in Figure 3 regarding Pigeon 521's consistent responding on Key 1 and Key 2 throughout most of the interval in the Variable component.

To more closely analyze responding between the components, trials were divided into four types: (1) trials on which no reinforcer was delivered for responding on Key 1 or Key 2, (2) trials on which at least one reinforcer for responding only on Key 1 occurred, (3) trials on which at least one reinforcer for responding only on Key 2 occurred, and (4) trials on which at least one reinforcer for responding on both Key 1 and Key 2 occurred. Other studies using the FOPP have used responding on trials in which no reinforcers were delivered as indicative of true temporal 
Fixed-Interval Performance 36

\section{Next Page}

Figure 4 . The probability of Key-2 responses (the number of Key-2 responses divided by the total number of responses on Key 1 and Key 2) are shown for the Fixed component (left column) and the Variable component (right column) across twenty 3-s intervals in each trial. Each graph represents the last ten sessions of exposure to the FOPP for each pigeon. 
FIXED

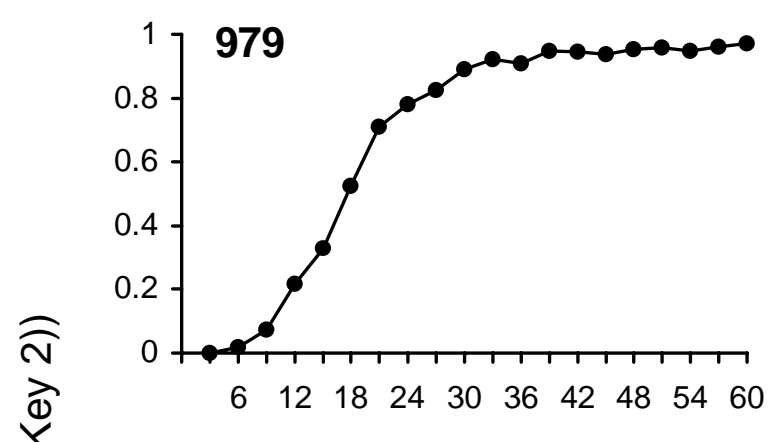

함

बे

N

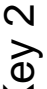

y

\&

$\stackrel{\infty}{\circ}$

$\frac{0}{0}$

$\stackrel{8}{\simeq}$

啇

¿

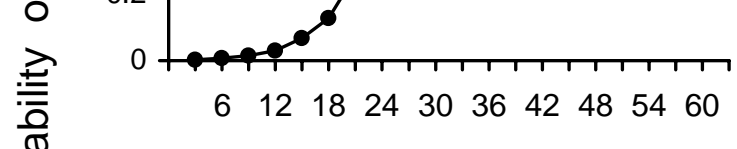

응

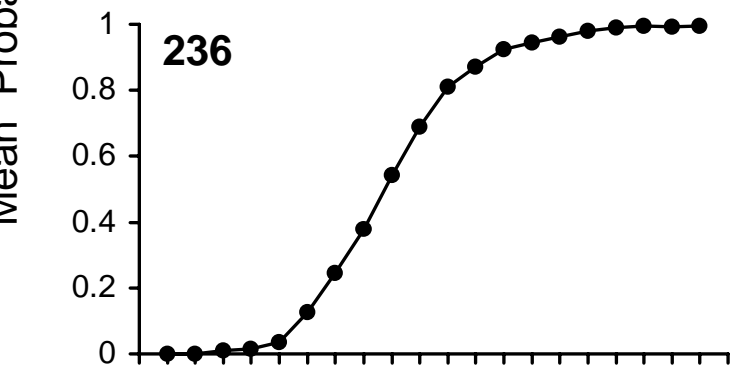

$\begin{array}{llllllllll}6 & 12 & 18 & 24 & 30 & 36 & 42 & 48 & 54 & 60\end{array}$
VARIABLE
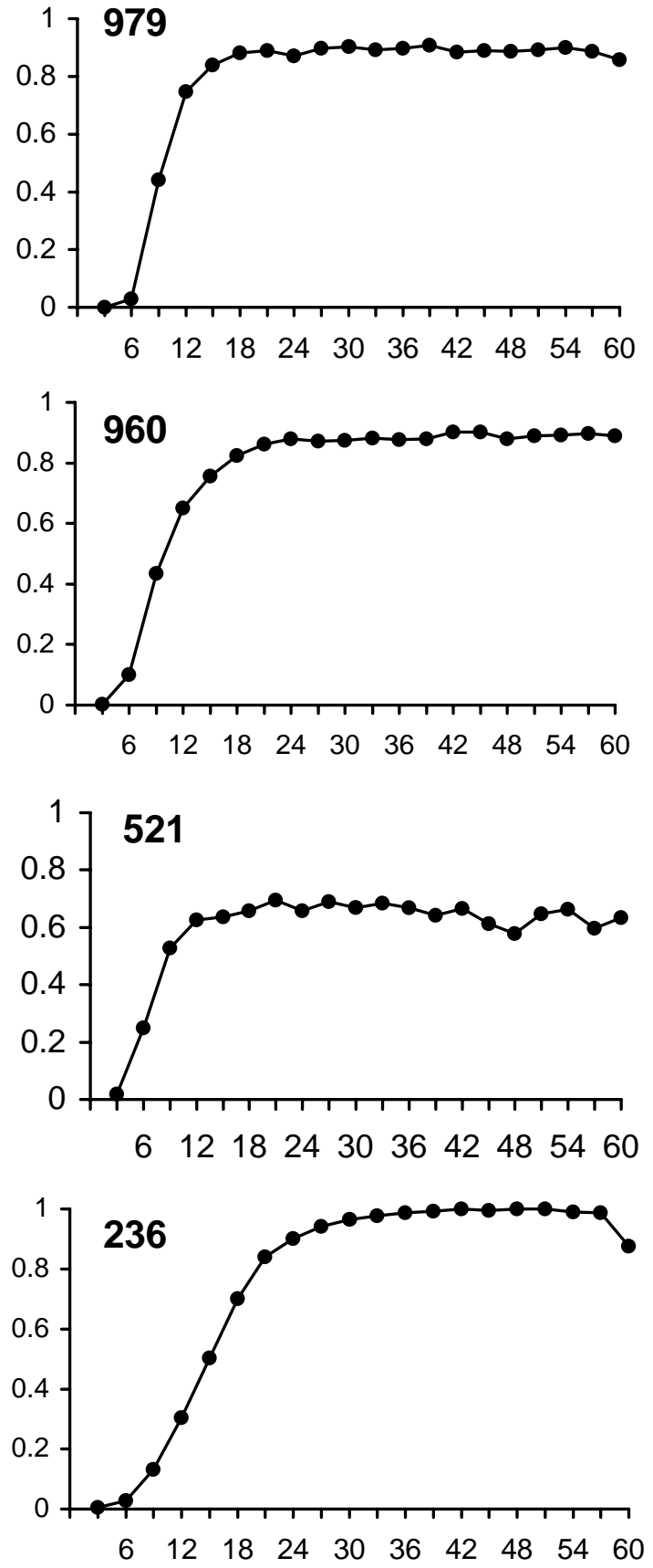

Time into Trial (s) 
discrimination (because the delivery of a reinforcer cannot serve a discriminative function for switching from Key 1 to Key 2).

Figure 5 shows mean Key-1 and Key- 2 responses by each pigeon during the last five sessions of exposure to the FOPP in each of the four trial types. For Pigeon 979, responding was similar across all four trial types in the Variable component, and responding was similar across three of the four trial types in the Fixed component. In the Fixed component, responding persisted longer on Key 1 during trials in which only a Key-1 reinforcer was delivered than during other trial types. For Pigeon 960, differential responding occurred during each of the four trial types in the Fixed and Variable components. For Pigeon 521, responding did not differ systematically across the four trial types in the Variable component; responding occurred on both keys throughout the interval during each trial type. Responding in the Fixed component, however, changed slightly across the four trial types. Responding on Key 1 persisted for the longest periods time into the interval during trials in which only a Key-2 reinforcer was delivered. Responding switched from Key 1 to Key 2 at the earliest time into the interval during trials in which both a Key-1 and a Key-2 reinforcer were delivered. Pigeon 236 responded differently during each of the four trial types in the Fixed and Variable component.

Figures 6-9 show responses on each key, reinforcers delivered on each key, and changeovers between each key on a single trial of each of the four trial types for each pigeon. There was no systematic process for selecting representative trials; however, all trials are from the last session of exposure to the FOPP and the trials shown are from various times throughout the session. Because responding persisted for varied times into the interval depending upon the delivery of a Key-1 or Key-2 reinforcer, individual trials were assessed to determine whether responding was under discriminative control of reinforcer deliveries. Responding illustrated by 


\section{Next Page}

Figure 5. Mean number of responses by each pigeon in the Fixed component (left column) and the Variable component (right column) across twenty 3-s intervals in each of four trial types: (1) trials with no reinforcers, (2) trials with Key-1 reinforcers only, (3) trials with Key-2 reinforcers only, and (4) trials with Key-1 and Key-2 reinforcers. Each graph represents the last five sessions of exposure to the FOPP. Note: The y-axes are scaled differently for each pigeon. 


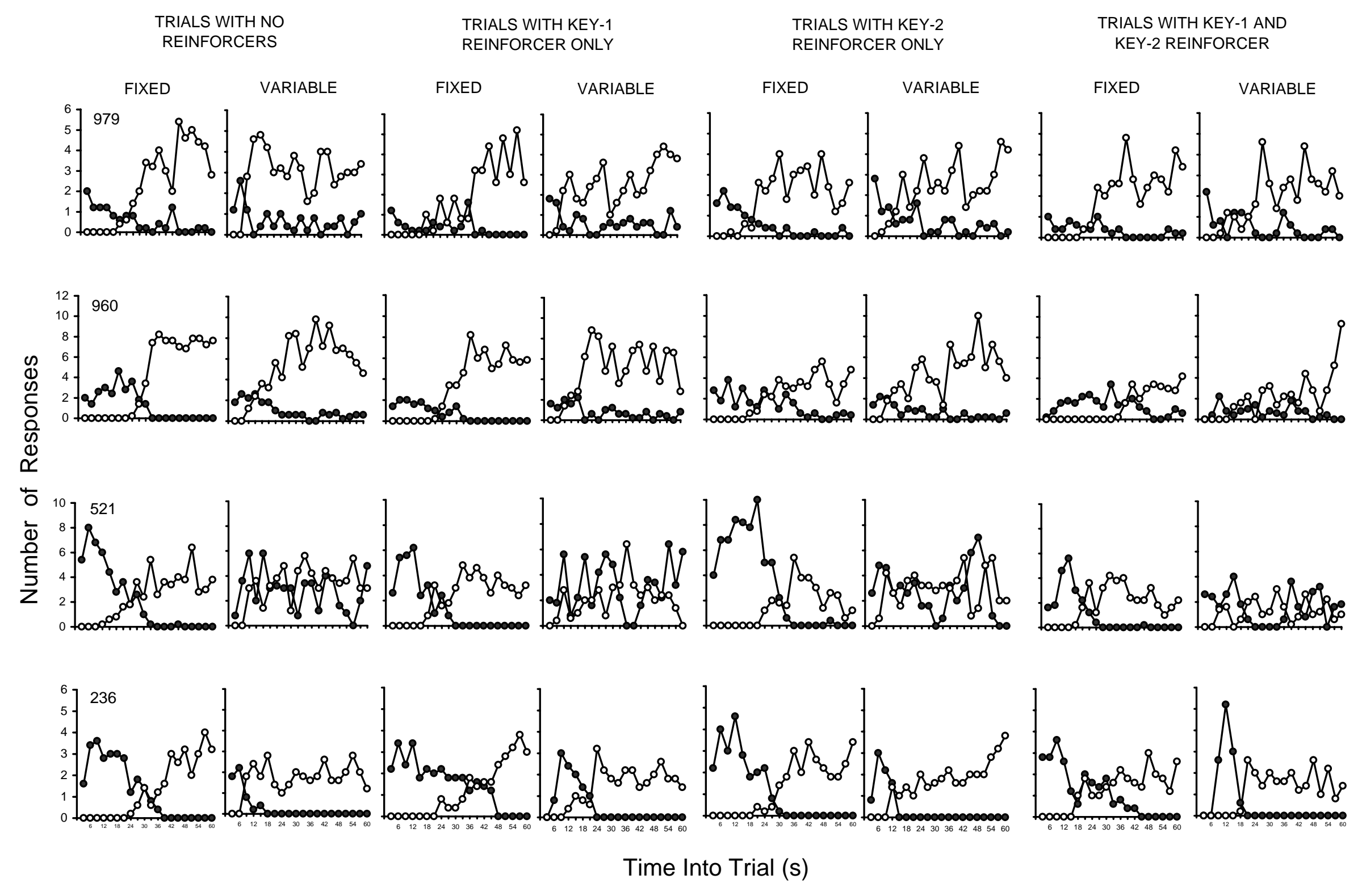




\section{Next Page}

Figure 6. Number of Key-1 and Key-2 responses across 3-s intervals of an individual trial of each trial type from the last session of exposure to the FOPP for Pigeon 979. Arrows indicate the time at which a reinforcer was delivered. A " 2 " above an arrow in the bottom figures indicate that the reinforcer was delivered for responding on Key 2. 
FXED
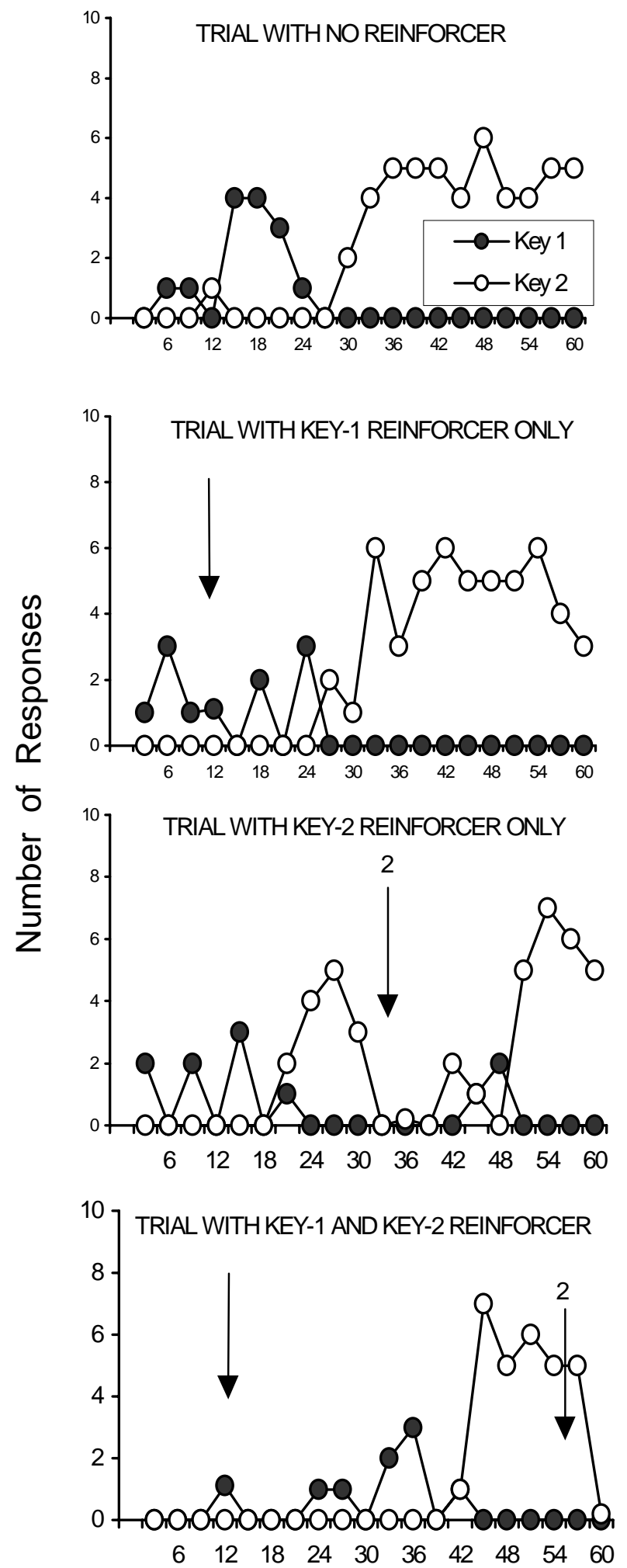

\section{9}
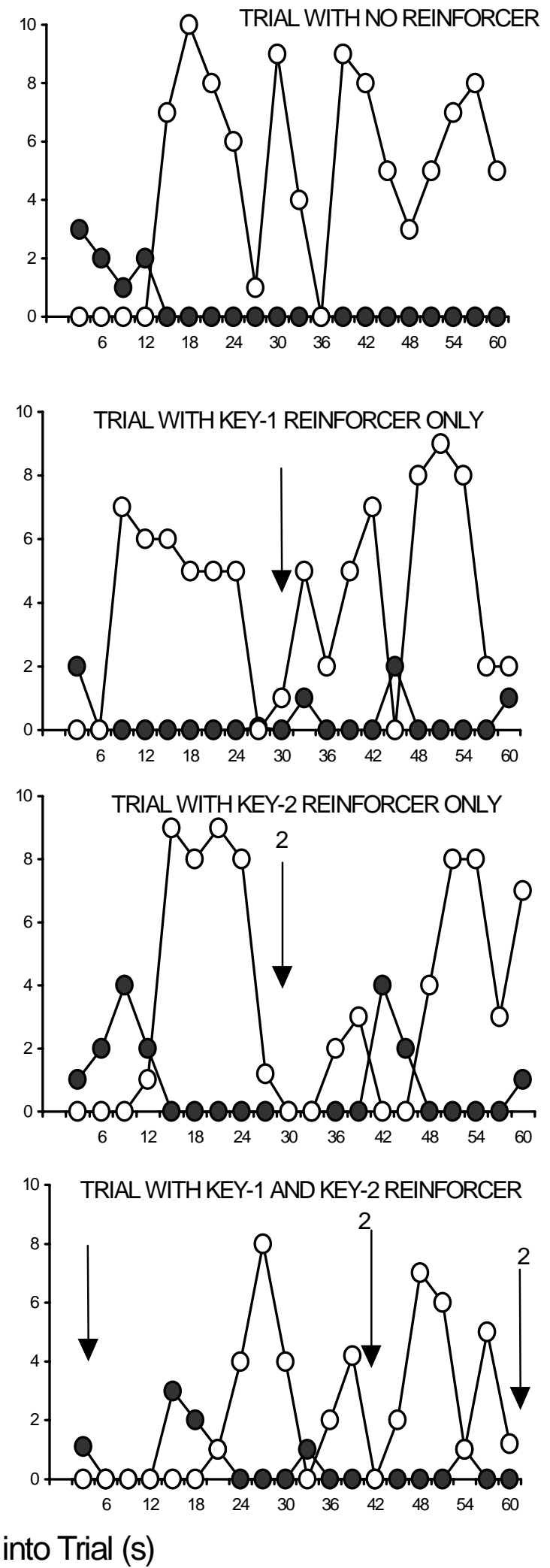


\section{Next Page}

Figure 7. Number of Key-1 and Key-2 responses across 3-s of an individual trial of each trial type from the last session of exposure to the FOPP for Pigeon 960. Arrows indicate the time at which a reinforcer was delivered. A " 2 " above an arrow in the bottom figures indicate that the reinforcer was delivered for responding on Key 2. 
FIXED
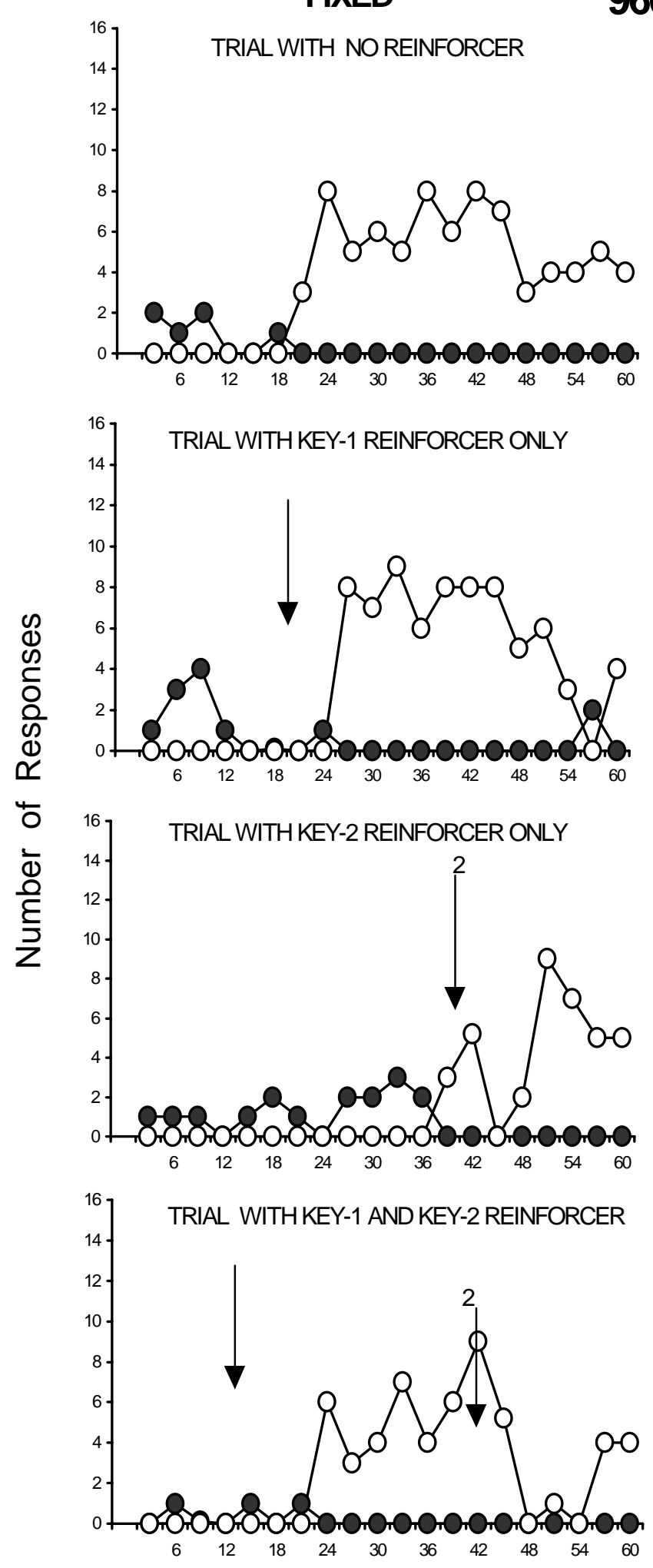

960
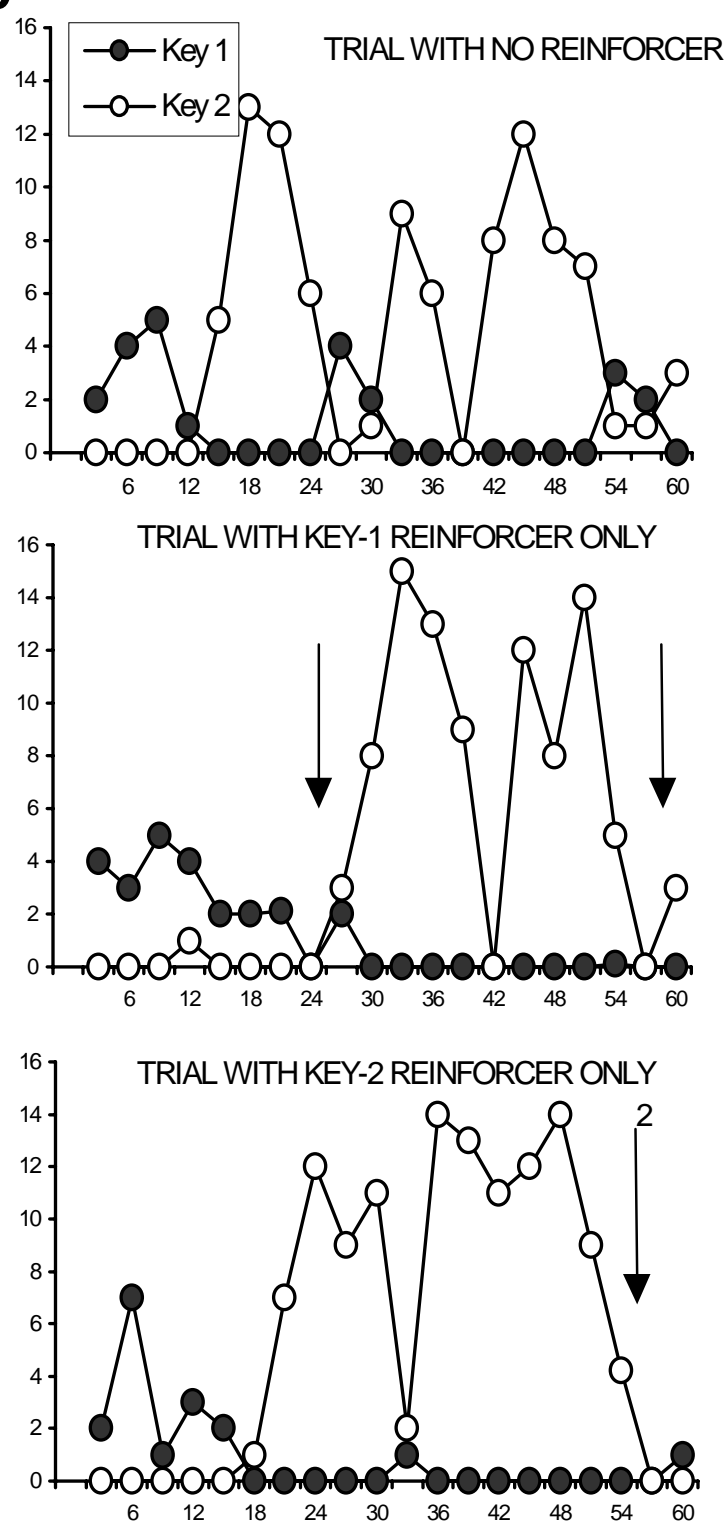

$\left.{ }_{16}^{16}\right]$ TRIAL WITH KEY-1AND KEY-2 REINFORCER

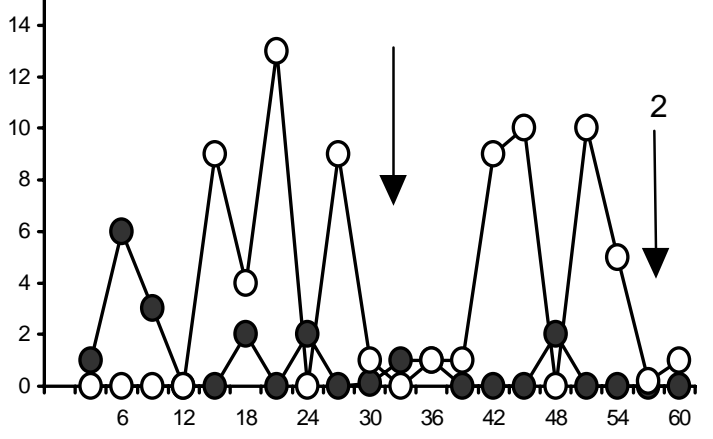

Time into Trial (s) 


\section{Next Page}

Figure 8. Number of Key-1 and Key-2 responses across 3-s of an individual trial of each trial type from the last session of exposure to the FOPP for Pigeon 521. Arrows indicate the time at which a reinforcer was delivered. A " 2 " above an arrow in the bottom figures indicate that the reinforcer was delivered for responding on Key 2. 
FIXED

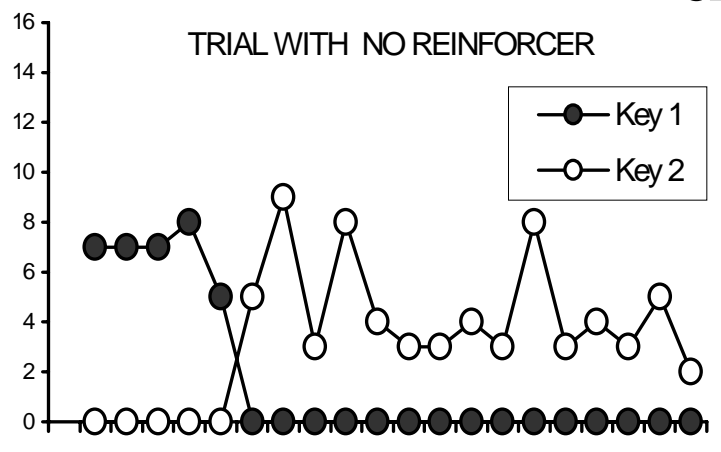

$\begin{array}{llllllllll}6 & 12 & 18 & 24 & 30 & 36 & 42 & 48 & 54 & 60\end{array}$
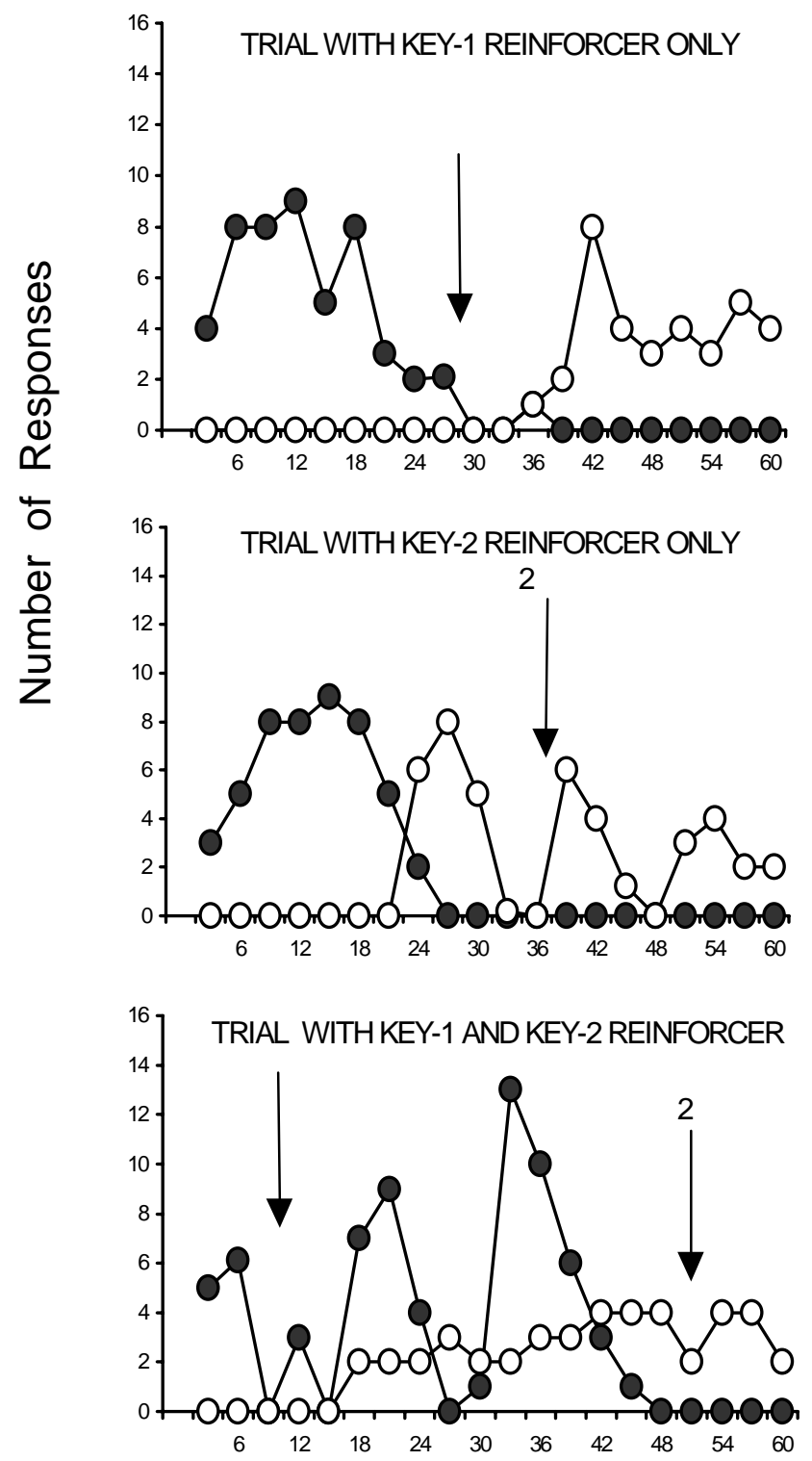

521
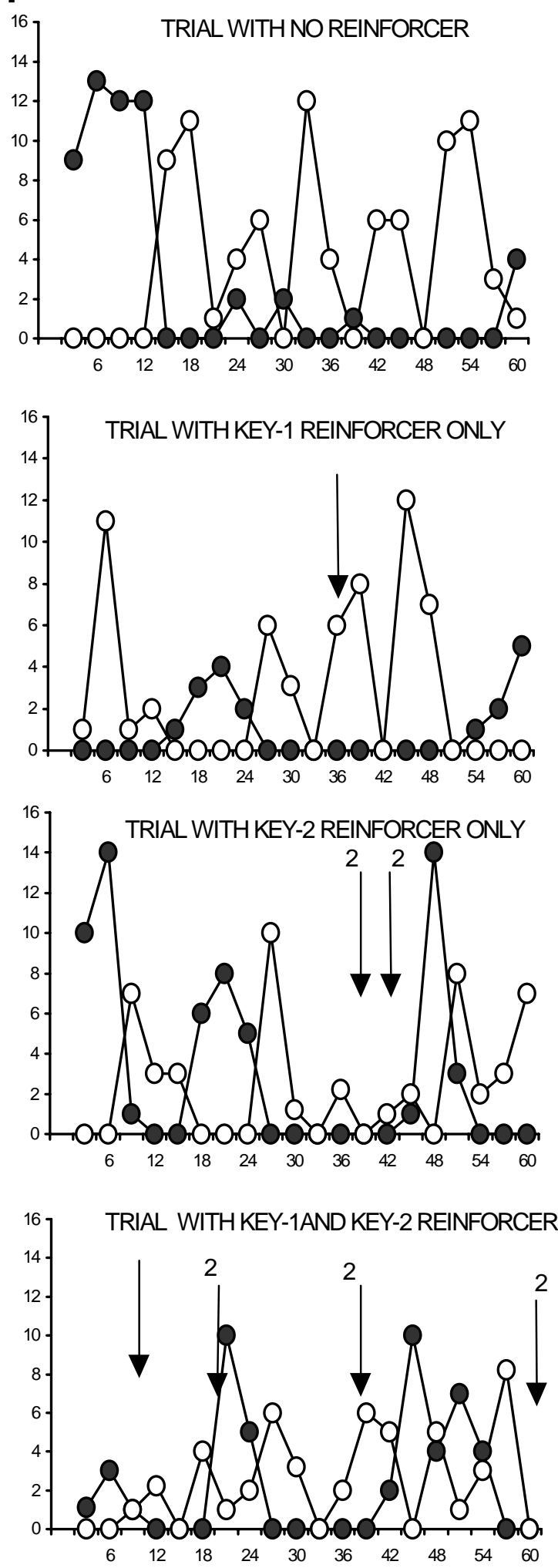

Time into Trial (s) 


\section{Next Page}

Figure 9. Number of Key-1 and Key-2 responses across 3-s intervals of an individual trial of each trial type from the last session of exposure to the FOPP for Pigeon 236. Arrows indicate the time at which a reinforcer was delivered. A " 2 " above an arrow in the bottom figures indicate that the reinforcer was delivered for responding on Key 2. 
FIXED

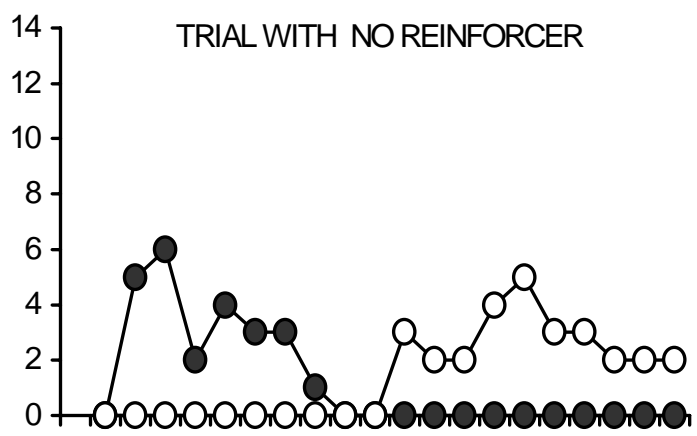

$\begin{array}{llllllllll}6 & 12 & 18 & 24 & 30 & 36 & 42 & 48 & 54 & 60\end{array}$
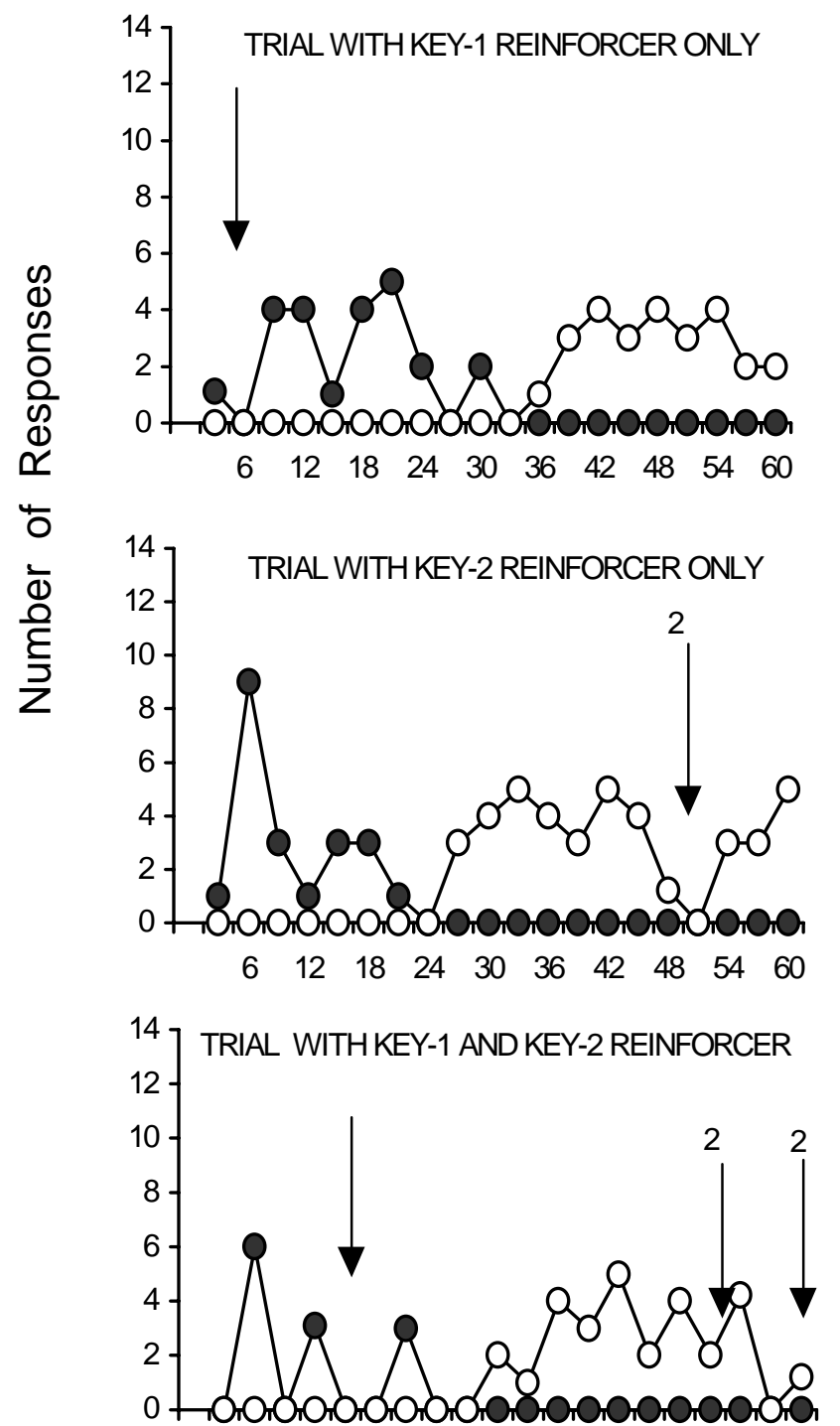

$\begin{array}{llllllllll}6 & 12 & 18 & 24 & 30 & 36 & 42 & 48 & 54 & 60\end{array}$
236
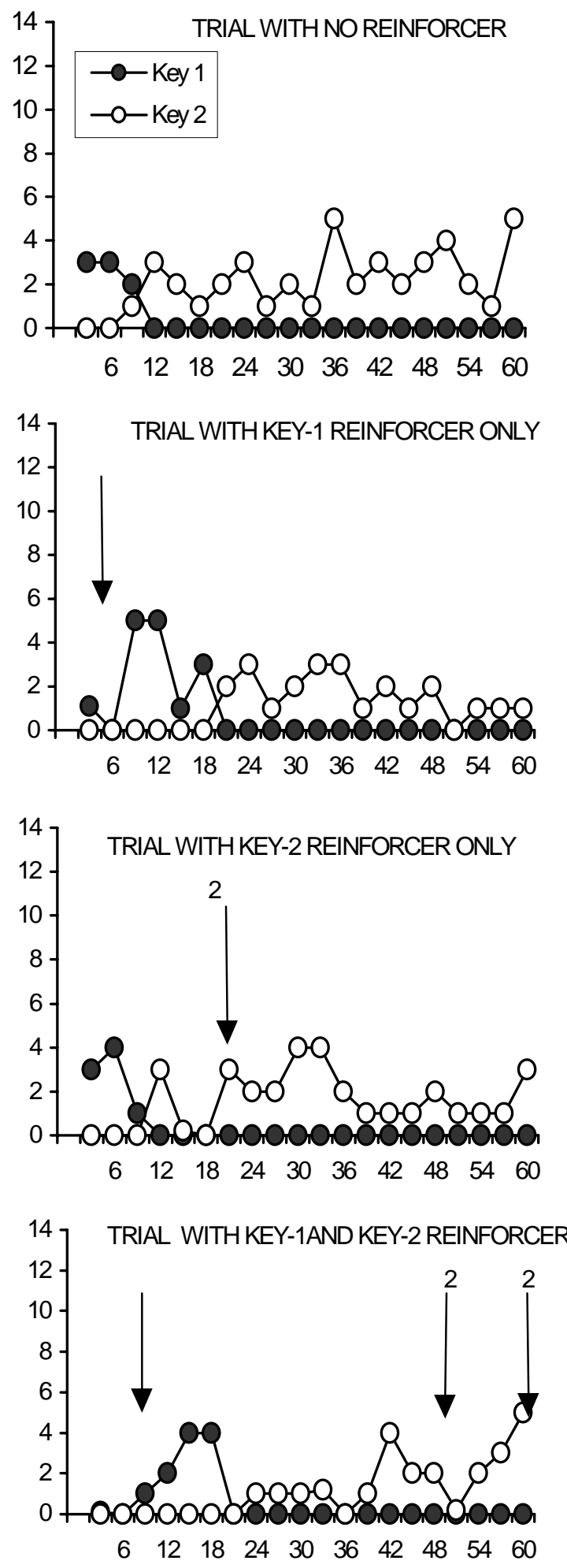

Time into Trial (s) 
functions from individual trials did not differ systematically from responding illustrated by the aggregated functions from the last five sessions. Overall, it appears that Key -1 responding by Pigeons 979 and 236 persisted for longer times into the interval on trials in which only a Key-1 reinforcer was delivered. Responding by Pigeons 960 and 521, contrarily, persisted for longer times into the interval on trials in which only a Key-2 reinforcer was delivered.

\section{History-Testing Condition}

Table 3 provides the mean index of curvature (Fry, Kelleher, \& Cook, 1960), quarter-life measures, and post-reinforcement pauses for each pigeon in the Fixed and Variable components under the FI. There were no consistent differences between the Fixed and Variable components on any of these measures. Responding by Pigeons 979 and 960 yielded larger indexes of curvature and quarter-life measures, and longer post-reinforcement pauses in the Variable component than in the Fixed component during the first session of exposure to the FI. Fixedinterval responding by Pigeon 236, however, yielded the opposite effect, so that all measures were larger for responding in the Fixed component than the Variable component. The differences in responding by Pigeons 979, 960, and 236 dissipated after the first session of FI exposure and response measures were mixed throughout the rest of the history-testing condition. Responding by Pigeon 521 was discrepant in each component throughout the first three sessions of exposure to the FI. Indexes of curvature and quarter-life measures were higher in the Fixed component than in the Variable component prior to the fourth session of FI exposure, after which these same measures were higher in the Variable component rather than the Fixed component for the remainder of the history-testing condition. 
Table 3

Mean Index of Curvature (IC), Quarter-life measures (QL), and PRPs for each subject during each of the first five sessions and each set of five sessions thereafter.

\begin{tabular}{|c|c|c|c|c|c|c|c|c|c|c|c|c|}
\hline & & 979 & & & 960 & & & 521 & & & 236 & \\
\hline & IC & $\mathrm{QL}$ & $\operatorname{PRP}(\mathrm{s})$ & IC & $\mathrm{QL}$ & $\mathrm{PRP}(\mathrm{s})$ & IC & $\mathrm{QL}$ & $\mathrm{PRP}(\mathrm{s})$ & IC & $\mathrm{QL}$ & $\mathrm{PRP}(\mathrm{s})$ \\
\hline$\underline{\text { Session }}$ & Fix/Var & Fix/Var & Fix/Var & Fix/Var & Fix/Var & Fix/Var & Fix/Var & Fix/Var & Fix/Var & Fix / Var & Fix / Var & Fix / Var \\
\hline 1 & $.26 / .32$ & $45.5 / 50.2$ & $4.8 / 6.0$ & $.16 / .21$ & $38.1 / 41.0$ & $2.4 / 3.0$ & $.11 / .08$ & $34.1 / 33.0$ & $3.6 / 4.2$ & $-.02 /-.11$ & $28.0 / 23.2$ & $4.8 / 4.2$ \\
\hline 2 & $.33 / .32$ & $50.5 / 49.5$ & $5.4 / 6.0$ & $.17 / .30$ & $38.6 / 48.1$ & $3.6 / 3.0$ & $.23 / .14$ & $42.3 / 35.4$ & $4.8 / 3.0$ & $-.12 /-.10$ & $23.0 / 23.7$ & $5.4 / 5.4$ \\
\hline 3 & $.38 / .39$ & $53.3 / 55.2$ & $7.2 / 6.6$ & $.22 / .31$ & $42.1 / 49.2$ & $4.8 / 6.6$ & $.35 / .33$ & $51.5 / 48.6$ & $9.0 / 6.0$ & $-.04 / .27$ & $28.3 / 49.3$ & $5.4 / 14.4$ \\
\hline 4 & $.45 / .45$ & $61.7 / 60.7$ & $7.8 / 7.8$ & $.31 / .30$ & $50.9 / 48.7$ & $7.2 / 7.2$ & $.39 / .44$ & $55.0 / 58.1$ & $10.8 / 12.0$ & $.15 / .30$ & $39.7 / 50.0$ & $16.2 / 18.6$ \\
\hline 5 & $.50 / .46$ & $63.0 / 61.7$ & $9.0 / 9.0$ & $.33 / .30$ & $51.1 / 49.0$ & $10.8 / 7.8$ & $.31 / .34$ & $47.5 / 51.7$ & $8.4 / 7.2$ & $.23 / .29$ & $47.1 / 53.8$ & $18.6 / 18.6$ \\
\hline $6-10$ & $.46 / .40$ & $61.3 / 56.5$ & $9.7 / 8.6$ & $.31 / .33$ & $50.8 / 51.1$ & $10.2 / 10.0$ & $.40 / .45$ & $55.9 / 60.2$ & $9.0 / 9.8$ & $.27 / .25$ & $49.3 / 45.7$ & $16.3 / 18.0$ \\
\hline $11-15$ & $.48 / .44$ & $62.7 / 60.1$ & $9.0 / 7.8$ & $.26 / .28$ & $47.6 / 47.9$ & $9.0 / 9.7$ & $.51 / .56$ & $63.7 / 67.6$ & $11.8 / 12.7$ & $.22 / .29$ & $47.2 / 51.4$ & $12.8 / 14.3$ \\
\hline $16-20$ & $.52 / .44$ & $65.0 / 59.8$ & $8.3 / 7.9$ & $.31 / .30$ & $50.9 / 50.6$ & $8.4 / 9.1$ & $.52 / .53$ & $64.2 / 64.7$ & $11.6 / 11.8$ & $.13 / .18$ & $44.4 / 46.7$ & $13.4 / 14.0$ \\
\hline $21-25$ & $.48 / .42$ & $64.8 / 58.4$ & $7.7 / 7.1$ & $.30 / .26$ & $50.3 / 48.1$ & $9.5 / 7.9$ & $.51 / .55$ & $63.5 / 67.2$ & $11.6 / 12.6$ & $.17 / .09$ & $44.5 / 37.5$ & $15.2 / 13.2$ \\
\hline
\end{tabular}




\section{Next Page}

Figure 10. Mean cumulative responses across tenths of each interval in the Fixed component (open circles) and the Variable component (closed circles) of the first five sessions of exposure to an FI schedule for each pigeon. Pigeons 979, 960, 521, and 236 were exposed to an FI 16-s, 24-s, 25-s, and 25-s schedule, respectively. 

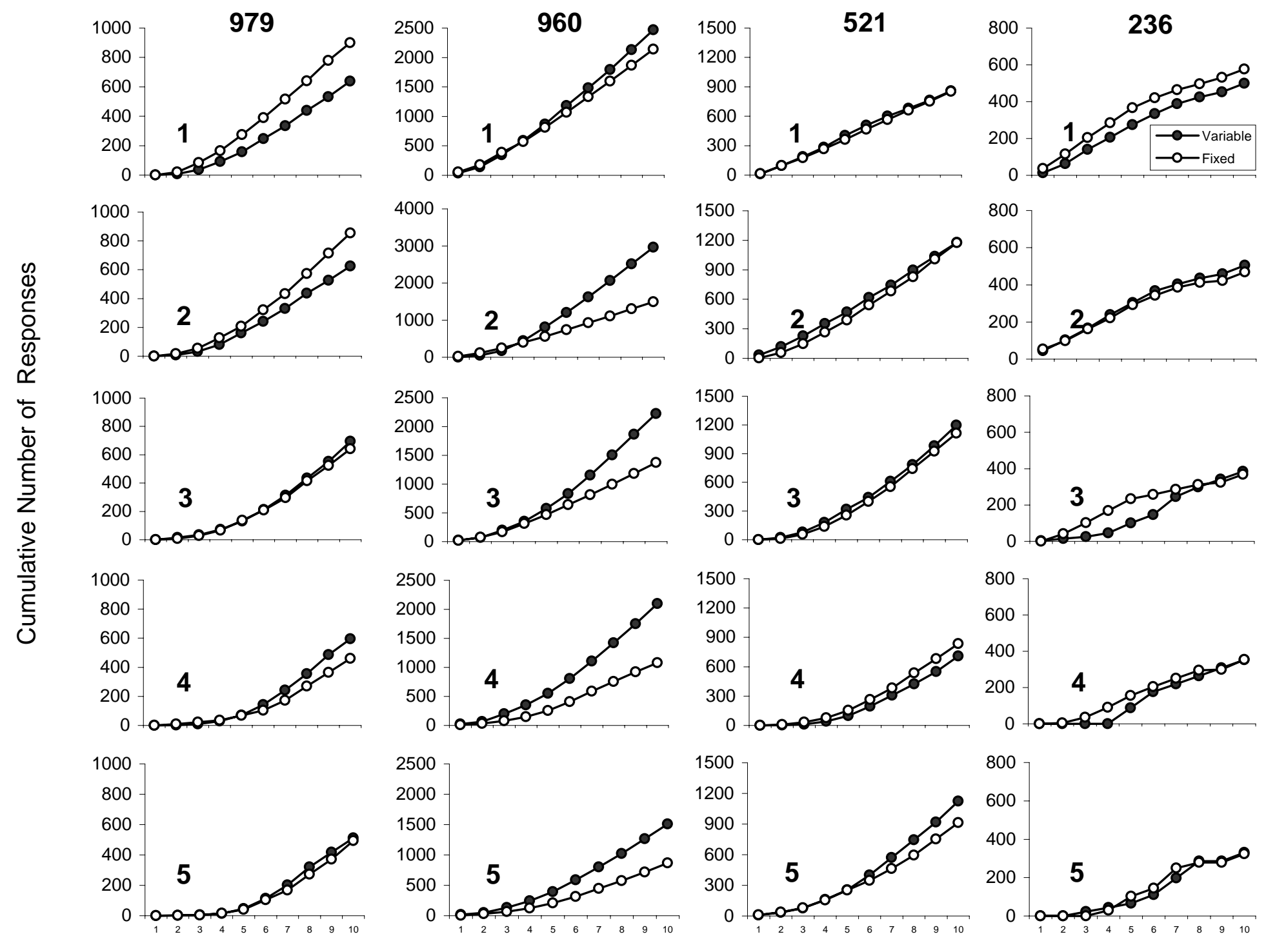

Tenths of the Interval 
Figure 10 shows cumulative response distributions for each pigeon across tenths of the interval in each component during each of the first five sessions of FI exposure. Pigeon 979 responded at higher rates in the Fixed component relative to the Variable component for the first two sessions of exposure to the FI, but the rates between components became more similar in subsequent sessions. Response rates were slightly higher in the Variable component than in the Fixed component during the third and fourth sessions of FI exposure. Pigeon 960 responded at consistently higher rates in the Variable component than in the Fixed component. Despite this difference in rate, no differences in patterns resulted. The response distributions by Pigeon 521 during the first three sessions of exposure to the FI support what the previously discussed response measures indicated. That is, fewer responses occurred during the beginning and middle of the interval in the Fixed component than in the Variable component, although the total number of cumulative responses in each component were similar. These differences in response patterns by Pigeon 521 are no longer present in the fourth and fifth sessions of FI exposure provided. Pigeon 236 responded at higher rates in the Variable component during the first session of exposure to the FI schedule; thereafter, there were no differences in responding between the Fixed and Variable components under the FI.

Figure 11 shows the number of responses by each pigeon during each of the first 25 sessions of exposure to the FI. For Pigeons 979, 960, and 236 the number of responses decreased throughout approximately the first ten sessions under the FI. Pigeon 960 responded more often in the Variable component than in the Fixed component during the first eight sessions, whereas Pigeon 979 responded more often in the Fixed component than in the Variable component during the first two sessions. Other than these noted differences in response rates, the number of responses by each pigeon were similar in each component. 
Fixed-Interval Performance 54

\section{Next Page}

Figure 11. Mean number of responses in the Fixed component (left column) and the Variable component (right column) by each pigeon during the first 25 sessions of exposure to the FI. Note: The y-axes are scaled differently for each pigeon. 

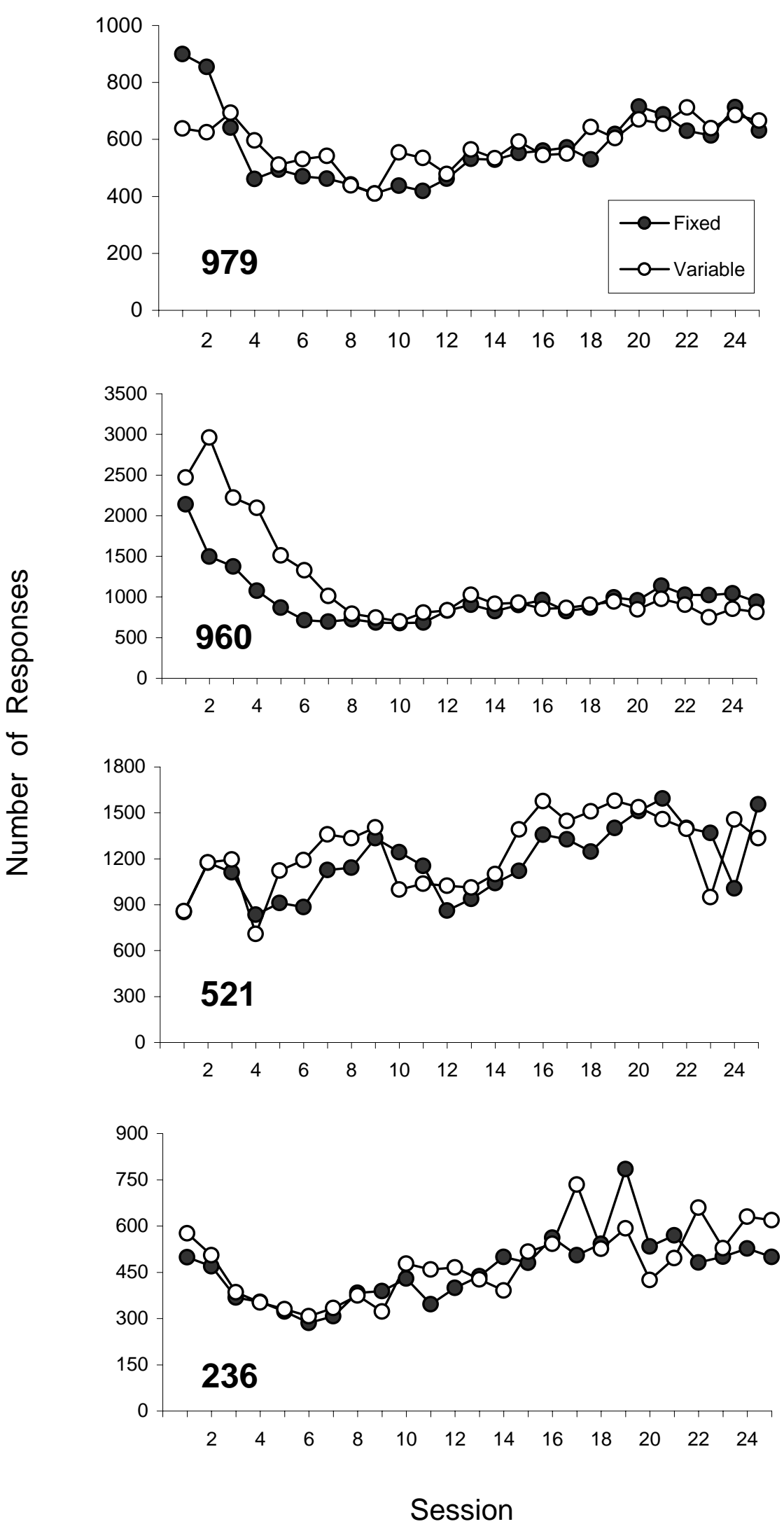


\section{DISCUSSION}

There were no systematic differences between response patterns or rates under the FI in the presence of the stimuli previously correlated with the Fixed FOPP and response patterns or rates under the FI in the presence of the stimuli previously correlated with the Variable FOPP. Post-reinforcement pauses, indexes of curvature, and quarter-life measures were similar in the Fixed and Variable components for at least three of four pigeons, even during the first few sessions of exposure to the FI schedule. Additionally, FI response patterns in the Fixed and Variable components changed similarly throughout exposure to the FI. Patterns of responding by Pigeon 521 were discrepant in each component, but only during the first three sessions of exposure to the FI. The effects obtained, therefore, were dissimilar across pigeons and, at best, transient. Thus, contrary to the expected results of this experiment, FI patterns were not differentially affected by prior exposure to temporal discrimination training. One of two conclusions might be drawn from these findings, although each requires further empirical investigation: Either FI patterns are not sensitive to prior temporal discrimination training, or the absence of an experimental effect can be attributed to procedural limitations.

Although temporal control plays a role in both temporal discrimination and temporal differentiation procedures, it has been suggested that there may be other factors within temporal differentiation procedures that affect responding in addition to temporal control. Temporal discrimination, therefore, has been suggested to be a more refined form of temporal control than temporal differentiation (e.g., Platt, 1979; Stubbs \& Dreyfus, 1981). Zeiler (1985), for example, showed that responding under a temporal differentiation procedure conformed to Weber's Law when response duration requirements usually employed within temporal differentiation procedures were removed. A two-component concurrent schedule was used in which one key 
served as a changeover key that alternated the color of the main key (cf. Findley, 1958).

Responding on the main key was reinforced according to a random-interval (RI) schedule in one component and the absence of responding was reinforced according to a DRO schedule in the alternate component. Reinforcement availability was assigned randomly by an equal probability gate to one of the two components at a given time. Responses on the changeover key in the presence of the DRO schedule were assessed, emphasizing the time at which responses on the changeover key occurred when no reinforcer was available in the presence of the DRO. That is, if the length of the required pause on the DRO yielded discriminative control over responding, probability of responding on the changeover key would peak at times into the component similar to the length of the DRO interval. Responses on the changeover key, therefore, were used to measure temporal control. Zeiler used DRO values ranging from $5 \mathrm{~s}$ to $80 \mathrm{~s}$, and response distributions on the changeover key corresponded with the length of the DRO intervals. The variability in response durations increased as a function of the length of the DRO interval, moreover, showing that the temporal differentiation conformed to Weber's Law.

Zeiler (1985), in a sense, assessed temporal control alone in temporal differentiation (by removing other controlling variables) and found that the results were similar to what would be obtained using a temporal discrimination procedure when previous researchers had failed to find such results (e.g., Platt, 1979; Zeiler, 1983). This suggests that other controlling properties of the environment under temporal differentiation procedures, such as the response requirement or delay of reinforcement, may interfere or compete with the control exerted by the temporal properties of the environment. That is, because there are other factors involved in temporal control by FI schedules, FI response patterns may not be sensitive to prior temporal discrimination training. One possibility, then, is that the role of temporal control in FI responding 
is not sufficiently large for a history effect of such prior temporal discrimination training to occur.

Although the present findings are consistent with some research suggesting that differences exist between temporal discrimination and temporal differentiation, they are inconsistent with other findings suggesting that the difference in temporal discrimination and differentiation is only procedural. Stubbs et al. (1978), for instance, found that accuracy of choice responses following short or long stimulus presentations was correlated positively with indexes of curvature used to describe FI performance, suggesting that FI performance and temporal discrimination are functionally related. Lowe and Wearden (1981), moreover, found that the mean and standard deviation of PRPs on FI schedules conformed to Weber's Law (just as discrimination in psychophysical procedures) suggesting, again, that FI performance and temporal discrimination are functionally related.

Before making any definitive conclusions concerning the results of the present experiment, however, it is necessary to address some procedural limitations that may have been a factor in this study. These limitations may have been a function of the history-building or the history-testing condition; these are discussed separately below.

\section{$\underline{\text { History-Building Condition }}$}

Temporal discrimination training. One reason why FI response patterns were not affected by temporal discrimination training may be the type of temporal discrimination training used in the history-building condition. Because the FOPP was developed to include free-operant aspects of temporal differentiation within a psychophysical temporal discrimination, the responding that occurs under a FOPP may not be a function of temporal properties of the environment alone. That is, as in the presence of FI schedules, there may be non-temporal factors controlling 
responding in the presence of the FOPP. The reinforcers delivered according to the VI schedule on each key, for example, may have selected some pattern of responses that occurred independently of the time into the interval at which reinforcement availability changed from Key 1 to Key 2. Therefore, FI response patterns may not have been affected by the temporal discrimination training because the temporal properties of the FOPP were one of many controlling variables present in the history-building condition.

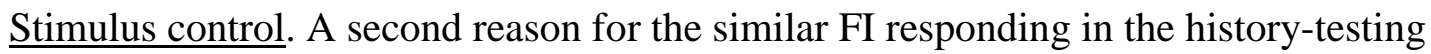
condition is the type of multiple schedule used in the history-building condition and the stimulus control it may have fostered. Lawrence (1963) stated that discrimination is produced primarily by comparisons of the discriminative stimuli correlated with each differential reinforcement schedule, suggesting that discriminative control of responding is optimal when components are temporally proximal. This view has been supported by other studies showing that sensitivity to differential reinforcement in each component of a multiple schedule decreases as the time into each component increases (e.g., McClean \& White, 1981; White, 1990; White, Pipe, McClean, \& Redman, 1985). Differential responding in each component, therefore, is under discriminative control of both the discriminative stimulus present in the current component (the control of which presumably remains constant throughout the component) and the transition between components (the control of which diminishes as the time since the transition increases). Thus, because the transition between components is separated by several hours, using two sessions per day to comprise two components of a multiple schedule may impede discriminative control of responding. Although this conclusion is supported further by some research on behavioral contrast showing that contrast effects are weakened when delays are introduced between components (e.g., Mackintosh, Little, \& Lord, 1972), Bloomfield (1967) obtained behavioral 
contrast effects using a multiple schedule in which one-hour sessions comprising each component alternated daily. Bloomfield, however, strictly alternated the two components of the multiple schedule, whereas multiple-schedule components in the present experiment were presented in a random order each day.

Another potential limitation of the stimulus control developed in this experiment is the similarity of the FOPPs used in each component. Sadowsky (1969) suggested that both differential reinforcement and differential stimuli control responding in multiple schedules. That is, disrimination is a function of both differential reinforcement as well as differential exteroceptive stimuli. Consequently, as the reinforcement parameters between components of a multiple schedule become more discrepant, sensitivity to differences between components increases. It is possible that the Fixed and Variable FOPP used in the present experiment were too similar to produce discriminative control over responding and, thus, qualitatively different responding in each component.

The weakness of stimulus control developed in the history-building condition is supported further by evidence of response interactions between the two components in the present experiment. When the COD was removed in the Variable component for three sessions under the FOPP, for example, the number of changeovers per session increased in both the Variable and Fixed components. Throughout most of the history-building condition, additionally, the response functions in the Fixed and Variable components were qualitatively similar. The functions differed only in that switching from Key 1 to Key 2 occurred at earlier times in the trial in the Variable than in the Fixed component. That is, although reinforcement was available for pecking Key 1 at times into the trial beyond 30 s and for pecking Key 2 at times into the trial prior to $30 \mathrm{~s}$, responding occurred consistently throughout the interval on Key 1 and Key 2 for 
only one of four pigeons (521). The functions produced by responding in the Variable component suggest that some degree of temporal control was present in the Variable component. Subsequent experiments should account for the presence of temporal control in the Variable component through the use of different procedures, such as extinction alone in the Variable component or the use of a concurrent arrangement in which the availability of reinforcement is equally probable on each of the two keys (e.g., Stubbs \& Pliskoff, 1969).

Whereas stimulus control may not have developed because the procedures in each component were similar, it also is possible that the differential FOPP in each component was controlling differential responding alone, independently of the discriminative stimuli (key colors and chamber interior) correlated with each component. Lattal (1973) distinguished between these

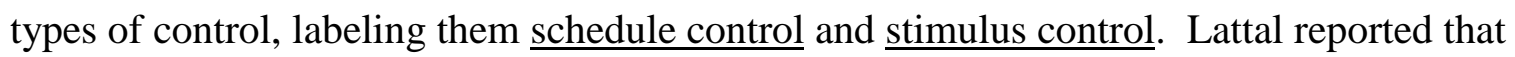
although differential response-reinforcer relations contributed to stimulus control developed under multiple schedules, differential response-reinforcer relations alone did not produce differential responding under certain mixed schedules. When components of a mixed schedule were lengthened, however, there was an increase in the control exerted by the responsereinforcer relations relative to when the components of the same mixed schedule were shorter. Thus, in the present experiment (where each component lasted nearly an hour), it is possible that differences in responding maintained by each component of the multiple schedule may have been a function of schedule control rather than stimulus control. The presence of schedule control is supported by the differences in responding that occurred in each of the four trial types reviewed in the results. Means of the last five sessions under the FOPP showed that Key-1 responding lasted for shorter or longer times into the trial depending upon whether a Key-1 reinforcer was delivered. This effect occurred in the Fixed and Variable component and indicates 
that responding may have been controlled, at least in part, by discriminative properties of reinforcer deliveries. This conclusion is questionable, however, in that for at least one pigeon (960) there were differences in response rates in each component of the history-testing condition as a result of differential rates of responding that occurred in the history-building condition.

\section{$\underline{\text { History-Testing Condition }}$}

Fixed-interval values. Because the FI values used in the history-testing condition were determined by the PSEs produced by the FOPP in the Fixed component of the history-building condition, the FI was shorter than $30 \mathrm{~s}$ for each pigeon. These short FI values may have contributed to the absence of different response patterns in each component. Differences in FI response patterns following differential behavioral histories have been obtained using FI 2-min (Trapold et al., 1965) and FI 30-s (Cole, 2001; Tatham et al., 1993) schedules of reinforcement. Freeman and Lattal (1992), however, reported differential FI response patterns (using quarter-life measures) between components for only one of three pigeons when FI 19-s, 21-s, and 24-s schedules were used. The FI values used in the present experiment may have been too short to produce differences in response patterns as a result of the behavioral history. That is, shorter FIs are less likely to produce a scalloped or break-and-run response pattern than longer FIs because shorter intervals more tightly constrain responding. Catania and Reynolds (1968), for example, found that response rates increased monotonically throughout FI 30-s and FI 50-s schedules. In the presence of FI 200-s schedules, however, responding decreased from the onset of the interval to the middle portion of the interval, and then increased to asymptotic levels prior to the end of the interval. Overall response rates, moreover, under the FI 200-s schedule were lower than overall response rates under the FI 30-s and FI 50-s schedules. Responding in the presence of shorter FIs, therefore, may occur at higher and more steady rates than responding in the presence 
of relatively longer FIs. Thus, shorter FIs may be less susceptible to history effects, at least history effects revealed through response patterns, than longer FIs.

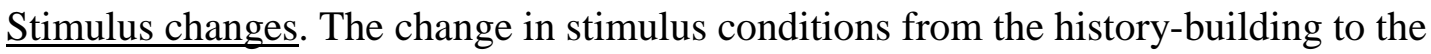
history-testing condition also may have minimized the history effects in the present experiment. Presenting stimuli to signal condition changes may facilitate contact with the new contingencies in the history-testing condition and, thus, decrease the sensitivity of responding in the historytesting condition to variables present in the history-building condition. Metzger (1992, Experiments 1 and 2), for example, introduced a visual stimulus change in each component of a two-component multiple schedule from the history-building to the history-testing conditions while holding reinforcement rate constant. For two of three pigeons, differential responding persisted for more sessions when a stimulus change was present between the history-building and history-testing condition than when a stimulus change was not present between the two conditions. Therefore, a stimulus change enhanced the control of responding by the new schedule, thereby decreasing the persistence of the history effects (see also Nader and Thompson, 1987). In the present experiment, two side keys were transilluminated throughout each trial in the history-building condition and reinforcers were delivered at variable times throughout the interval. In the history-testing condition, however, only a center key was transilluminated and reinforcers were delivered after a fixed amount of time (as long as a response occurred). This change in key presentations and reinforcer deliveries may have signaled the change in conditions and lessened the response sensitivity to prior conditions.

\section{$\underline{\text { Conclusions }}$}

It is difficult to ascertain whether the results obtained are reliable or if they can be attributed to procedural limitations. The absence of differential FI responding in the present 
experiment is not only contrary to what would be expected if a relation exists between temporal differentiation and temporal discrimination, but it also raises questions concerning the results of Trapold et al. (1965). Differences in FI response patterns that occurred in the Trapold et al. study as a function of prior exposure to either an FT or VT schedule may have occurred because the response-independent food delivery present in the history-building condition served as a discriminative stimulus for the passage of time. If this were true, the discriminative functions of the food delivery presumably were maintained in the subsequent history-testing condition in which an FI schedule was in effect. If the results of Trapold et al. can be couched in these terms, however, then the present experiment should have yielded differences in FI response patterns as a result of differential temporal discrimination training. If the food delivery in the Trapold et al. study served discriminative functions for the passage of time, the time into the trial at which responding switched from Key 1 to Key 2 would be expected to serve a similar function in the present experiment. Perhaps the history effect obtained by Trapold et al. was not a function of discriminative control over the passage of time.

An alternative explanation for the results of Trapold et al. (1965) that coincides with those obtained in the present study is one in terms of adjunctive behavior. Staddon and Simmelhag (1971) analyzed interim and terminal responding by pigeons in the presence of FI 12-s schedule of reinforcement, and FT 12-s and VT 12-s schedules of food delivery. Interim activities were defined as those responses occurring temporally distal from the onset of food delivery (or following food delivery), whereas terminal activities were defined as those responses occurring temporally proximal to the onset of food delivery. Responding by each pigeon was consistent across each interval where, according to Staddon and Simmelhag, responding was distinctly defined as interim or terminal. The following findings were obtained 
through systematic observations: (1) Terminal responding was similar across pigeons, whereas interim activities were more variable across pigeons, (2) There were no differences in interim or terminal responding between the pigeons under the FI and pigeons under the FT, (3) Interim activities generally occurred throughout six or seven seconds of the interval in the presence of the FI or FT schedules, but interim activities occurred throughout only the first two or three seconds of the interval in the presence of the VT schedule, and (4) Once the terminal response began it persisted until food delivery. From this, it may be said that the addition of the response requirement had no effect on the pattern of interim and terminal activities and that terminal responding occurs earlier in the interval under VT schedules than under FI or FT schedules. Responding by the rats in Trapold et al.'s experiment may have responded differently as a function of prior exposure to either an FT or VT schedule because these interim and terminal activities were produced in the history-building condition and persisted in the presence of the history-testing condition.

Adjunctive responding is used to describe induced responding that occurs at times when reinforcement probability is low for a currently reinforced set of responses (Falk, 1977; Wetherington, 1981). In the present case, interim responses would be considered induced by the low probability of reinforcement that occurs following the delivery of food and, thus, a form of adjunctive behavior. In the presence of the VT schedule interim responses occur for a shorter period of time than in the presence of FI or FT schedules, because the probability of reinforcement is higher in the VT at earlier times in the interval. Head bobbing, for example, may be an interim response that occurs for the first seven seconds of an interval in the presence of an FI or FT schedule until hopper-checking (a terminal response) begins. In the presence of the VT, however, a programmed reinforcer may be missed or time in the hopper may be 
decreased if head bobbing (the interim response) occurs for longer than the first few seconds of the interval. In this case, the time since food delivery does not function as a discriminative stimulus for the passage of time (as in temporal discrimination procedures), but the response duration is temporally defined by the schedule (as in temporal differentiation procedures). This difference between interim and terminal responding, consequently, may be an example of temporal differentiation similar to what occurs in the presence of FI schedules. According to this viewpoint, then, it is not surprising that the results of Trapold et al. were obtained whereas no differences in FI responding were obtained in the present study.

This analysis is consistent with current theories of timing. According to the behavioral theory of timing (BET) (Killen \& Fetterman, 1988) and Learning to Time (LeT) (Machado, 1997), responding under an FI and the response functions produced by a FOPP occur as a result of adjunctive behavior. In the presence of the FI, there are behavioral states associated at different strengths with the operant response throughout the interval. According to LeT, for example, the offset of a reinforcer delivery activates series of behavioral states. Each of these states is induced through the probability of reinforcement at any given time throughout the interval and, thus, more operant responding occurs as the probability of reinforcement increases. (Note that this analysis is very similar to that described by Staddon and Simmelhag, 1971.) In the presence of the FOPP, responses induced by the reinforcement schedules on each key produce differential states in which responding on one key is more probable than responding on the other key. From this, the adjunctive behavior (or behavioral states) serves discriminative functions for the time at which switching from Key 1 to Key 2 occurs (see Bizo \& White, 1995; Machado \& Guilhardi, 2000). 
In the present experiment, a FOPP was used in the history-building condition so that, if these timing analyses are predictive, would have produced two or three different behavior states: one for the first part of the trial (during which responding on Key 1 is most probable), one for the middle part of the trial (during which the probability of responding on either key is similar), and one for the last part of the trial (during which responding on Key 2 is most probable). Key pecking on Key 1 or Key 2 is induced by each of these states activated by the onset of the trial. When the FI was introduced in the history-testing condition, these timing models predict that two or more behavioral states would be produced throughout each interval. The absence of key pecking or key pecking is induced by each of these stated activated by the offset of the reinforcer delivery. Because the value of the FIs used in the history-testing condition were determined by the PSEs obtained under the FOPP in the history-building condition, it is possible that, initially, the entire FI was correlated with a single behavioral state produced during the first part of the interval under the FOPP. In this case, the FI would not have been long enough to allow the differences in the temporal training (i.e., the differences in times into the interval at which transitions between behavioral states occurs) to surface. It may be unlikely, furthermore, that the adjunctive behavior produced by variable schedules of reinforcement for pecking on one of two side keys under the FOPP would persist in the presence a fixed schedule of reinforcement for pecking on the center key under the FI.

\section{$\underline{\text { Summary }}$}

The results of the present experiment are consistent with some of the extant literature on the relation between temporal differentiation and temporal discrimination, but inconsistent with other research. It is unknown whether the current findings are reliable, however, because the absence of the history effect may be due to procedural limitations such as the type of temporal 
discrimination, the multiple schedule, or the FI values used. If the present results are reliable, it suggests that the results of Trapold et al. (1965) are most likely due to other factors other than the reinforcer deliveries having served a discriminative function for the passage of time in the history-building condition. The interpretation that best describes the results of the present experiment in light of those of Trapold et al. (1965) is suggested to be one involving the production of adjunctive behavior in the history-building condition and its subsequent effects on instrumental responding in the history-testing condition. This conclusion is consistent with other observations in the area of adjunctive behavior and with standing timing theories. 


\section{REFERENCES}

Baron, A., \& Leinenweber, A. (1994). Molecular and molar analyses of fixed-interval performance. Journal of the Experimental Analysis of Behavior, 61, 11-18.

Baron, A., \& Leinenweber, A. (1995). Effects of variable-ratio conditioning history on sensitivity to fixed-interval contingencies in rats. Journal of the Experimental Analysis of Behavior, 63, 97-110.

Bizo, L. A., \& White, K. G. (1995). Reinforcement context and pacemaker rate in the behavioral theory of timing. Animal Learning \& Behavior, 23(4), 376-382.

Bloomfield, T. M. (1967). Some temporal properties of behavioral contrast. Journal of the Experimental Analysis of Behavior, 10, 159-164.

Branch, M. N., \& Gollub, L. R. (1974). A detailed analysis of the effects of damphetamine on behavior under fixed-interval schedules. Journal of the Experimental Analysis of Behavior, 21, 519-539.

Catania, A. C. (1970). Reinforcement schedules and psychophysical judgements: A study of some temporal properties of behavior. In W. N. Schoenfeld (Eds.), The theory of reinforcement schedules (pp. 1-42). New York: Appleton-Century-Crofts.

Catania, A. C., \& Reynolds, G. S. (1968). A quantitative analysis of the responding maintained by interval schedules. Journal of the Experimental Analysis of Behavior, 11, 327383.

Church, R. M., \& Deluty, M. Z. (1977). Bisection of temporal intervals. Journal of Experimental Psychology: Animal Behavior Processes, 3, 216-228.

Church, R. M., Getty, D. J., \& Lerner, N. D. (1976). Duration discrimination by rats. Journal of Experimental Psychology: Animal Behavior Processes, 2, 303-312. 
Cohen, S. L., Pederson, J., Kinney, G. G., \& Myers, J. (1994). Effects of reinforcement history on responding under progressive-ratio schedules of reinforcement. Journal of the Experimental Analysis of Behavior, 61, 375-387.

Cole, M. R. (2001). The long-term effect of high- and low-rate responding histories on fixed-interval responding by rats. Journal of the Experimental Analysis of Behavior, 75, 43-54.

Dews, P. B. (1962). The effects of multiple $S^{\Delta}$ periods on responding in a fixed-interval schedule. Journal of the Experimental Analysis of Behavior, 5, 369-374.

Falk, J. L. (1977). The origin and function of adjunctive behavior. Animal Learning \& Behavior, 5(4), 325-335.

Ferster, C. B., \& Skinner, B. F. (1957). Schedules of Reinforcement. New York: Appleton-Century-Crofts.

Findley, J. D. (1958). Preference and switching under concurrent scheduling. Journal of the Experimental Analysis of Behavior, 1, 123-144.

Freeman, T., \& Lattal, K. A. (1992). Stimulus control of behavioral history. Journal of the Experimental Analysis of Behavior, 57, 5-15.

Fry, W., Kelleher, R. T., \& Cook, L. (1960). A mathematical index of performance on fixed-interval schedules of reinforcement. Journal of the Experimental Analysis of Behavior, 3 , 193-199.

Hernstein, R. J., \& Morse, W. H. (1957). Effect of pentobarbital on intermittently reinforced behavior. Science, 125, 929-931.

Holland, J. G. (1958). Human vigilance. Science, 128, 61-63. 
Ishida, M., Couvillon, P. A., \& Bitterman, M. E. (1992). Acquisition and extinction of a shutting response in honeybees (Apis mellifera) as a function of the probability of reward. Journal of Comparative Psychology, 106, 262-270.

Johnson, L. M., Bickel, W. K., Higgins, S. T., \& Morris, E. K. (1991). The effects of schedule history and the opportunity for adjunctive responding on behavior during a fixedinterval schedule of reinforcement. Journal of the Experimental Analysis of Behavior, 55, 313322.

Killeen, P. R., \& Fetterman, J. G. (1988). A behavioral theory of timing. Psychological Review, 95, 274-295.

Lattal, K. A. (1973). Response-reinforcer dependence and independence in multiple and mixed schedules. Journal of the Experimental Analysis of Behavior, 20, 265-271.

Lawrence, D. H. (1963). The nature of a stimulu: Some relationships between learning and perception. In S. Koch (Ed.), Psychology: A study of science: Vol. 5. The process areas, the person, and some applied fields: Their place in psychology and in science (pp. 179-212). New York: McGraw-Hill.

LeFrancois, J. R., Chase, P. N., Joyce, J. H. (1988). The effects of a veriety of instructions on human fixed-interval performance. Journal of the Experimental Analysis of Behavior, 49, 383-393.

LeFrancois, J. R., \& Metzger, B. A. (1993). Low-response-rate conditioning history and fixed-interval responding in rats. Journal of the Experimental Analysis of Behavior, 59, 543549.

Lowe, C. F., \& Wearden, J. H. (1981). Weber's law and the fixed-interval postreinforcement pause. Behaviour Analysis Letters, 1, 27-32. 
Machado, A. (1997). Learning the temporal dynamics of behavior. Psychological Review, 104 (2), 241-265.

Machado, A., \& Guilhardi, P. (2000). Shifts in the psychometric function and their implications for models of timing. Journal of the Experimental Analysis of Behavior, 74, 25-54.

Mackintosh, N. J., Little, L., \& Lord, J. (1972). Some determinants of behavioral contrast in pigeons and rats. Learning and Motivation, 3, 148-161.

McClean, A. P. \& White, K. G. (1981). Undermatching and contrast within components of multiple schedules. Journal of the Experimental Analysis of Behavior, 35, 283-291.

Metzger, B. A. (1992). Stimulus control of behavioral history and subsequent fixedinterval performance. Unpublished doctoral dissertation, West Virginia University, Morgantown.

Metzger, B. A., \& Lattal, K. A. (1998). Variable-interval schedule control following response acquisition with delayed reinforcement. The Psychological Record, 48, 685-689.

Nader, M. A., \& Thompson, T. (1987). Interaction of methadone, reinforcement history, and variable-interval performance. Journal of the Experimental Analysis of Behavior, 48, 303315.

Nevin, J. A. (1995). Contingencies of reinforcement and behavioral momentum: Research and applications. Mexican Journal of Behavior Analysis, 21, 107-122.

Ono, K., \& Iwabuchi, K. (1997). Effects of histories of differential reinforcement of response rate on variable-interval responding. Journal of the Experimental Analysis of Behavior, 67, 311-322. 
Platt, J. R. (1979). Temporal differentiation and the psychophysics of time. In M. D. Zeiler and P. Harzem (Eds.), Advances in the Analysis of Behavior, Vol. 1: Reinforcement and the Organisation of Behavior (pp. 1-30). Chichester: John Wiley \& Sons.

Poling, A., Krafft, K., \& Chapman, L. (1980). d-Amphetamine, operant history, and variable-interval performance. Pharmacology, Biochemistry, \& Behavior, 12, 559-562.

Sadowsky, S. (1969). Discriminative responding on associated mixed and multiple schedules as a function of food and ICS reinforcement. Journal of the Experimental Analysis of Behavior, 12, 933-946.

Schneider, B. A. (1969). A two-state analysis of fixed-interval responding in the pigeon. Journal of the Experimental Analysis of Behavior, 12, 677-687.

Shahan, T. A., \& Lattal, K. A. (1998). On the functions of the changeover delay. Journal of the Experimental Analysis of Behavior, 69, 141-160.

Sidman, M. (1960). Tactics of Scientific Research. New York: Basic Books.

Skinner, B. F. (1953). Science and Human Behavior. New York: Macmillan.

Spencer, P. T. (1981). Temporal control of behaviour and the law of effect: A description of fixed-interval performance. Behaviour Analysis Letters, 1, 325-329.

Staddon, J. E. R. (1977). Schedule-induced behavior. In W. K. Honig and J. E. R. Staddon (Eds.), Handbook of Operant Behavior (pp. 125-152). Englewood Cliffs, NJ: Prentice Hall.

Staddon, J. E. R., \& Simmelhag, V. L. (1971). The "superstitious" experiment: A reexamination of its implications for the principles of adaptive behavior. Psychological Review, 78, 3-43. 
Stubbs, D. A. (1968). The discrimination of stimulus duration by pigeons. Journal of Experimental Analysis of Behavior, 11, 223-258.

Stubbs, D. A. (1976a). Response bias and the discrimination of stimulus duration. Journal of the Experimental Analysis of Behavior, 25, 243-250.

Stubbs, D. A. (1976b). Scaling of stimulus duration by pigeons. Journal of the Experimental Analysis of Beahvior, 26, 15-25.

Stubbs, D. A. (1979). Temporal discrimination and psychophysics. In M. D. Zeiler \& P. Harzem (Eds.), Advances in analysis of behavior, Vol 1: Reinforcement and the organization of behaviour. Chicester, England: Wiley.

Stubbs, D. A. (1980). Temporal discrimination and a free-operant psychophysical procedure. Journal of the Experimental Analysis of Behavior, 33, 167-185.

Stubbs, D. A., \& Dreyfus, L. R. (1981). Temporal discrimination: From psychophysics to reinforcement schedules. In M. L. Commons \& J. A. Nevin (Eds.), Quantitative Analysis of Behavior (pp. 137-156). Cambridge: Ballinger.

Stubbs, D. A., \& Pliskoff, S. S. (1969). Concurrent responding with fixed relative rate of reinforcement. Journal of the Experimental Analysis of Behavior, 12, 887-895.

Stubbs, D. A., Vautin, S. J., Reid, H. M., \& Delehanty, D. L. (1978). Discriminative functions of schedule stimuli and memory: A combination of schedule and choice procedures. Journal of Experimental Analysis of Behavior, 29, 167-180.

Tatham, T. A., Wanchisen, B. A., \& Yasenchack, M. P. (1993). Effects of differentialreinforcement-of-low-rate schedule history on fixed-interval responding. The Psychological

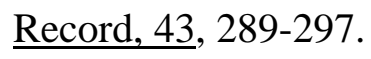


Trapold, M. A., Carlson, J. G., \& Myers, W. A. (1965). The effect of non-contingent fixed- and variable-interval reinforcement upon subsequent acquisition of the fixed-interval scallop. Psychonomic Science, 2, 261-262.

Urbain, C., Poling, A., Millam, J., \& Thompson, T. (1978). d-Amphetamine and fixedinterval performance: Effects of operant history. Journal of the Experimental Analysis of Behavior, 29, 385-392.

Wanchisen, B. A. (1990). Forgetting the lessons of history. The Behavior Analyst, 13, 31-37.

Wanchisen, B. A., Sutphin, G. E., Balogh, S. A., \& Tatham, T. A. (1998). Lasting effects of a behavioral history of low-rate responding in rats. Learning and Motivation, 29, 220235.

Wanchisen, B. A., Tatham, T. A., \& Mooney, S. E. (1989). Variable-ratio conditioning history produces high- and low-rate fixed-interval performance in rats. Journal of the Experimental Analysis of Behavior, 52, 167-179.

Weiner, H. (1964). Conditioning history and human fixed-interval performance. Journal of the Experimental Analysis of Behavior, 7, 383-385.

Weiner, H. (1969). Controlling human fixed-interval performance. Journal of the Experimental Analysis of Behavior, 12, 349-373.

Wetherington, C. L. (1981). Is adjunctive behavior a third class of behavior? Neuroscience and biobehavioral reviews, 6, 329-350.

White, K. G. (1990). Delayed and current stimulus control in successive discriminations. Journal of the Experimental Analysis of Behavior, 54, 31-43. 
White, K. G., Pipe, M.-E., McClean, A. P., \& Redman, S. (1985). Temporal factors in successive discrimiantion. New Zealand Journal of Psychology, 14, 78-82.

Zeiler, M. D. (1983). Integration in response timing: The functional time requirement. Animal Learning \& Behavior, 11, 237-246.

Zeiler, M. D. (1985). Pure timing in temporal differentiation. Journal of the Experimental Analysis of Behavior, 43, 183-193. 


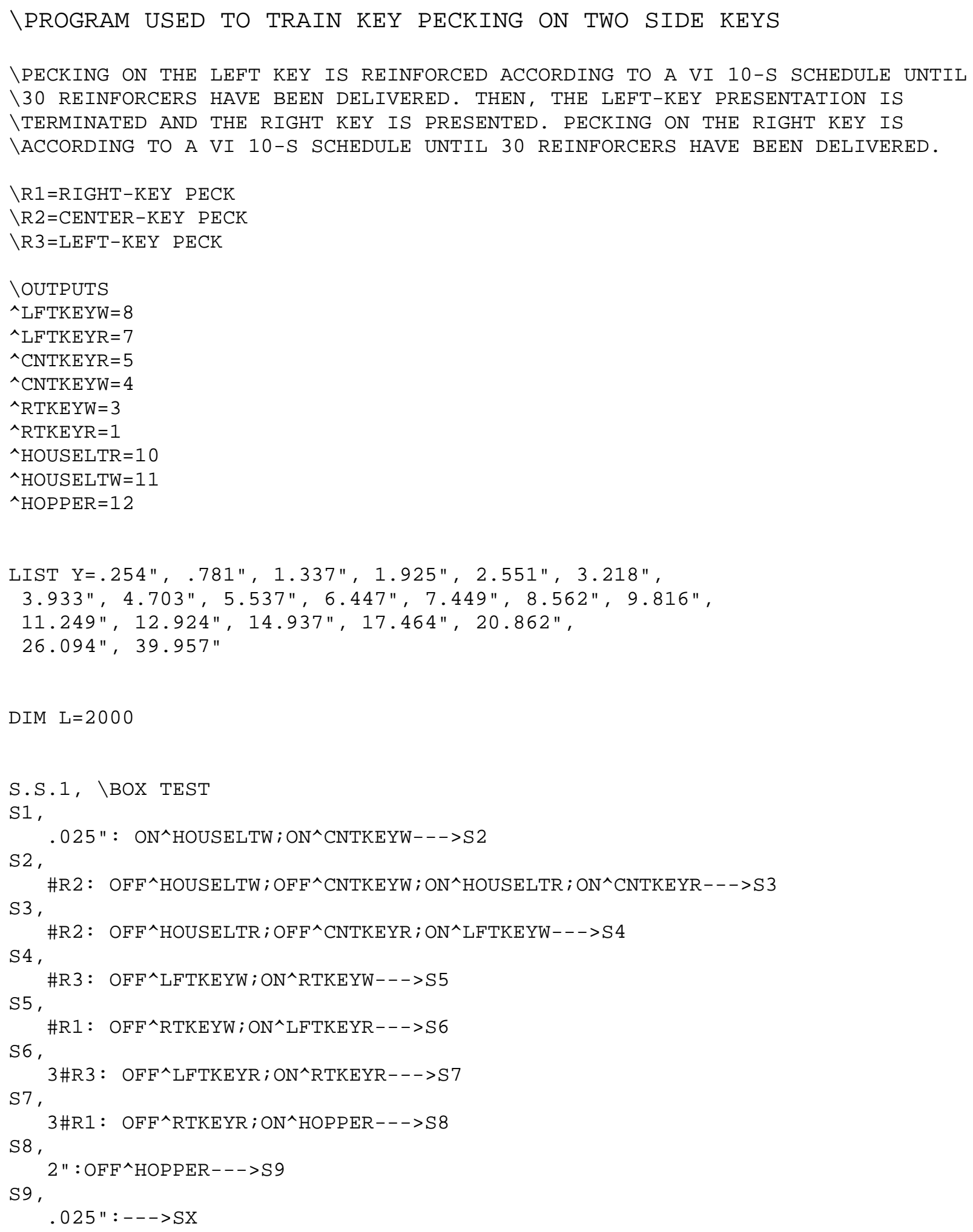




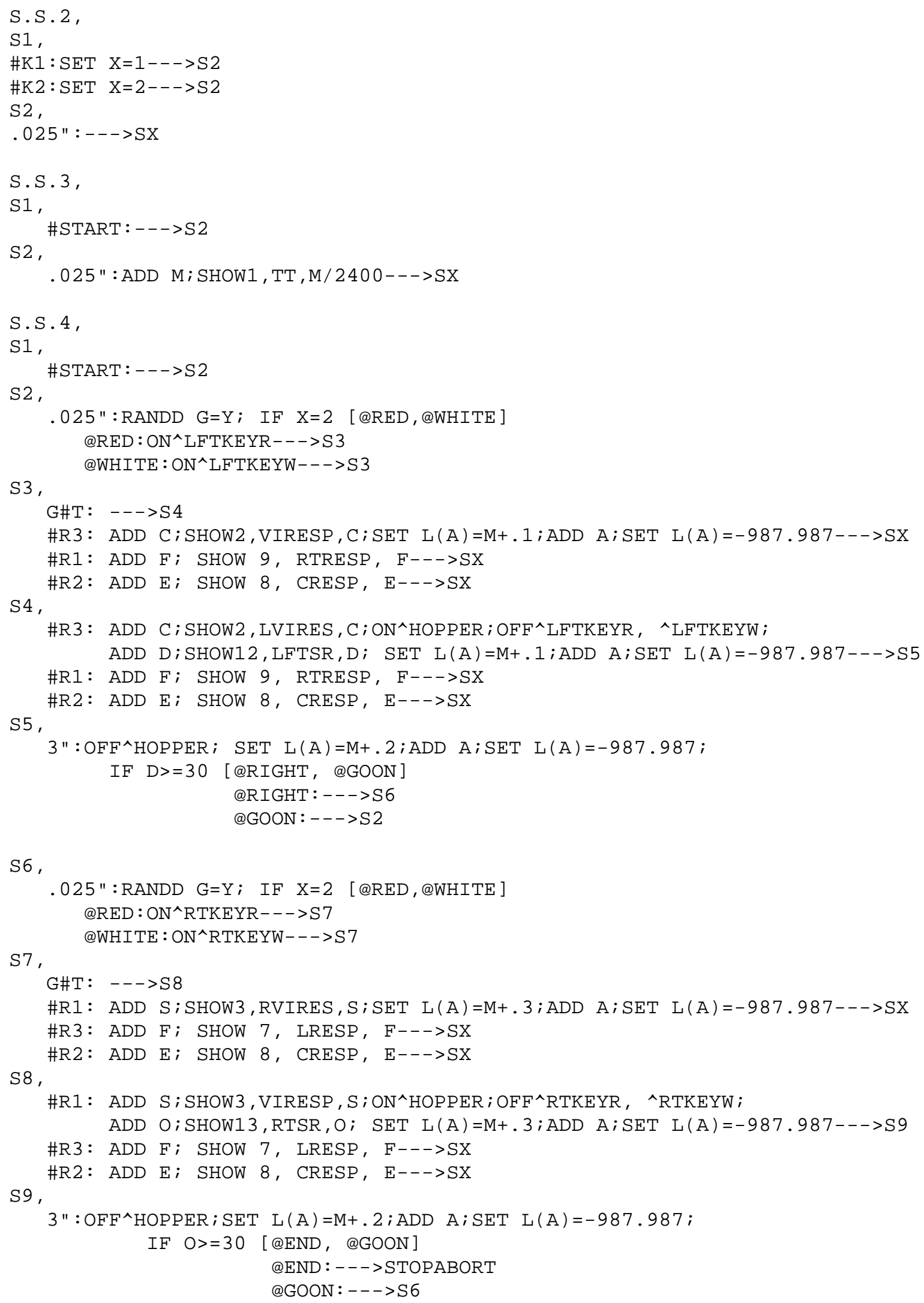




\section{IPROGRAM FOR THE FREE-OPERANT PSYCHOPHYSICAL PROCEDURE}

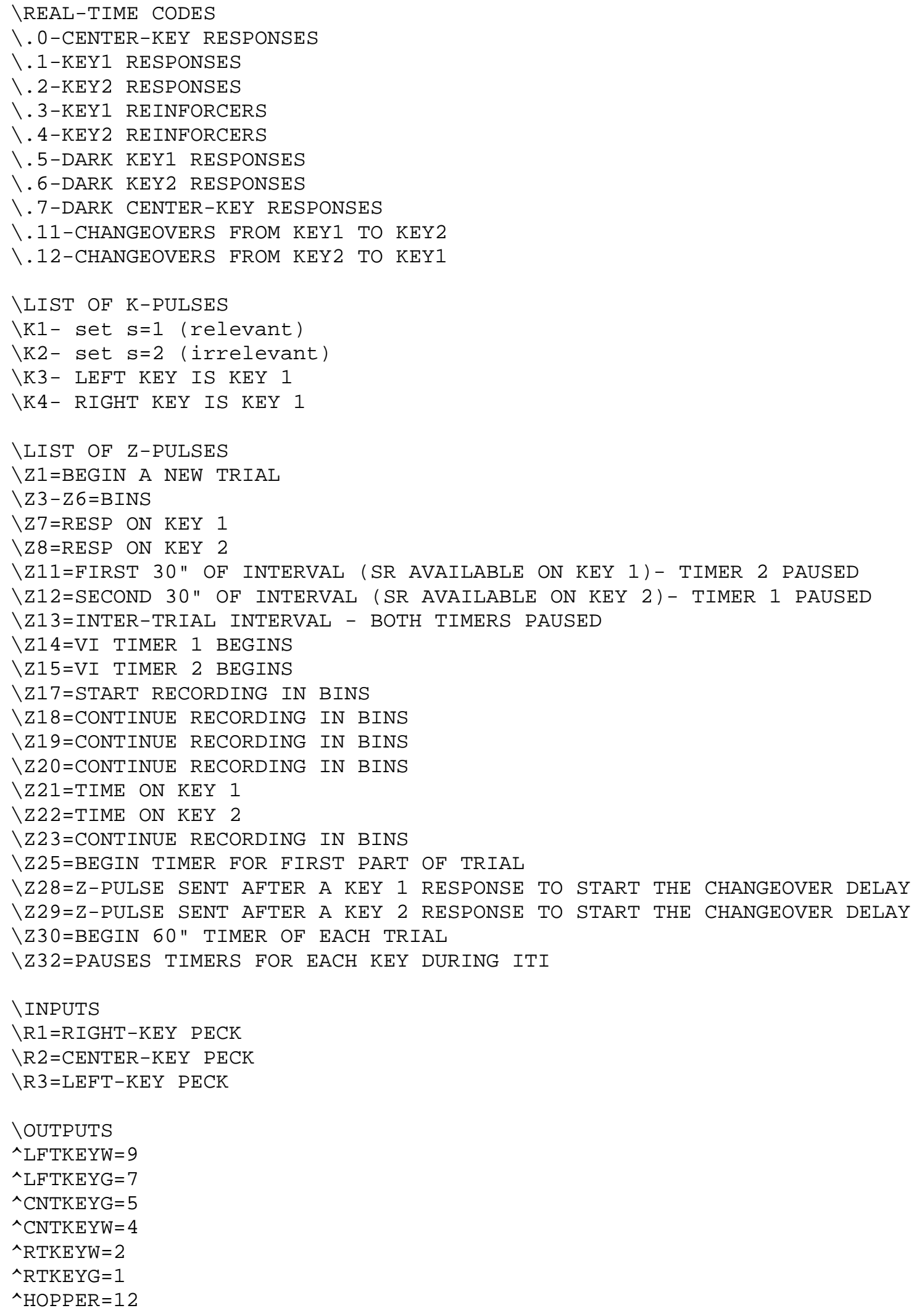




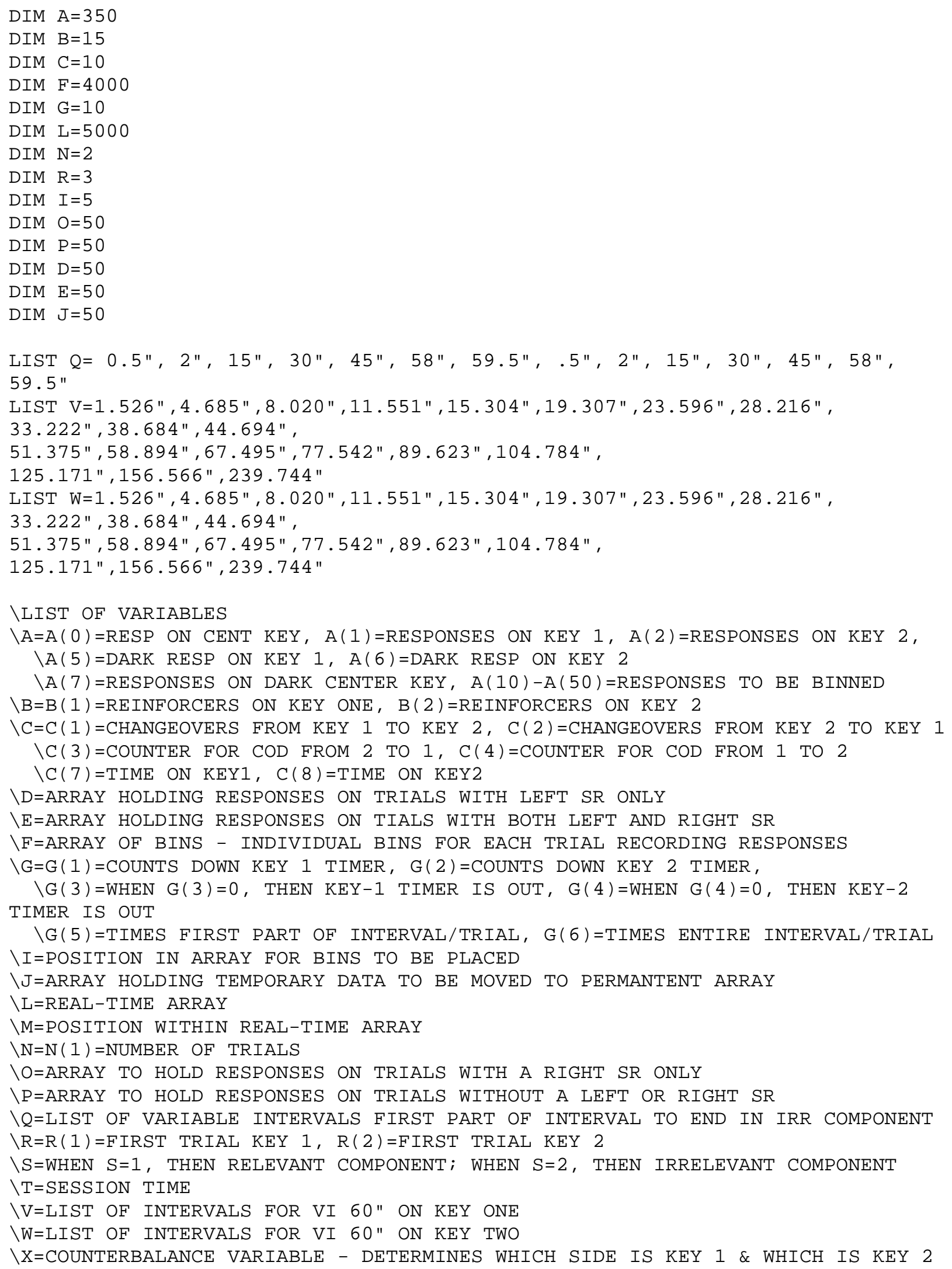


Fixed-Interval Performance 81

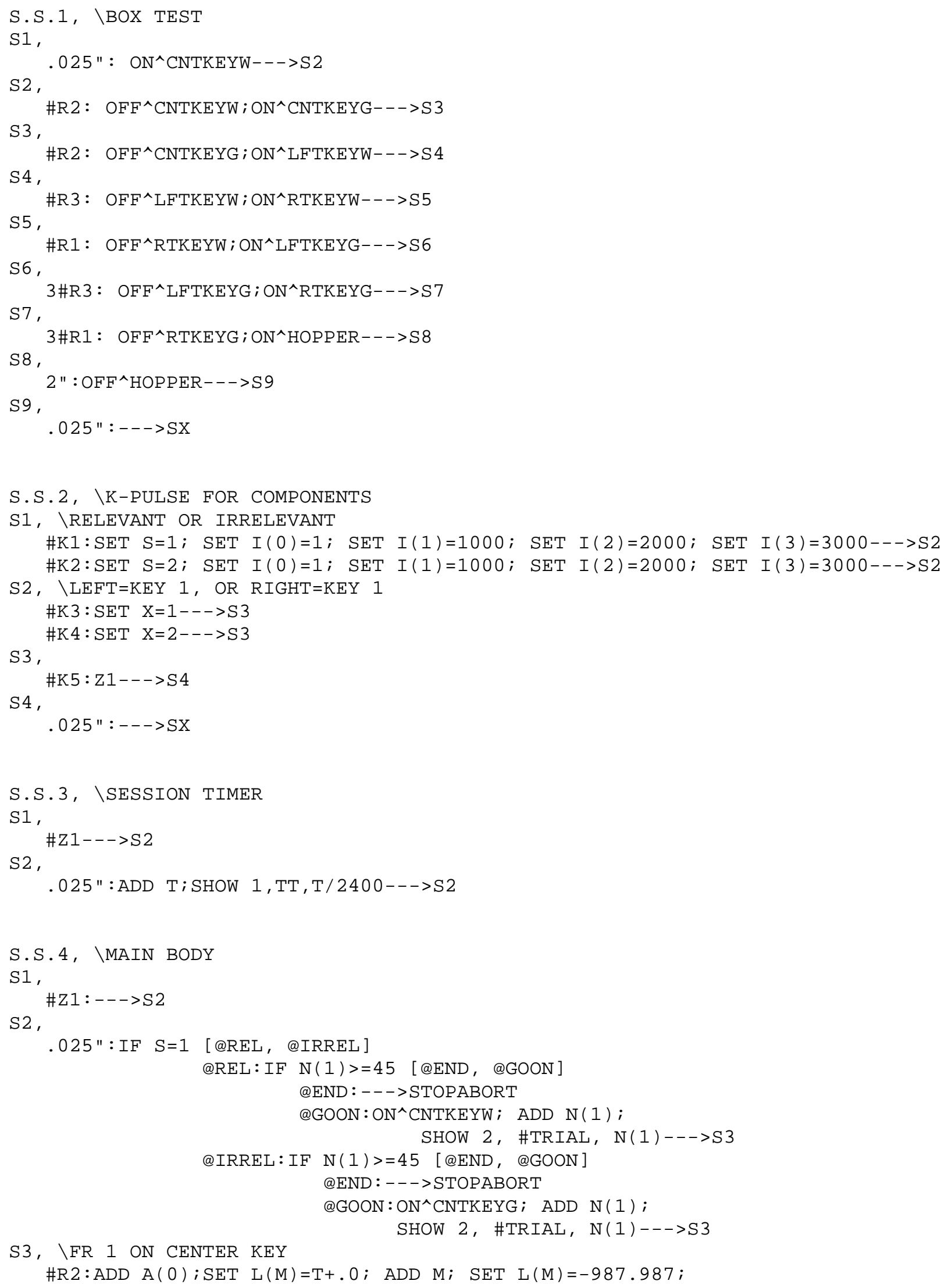




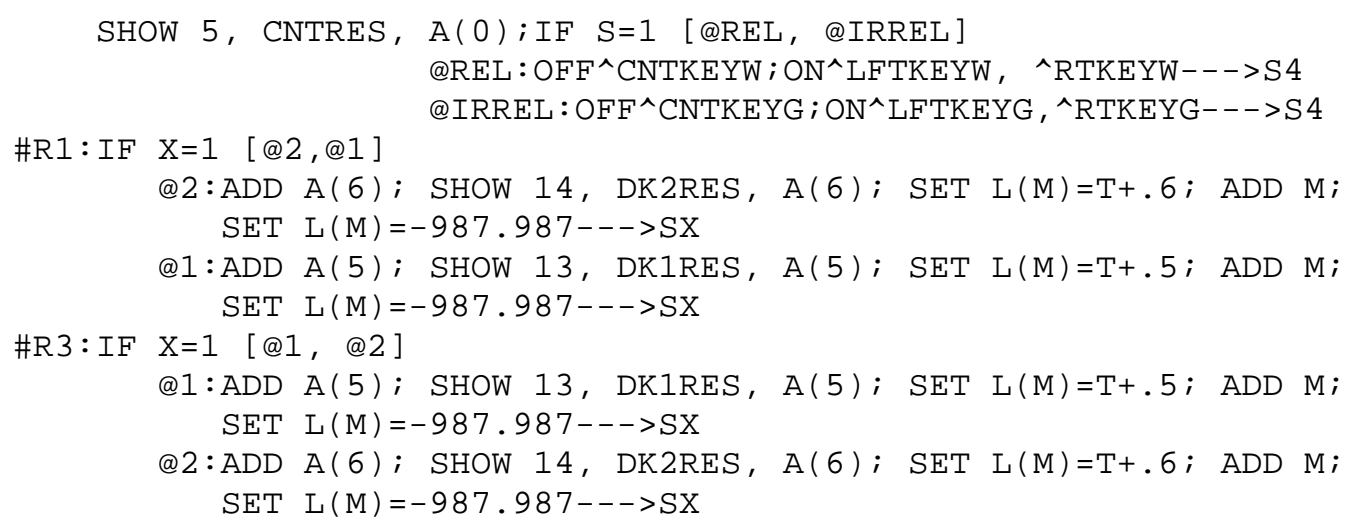




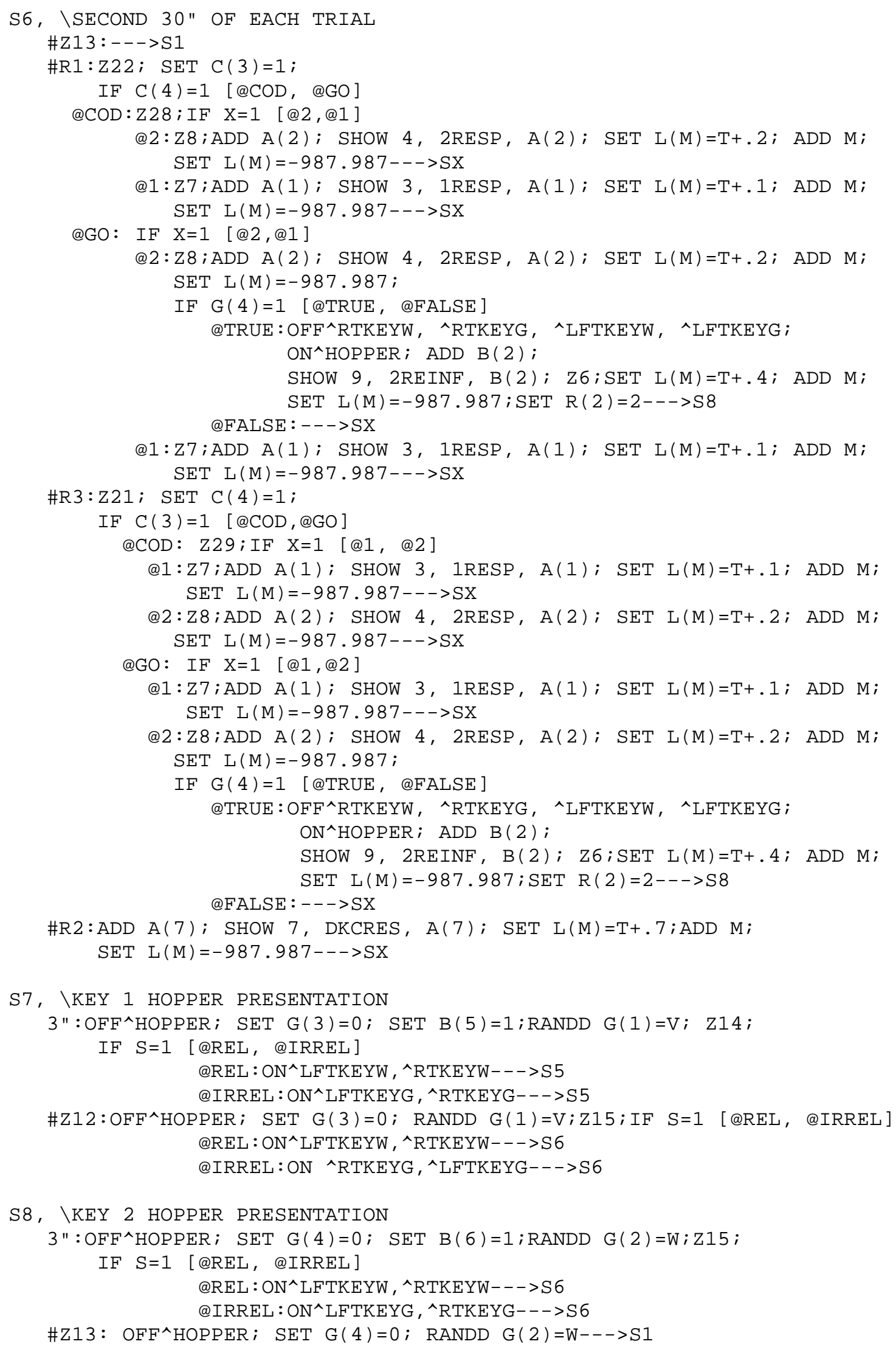




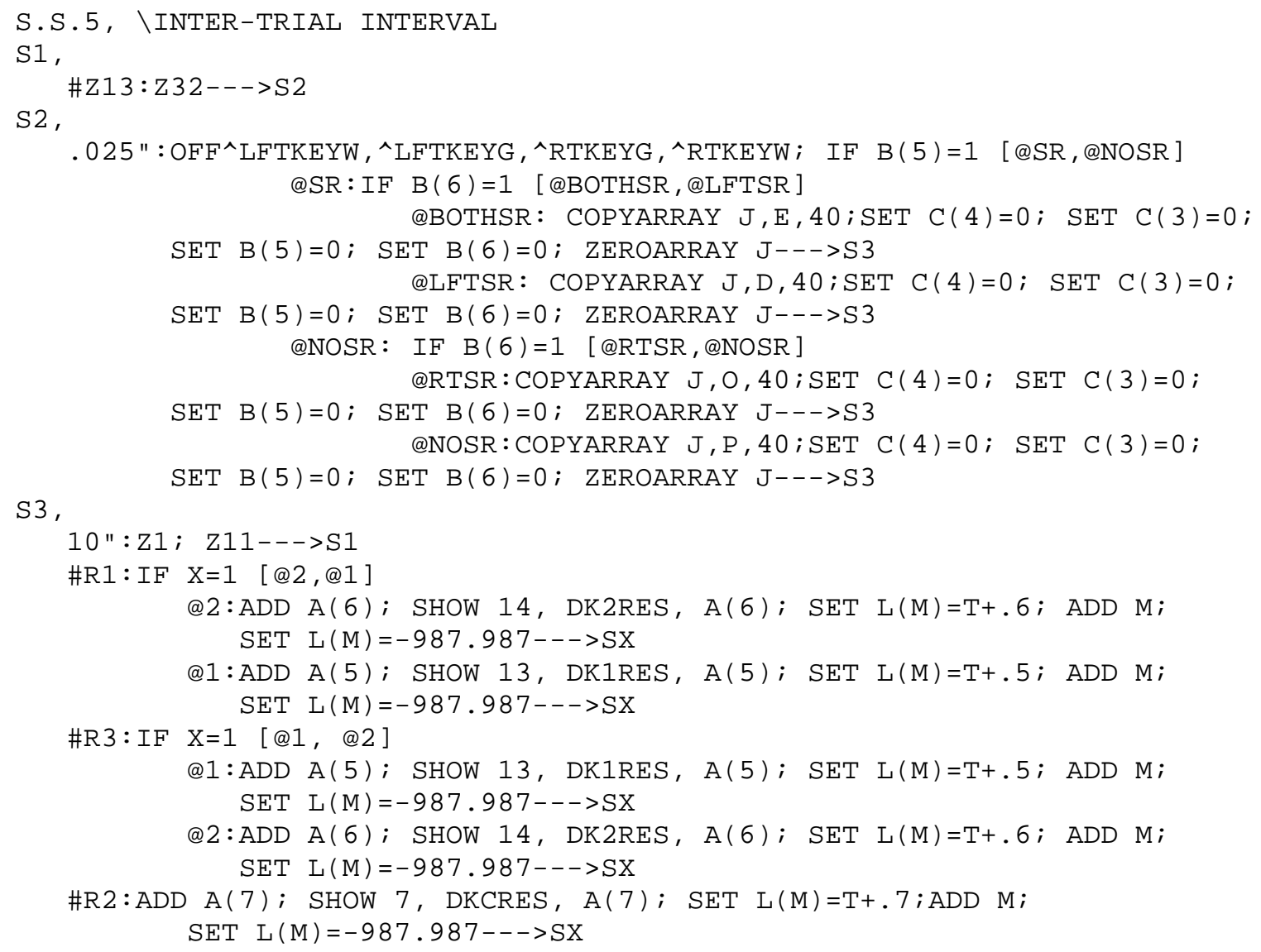


S.S.8, \PECK-PECK COD FROM KEY 1 TO KEY 2

S1,

\# Z28:--->S2

S2,

$3 ": \operatorname{SET} C(4)=0--->S 1$

\#R3:--->S1

S.S.9, \PECK-PECK COD FROM KEY 2 TO KEY 1

S1,

\#Z29:--->S2

S2,

$3 ": \operatorname{SET} C(3)=0--->S 1$

\#R1:--->S1

S.S.10, \TIME ON KEY 1

S1,

\#Z21:--->S2

$\mathrm{S} 2$,

$.025^{\prime \prime}: \mathrm{IF} \mathrm{X}=1$ [@KEY1, @KEY2]

@KEY1:ADD C (7); SHOW 18, K1TIME, C(7)/2400--->SX

@KEY2:ADD C(8); SHOW 19, K2TIME, C(8)/2400--->SX

\#Z22:ADD C(1); SHOW 23, CO1T2, C(1); Z3; SET L $(M)=T+.11 ; \operatorname{ADD}$ M; $\mathrm{SET} L(\mathrm{M})=-987.987--->\mathrm{S} 1$

\#Z32:--->S1

S.S.11, \TIME ON KEY 2

S1,

\#Z22:--->S2

S2,

$.025^{\prime \prime}: \mathrm{IF} \mathrm{X}=1$ [@KEY2, @KEY1]

@KEY2:ADD C(8); SHOW 19, K2TIME, C(8)/2400--->SX

@KEY1:ADD C (7); SHOW 18, K1TIME, C (7)/2400--->SX

\#Z21:ADD C(2); SHOW 24, CO2T1, C(2); Z4; SET L $(M)=T+.12 ; \operatorname{ADD} M$;

$\mathrm{SET} L(\mathrm{M})=-987.987--->\mathrm{S} 1$

\#Z32:--->S1

S.S.12, \TIMER FOR EACH TRIAL - ENDS AFTER $60 \mathrm{~s}$

$\mathrm{S} 1$,

\#Z30:SET G (6)=0--->S2

$\mathrm{S} 2$,

$.025 ": \operatorname{ADD} G(6) ; \operatorname{IF} G(6)>=2400$ [@END, @GOON]

@END : Z13--->S1

QGOON :--->S2

S.S.13, \TIMER FOR FIRST PART OF INTERVAL

S1,

\#Z25:IF S=1 [ [REL, @IRREL]

@REL:SET G (5)=1200--->S2

QIRREL:RANDD G (5)=Q--->S2

S2,

$.025 ":$ SUB G (5); IF G (5)<=0 [@NEXT, @STAY]

@NEXT:Z12--->S1

QSTAY: $--->S 2$ 


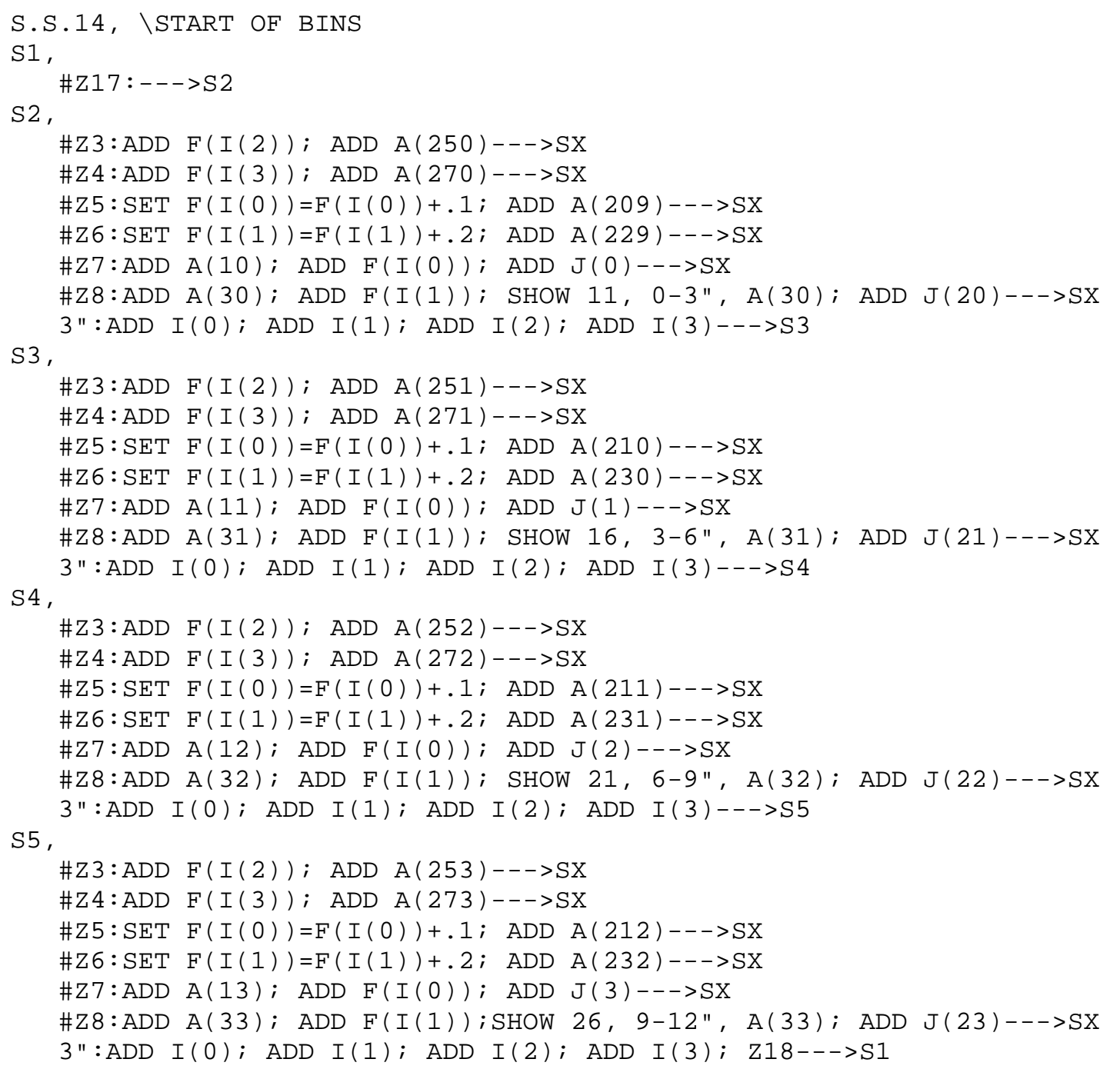

S.S.15, \MORE BINS

S1,

\# Z18--->S2

$\mathrm{S} 2$,

\#Z3:ADD F(I (2)); $\operatorname{ADD} A(254)--->S X$

\#Z4:ADD F(I (3)); ADD A (274)--->SX

\#Z5:SET $F(I(0))=F(I(0))+.1 ; \operatorname{ADD~A(213)--->SX~}$

\#Z6:SET $\mathrm{F}(\mathrm{I}(1))=\mathrm{F}(\mathrm{I}(1))+.2 ; \operatorname{ADD} \mathrm{A}(233)--->\mathrm{SX}$

\#Z7:ADD A (14); ADD F(I (0)); ADD J(4)--->SX

\#Z8:ADD A(34); ADD F(I (1)); SHOW 31, 12-15", A(34); ADD J(24)--->SX

$3 ": \operatorname{ADD} I(0) ; \mathrm{ADD} I(1) ; \mathrm{ADD} I(2) ; \mathrm{ADD} I(3)--->\mathrm{S} 3$

S3,

\#Z3:ADD $\mathrm{F}(\mathrm{I}(2))$; $\mathrm{ADD}$ A (255)--->SX

\#Z4:ADD $\mathrm{F}(\mathrm{I}(3)) ; \mathrm{ADD} A(275)--->S X$

\#Z5:SET $\mathrm{F}(\mathrm{I}(0))=\mathrm{F}(\mathrm{I}(0))+.1 ; \operatorname{ADD} \mathrm{A}(214)--->\mathrm{SX}$

\#Z6:SET $F(I(1))=F(I(1))+.2 ; \operatorname{ADD~A~}(234)--->S X$

\#Z7:ADD A(15); ADD $\mathrm{F}(\mathrm{I}(0)) ; \mathrm{ADD} J(5)--->\mathrm{SX}$

\#Z8:ADD A (35); ADD F(I (1)); SHOW 36, 15-18", A(35); ADD J(25)--->SX

$3 ": \operatorname{ADD} I(0) ; \operatorname{ADD} I(1) ; \operatorname{ADD} I(2) ; \operatorname{ADD} I(3)--->S 4$ 
S4,

\#Z3:ADD F(I (2)); ADD A (256)--->SX

\#Z4:ADD F(I (3)); ADD A (276)--->SX

\#Z5:SET $F(I(0))=F(I(0))+.1 ; \operatorname{ADD~A(215)--->SX~}$

\#Z6:SET F(I (1)) =F(I (1))+.2; ADD A (235)--->SX

\#Z7:ADD A(16); ADD F(I (0)); ADD J(6)--->SX

\#Z8:ADD A(36); ADD F(I(1)); SHOW 41, 18-21", A(36); ADD J(26)--->SX

$3 ": \operatorname{ADD} I(0) ; \operatorname{ADD} I(1) ; \operatorname{ADD} I(2) ; \operatorname{ADD} I(3)--->S 5$

S5,

\#Z3:ADD F(I (2)); ADD A (257)--->SX

\#Z4:ADD F(I (3)); ADD A (277)--->SX

\#Z5:SET F (I (0)) $=\mathrm{F}(\mathrm{I}(0))+.1 ;$ ADD A (216)--->SX

$\# Z 6: \operatorname{SET} F(I(1))=\mathrm{F}(I(1))+.2 ; \operatorname{ADD~A}(236)--->\mathrm{SX}$

\#Z7:ADD A(17); ADD F(I (0)); ADD J(7)--->SX

\#Z8:ADD A(37); ADD F(I(1)); SHOW 46, 21-24", A(37); ADD J(27)--->SX

$3 ": \operatorname{ADD} I(0) ; \operatorname{ADD} I(1) ; \operatorname{ADD} I(2) ; \operatorname{ADD} I(3) ; Z 19-->S 1$

S.S.16, \MORE BINS

S1,

\#Z19--->S2

$\mathrm{S} 2$,

\#Z3:ADD F(I (2)); ADD A(258)--->SX

\#Z4:ADD F(I (3)); ADD A(278)--->SX

$\# Z 5: \operatorname{SET} F(I(0))=F(I(0))+.1 ; \operatorname{ADD~A}(217)--->S X$

\#Z6:SET $F(I(1))=F(I(1))+.2 ; \operatorname{ADD~A(237)--->SX~}$

\#Z7:ADD A(18); ADD F(I (0)); ADD J(8)--->SX

\#Z8:ADD A(38); ADD F(I(1)); SHOW 51, 24-27", A(38); ADD J(28)--->SX

3":ADD I(0); $\operatorname{ADD} I(1) ; \operatorname{ADD} I(2) ; \operatorname{ADD} I(3)-->S 3$

S3,

\#Z3:ADD F(I (2)); ADD A (259)--->SX

\#Z4:ADD F(I (3)); ADD A (279)--->SX

\#Z5:SET F(I (0)) =F (I (0))+.1; ADD A (218)--->SX

\#Z6:SET $F(I(1))=F(I(1))+.2 ; \operatorname{ADD~A(238)--->SX~}$

\#Z7:ADD A(19); ADD F(I (0)); ADD J(9)--->SX

\#Z8:ADD A(39); ADD F(I (1)); SHOW 56, 27-30", A(39); ADD J(29)--->SX

$3 ": \operatorname{ADD} I(0) ; \operatorname{ADD} I(1) ; \operatorname{ADD} I(2) ; \operatorname{ADD} I(3)--->S 4$

S4,

\#Z3:ADD F(I (2)); ADD A (260)--->SX

\#Z4:ADD F(I (3)); ADD A (280)--->SX

$\# Z 5: \operatorname{SET} F(I(0))=F(I(0))+.1 ; \operatorname{ADD} A(219)--->S X$

\#Z6:SET F(I (1)) =F(I (1))+.2; ADD A (239)--->SX

\#Z7:ADD A(20); ADD F(I (0)); ADD J(10)--->SX

\#Z8:ADD A(40); ADD F(I(1)); SHOW 12, 30-33", A(40); ADD J(30)--->SX

3":ADD I(0); $\operatorname{ADD} I(1) ; \operatorname{ADD} I(2) ; \operatorname{ADD} I(3)-->S 5$

S5,

\#Z3:ADD F(I (2)); ADD A (261)--->SX

\#Z4:ADD F(I (3)); ADD A (281)--->SX

\#Z5:SET F(I (0)) =F (I (0))+.1; ADD A (220)--->SX

$\# Z 6: \operatorname{SET} F(I(1))=\mathrm{F}(\mathrm{I}(1))+.2 ; \operatorname{ADD~A}(240)--->\mathrm{SX}$

\#Z7:ADD A(21); ADD F(I (0)); ADD J(11)--->SX

\#Z8:ADD A(41); ADD F(I (1)); SHOW 17, 33-36", A(41); ADD J(31)--->SX

$3 ": \operatorname{ADD} I(0) ; \operatorname{ADD} I(1) ; \operatorname{ADD} I(2) ; \operatorname{ADD} I(3) ; Z 20--->S 1$ 


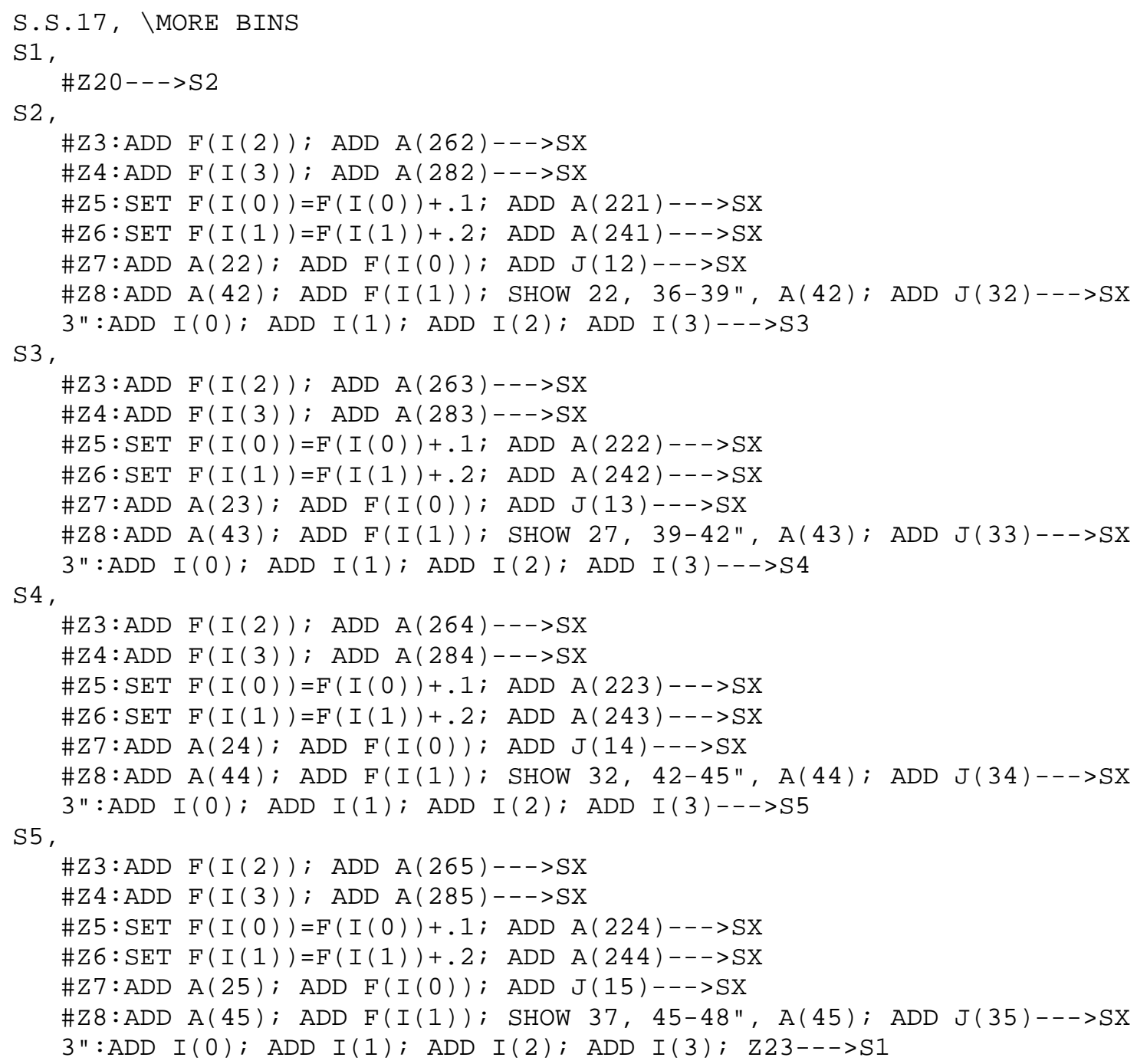

S.S.18, \MORE BINS

S1,

\#Z23--->S2

S2,

\#Z3:ADD F(I (2)); ADD A (266)--->SX

\#Z4:ADD F(I (3)); ADD A (286)--->SX

\#Z5:SET $F(I(0))=F(I(0))+.1 ; A D D A(225)--->S X$

\#Z6:SET $\mathrm{F}(\mathrm{I}(1))=\mathrm{F}(\mathrm{I}(1))+.2 ; \mathrm{ADD} A(245)--->\mathrm{SX}$

\#Z7:ADD A(26); ADD F(I (0)); ADD J(16)--->SX

\#Z8:ADD A(46); ADD F(I (1)); SHOW 42, 48-51", A(46); ADD J(36)--->SX

$3 ": \operatorname{ADD} I(0) ; \operatorname{ADD} I(1) ; \operatorname{ADD} I(2) ; \operatorname{ADD} I(3)--->S 3$

S3,

\#Z3:ADD F(I (2)); ADD A(267)--->SX

\#Z4:ADD $\mathrm{F}(\mathrm{I}(3)) ; \mathrm{ADD} A(287)--->S X$

\#Z5:SET $F(I(0))=F(I(0))+.1 ; \operatorname{ADD~A(226)--->SX~}$

\#Z6:SET $F(I(1))=F(I(1))+.2 ; \operatorname{ADD~A~}(246)--->S X$

\#Z7:ADD A(27); ADD F(I (0)); ADD J(17)--->SX

\#Z8:ADD A(47); ADD F(I(1)); SHOW 47, 51-54", A(47); ADD J(37)--->SX

$3 ": \operatorname{ADD} I(0) ; \operatorname{ADD} I(1) ; \operatorname{ADD} I(2) ; \operatorname{ADD} I(3)--->S 4$ 
S4,

\#Z3:ADD F(I (2)); ADD A (268)--->SX

\#Z4:ADD F(I (3)); ADD A (288)--->SX

\#Z5:SET $F(I(0))=F(I(0))+.1 ; \operatorname{ADD~A(227)--->SX~}$

\#Z6:SET $\mathrm{F}(\mathrm{I}(1))=\mathrm{F}(\mathrm{I}(1))+.2 ; \operatorname{ADD} \mathrm{A}(247)--->\mathrm{SX}$

\#Z7:ADD A(28); ADD F(I (0)); ADD J(18)--->SX

\#Z8:ADD A(48); ADD F(I(1)); SHOW 52, 54-57", A(48); ADD J(38)--->SX

$3 ": \operatorname{ADD} I(0) ; \operatorname{ADD} I(1) ; \operatorname{ADD} I(2) ; \operatorname{ADD} I(3)--->S 5$

S5,

\#Z3:ADD F(I (2)); ADD A(269)--->SX

\#Z4:ADD F(I (3)); ADD A (289)--->SX

\#Z5:SET F (I (0)) $=\mathrm{F}(\mathrm{I}(0))+.1 ; \operatorname{ADD} \mathrm{A}(228)--->\mathrm{SX}$

$\# Z 6: \operatorname{SET} \quad \mathrm{F}(\mathrm{I}(1))=\mathrm{F}(\mathrm{I}(1))+.2 ; \operatorname{ADD} \mathrm{A}(248)--->\mathrm{SX}$

\#Z7:ADD A(29); ADD F(I (0)); ADD J(19)--->SX

\#Z8:ADD A(49); ADD F(I(1)); SHOW 57, 57-60", A(49); ADD J(39)--->SX

$3 ": \operatorname{ADD} I(0) ; \operatorname{ADD} I(1) ; \operatorname{ADD} I(2) ; \operatorname{ADD} I(3)-->S 1$ 


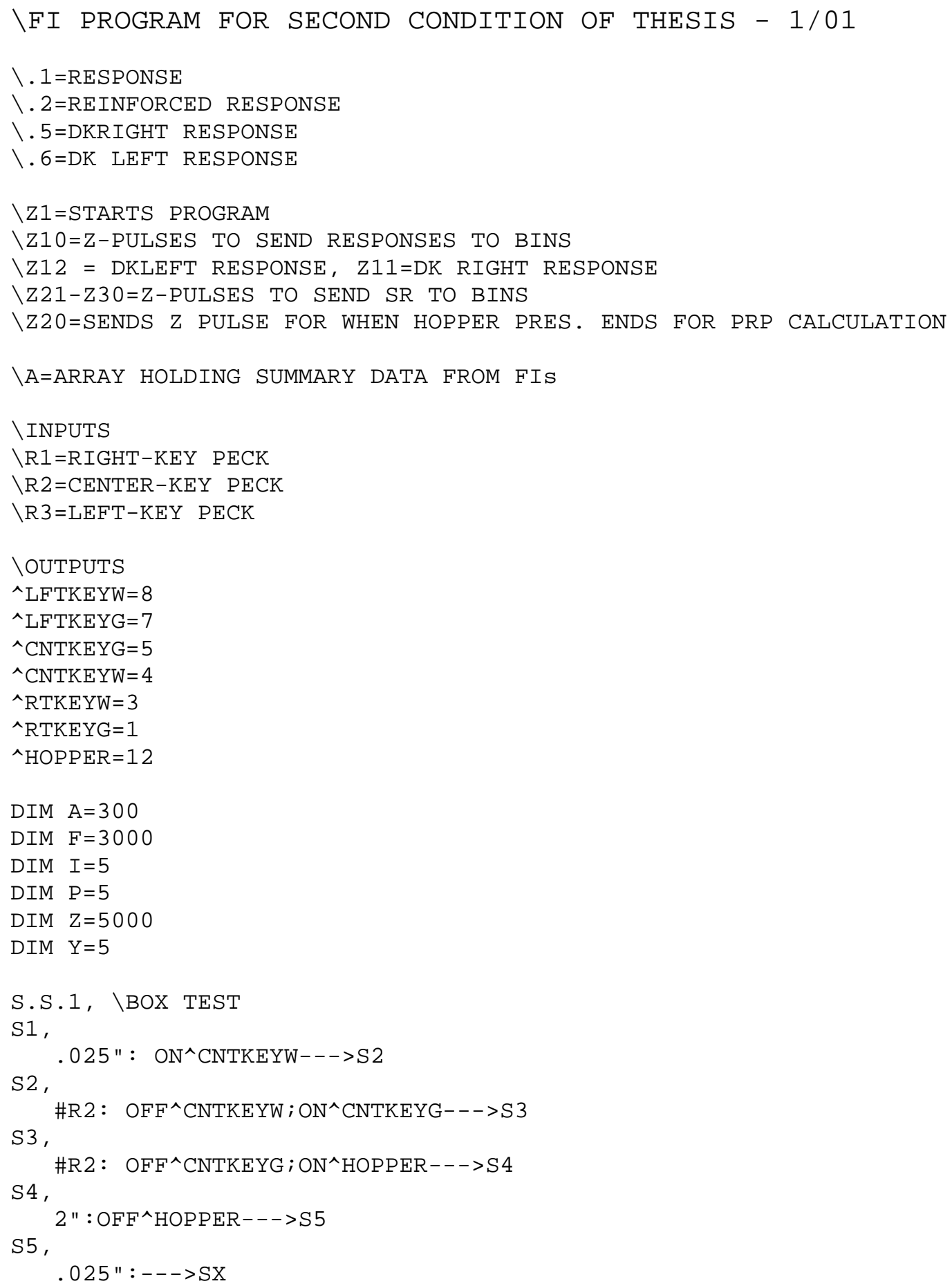




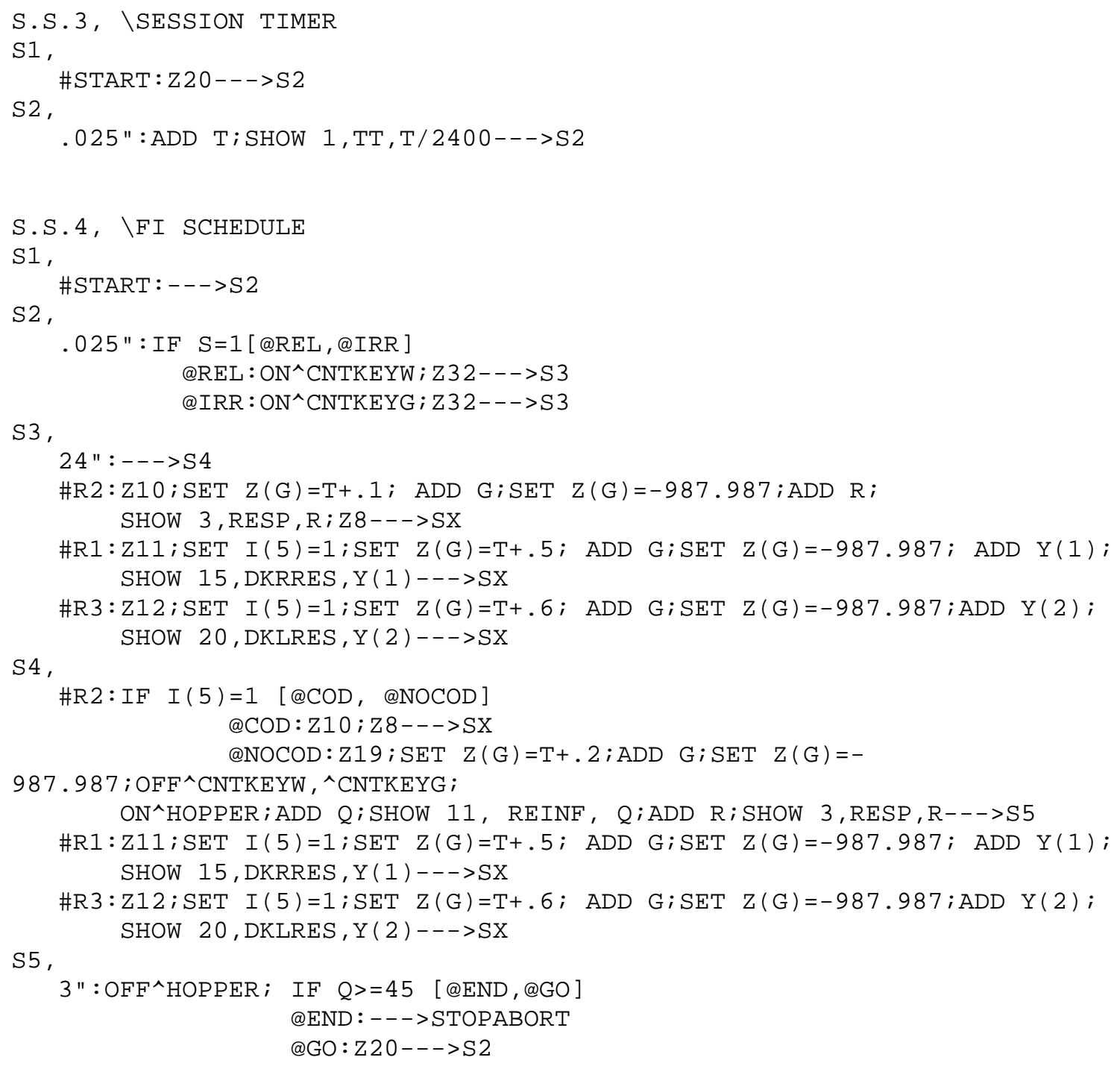




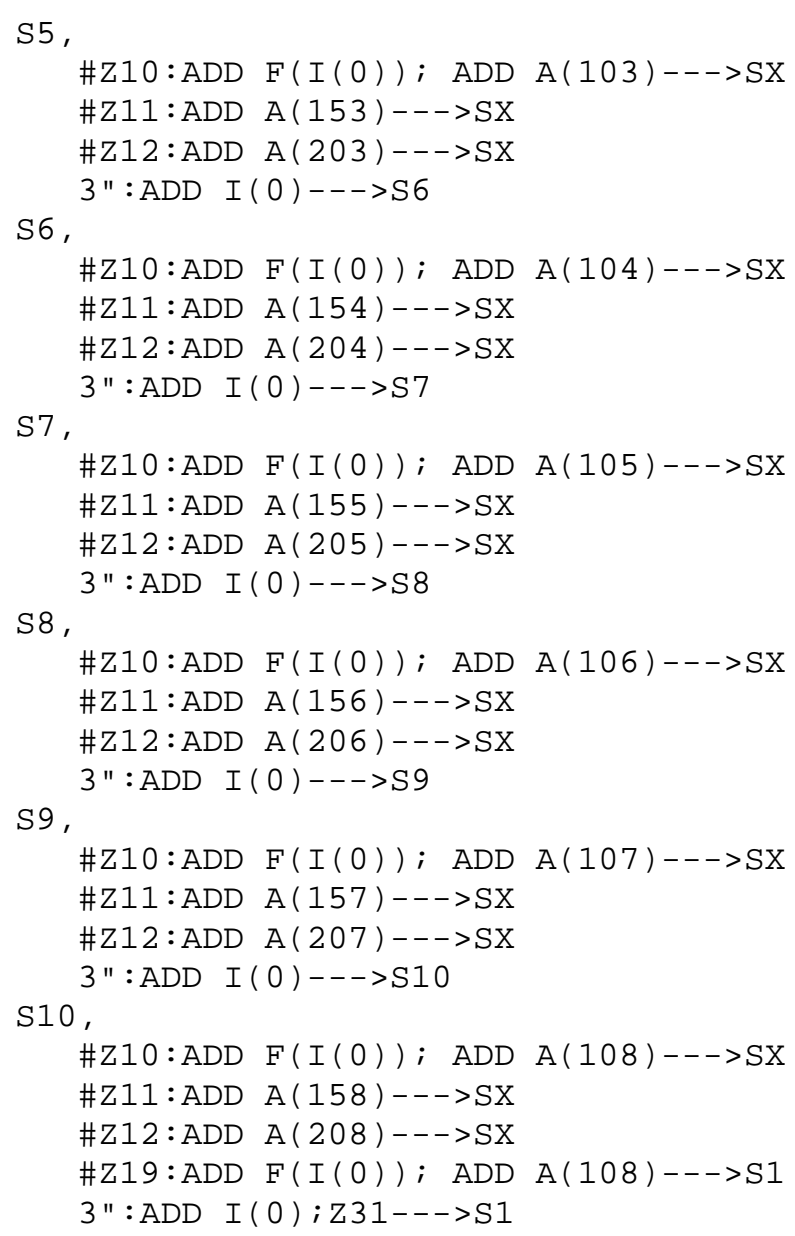




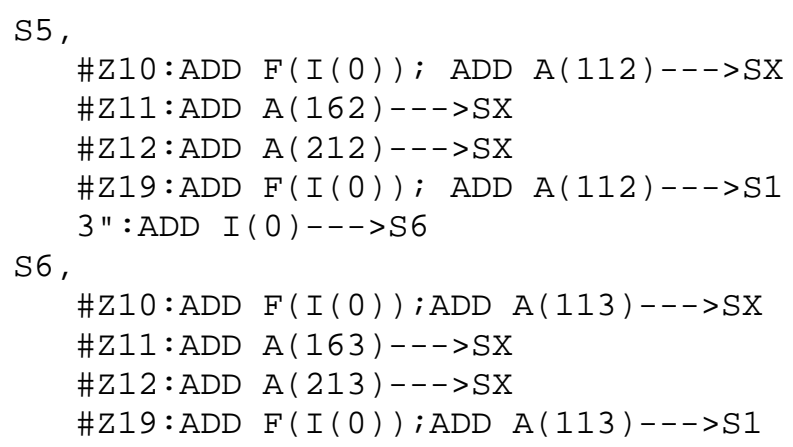

